\title{
Ecology and evolution of metabolic cross-feeding interactions in bacteria $\uparrow$
}

\author{
Glen D'Souza, (D) ab Shraddha Shitut, (D) ce Daniel Preussger, ${ }^{\mathrm{c}}$ Ghada Yousif, ${ }^{\text {cde }}$ \\ Silvio Waschina (D) $^{f}$ and Christian Kost (iD *ce
}

Literature covered: early 2000s to late 2017

Received 25th January 2018

DOI: $10.1039 / c 8 n p 00009 c$

rsc.li/npr

\begin{abstract}
Bacteria frequently exchange metabolites with other micro- and macro-organisms. In these often obligate cross-feeding interactions, primary metabolites such as vitamins, amino acids, nucleotides, or growth factors are exchanged. The widespread distribution of this type of metabolic interactions, however, is at odds with evolutionary theory: why should an organism invest costly resources to benefit other individuals rather than using these metabolites to maximize its own fitness? Recent empirical work has shown that bacterial genotypes can significantly benefit from trading metabolites with other bacteria relative to cells not engaging in such interactions. Here, we will provide a comprehensive overview over the ecological factors and evolutionary mechanisms that have been identified to explain the evolution and maintenance of metabolic mutualisms among microorganisms. Furthermore, we will highlight general principles that underlie the adaptive evolution of interconnected microbial metabolic networks as well as the evolutionary consequences that result for cells living in such communities.
\end{abstract}

$1 \quad$ Introduction

2 Metabolic cross-feeding interactions

$2.1 \quad$ Historical account

2.2 Classification of cross-feeding interactions

2.2.1 Unidirectional by-product cross-feeding

2.2.2 Bidirectional by-product cross-feeding

2.2.3 By-product reciprocity

2.2.4 Unidirectional cooperative cross-feeding

2.2.5 Bidirectional cooperative cross-feeding

2.3 Ways to study cross-feeding interactions

2.3.1

2.3.2

2.4
Culture-dependent approaches

Culture-independent approaches

Distribution of cross-feeding interactions in nature
${ }^{a}$ Department of Environmental Systems Sciences, ETH-Zürich, Zürich, Switzerland ${ }^{b}$ Department of Environmental Microbiology, Eawag: Swiss Federal Institute for Aquatic Sciences, Dübendorf, Switzerland

${ }^{\prime}$ Experimental Ecology and Evolution Research Group, Department of Bioorganic Chemistry, Max Planck Institute for Chemical Ecology, Jena, Germany. E-mail: christiankost@gmail.com

${ }^{d}$ Department of Botany and Microbiology, Faculty of Science, Beni-Suef University, Beni-Suef, Egypt

${ }^{e}$ Department of Ecology, School of Biology/Chemistry, Osnabrück University, Osnabrück, Germany

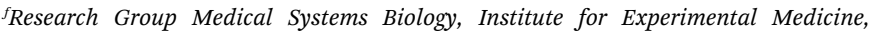
Christian-Albrechts-University Kiel, Kiel, Germany

$\dagger$ Electronic supplementary information (ESI) available. See DOI: $10.1039 / \mathrm{c} 8 \mathrm{np} 00009 \mathrm{c}$
2.5

2.5.1

2.5.1.1

2.5.1.2

2.5.1.3

2.5.2

2.5.2.1

2.5.2.2

2.5.2.3

2.5.2.4

3

3.1

3.1.1

3.1.2

Mechanisms of metabolite transfer

Contact-independent mechanisms

Passive diffusion

Active transport

Vesicle-mediated transport

Contact-dependent mechanisms

Vesicle chains

Nanotubes

Flagella-like filaments

Cell-cell contact

The evolution and maintenance of metabolic crossfeeding interactions

Metabolic factors

Economics of microbial metabolite trade

Molecular basis for comparative advantages and biochemical conflicts in metabolite production

3.1.2.1 Molecular causes of comparative advantages

3.1.2.2 Molecular causes of biochemical conflicts

3.2 Metabolite leakage: the first step towards the evolution of metabolic interactions

3.3 Emergence of by-product cross-feeding through gene loss

3.3.1 Auxotrophies are common in nature

3.3.2 Evolutionary mechanisms driving the loss of biosynthetic genes and functions

3.3.2.1 Adaptive loss of biosynthetic functions in metaboliterich environments 


\subsubsection{Random genetic drift}

3.3.3 Physiological consequences of biosynthetic gene loss

3.4 The emergence of by-product reciprocity

3.5 Evolution of cooperative cross-feeding

3.5.1 Positive assortment

3.5.2 Mechanisms promoting positive assortment

3.5.2.1 Partner fidelity

3.5.2.2 Partner choice

4 Consequences of obligate metabolite cross-feeding

4.1. Negative frequency-dependent selection

4.2 Coevolutionary dynamics

4.3 Formation of intercellular metabolic networks

4.4 Bacterial unculturability

4.5 Levels of selection and transitions in individuality

$5 \quad$ Concluding remarks

6 Conflicts of interest

$7 \quad$ Acknowledgements

8 References

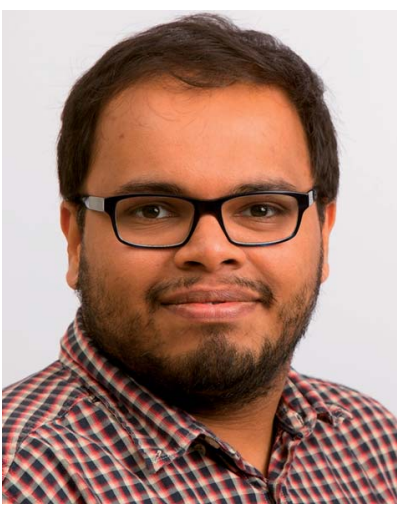

Glen D'Souza obtained his PhD in 2016 from the FriedrichSchiller-University and the Max Planck Institute for Chemical Ecology in Jena, Germany, where he studied the mechanistic basis for the evolution of metabolic dependency in bacteria. Currently, he is an ETH Postdoctoral Fellow, hosted by Prof. Martin Ackermann, at ETHZurich and Eawag: the Swiss federal institute for aquatic sciences in Zürich, Switzerland. His core research interests are focused on understanding the emergence and evolution of interactions between genotypes that coexist within microbial communities.

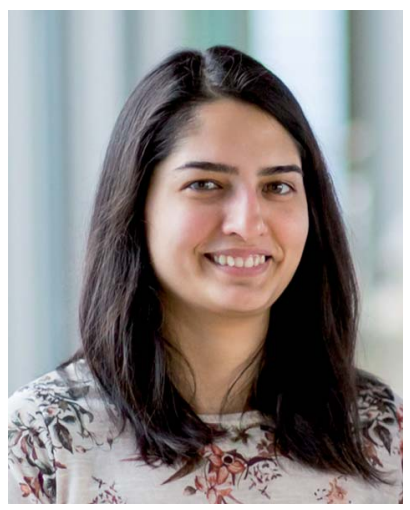

Shraddha Shitut obtained her BSc in 2006 in Industrial Microbiology from the University of Pune, India, and her MSc in Microbiology at the Maharaja Sayajirao University of Baroda, India. In 2018, she obtained her PhD from the FriedrichSchiller-University and Max Planck Institute for Chemical Ecology in Jena, Germany, where she studied the mechanistic and metabolic basis of bacterial cross-feeding interactions. Subsequently, she joined the Origins Center at Leiden University, Leiden, Netherlands as a postdoctoral fellow hosted by Prof. Daniel Rozen, Prof. Dennis Claessen and Prof. Alexander Kros. Her current work focusses on understanding the evolution of chromosomal coexistence in bacteria.

\section{Introduction}

Bacteria are amongst the most ancient life forms on our planet., Even, the last common universal ancestor (LUCA) has been suggested to strongly resemble bacteria that dwell in extreme environments. ${ }^{3,4}$ During their evolutionary history of about 3.2 billion years, bacteria managed to colonize virtually every conceivable habitat on earth including air, soil, water, as well as other organisms such as animals and plants. ${ }^{5}$ Due to their widespread distribution and high abundance, bacteria play significant ecological roles in driving global biogeochemical cycles, ${ }^{6}$ determining homeostasis of the biosphere, ${ }^{7}$ and controlling the development, behaviour, and health of multicellular organisms. ${ }^{8}$

In nature, bacteria usually exist within taxonomically and genotypically diverse communities..$^{9-11}$ In these assemblages, bacteria compete for a wide variety of limiting resources such as favourable living spaces, nutrients, and minerals. Moreover, due to their metabolic activities, bacteria transform the environments they live in, thus drastically influencing the growth

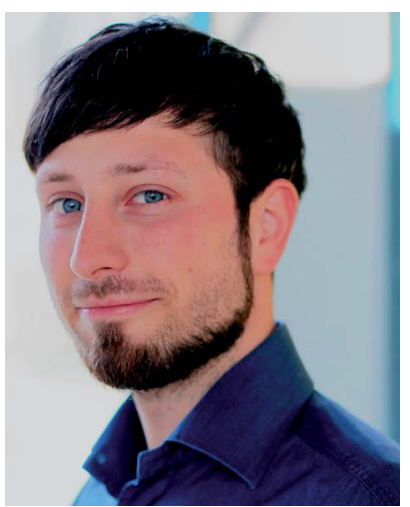

Daniel Preussger received a BSc in Biotechnology from the University of Applied Sciences Zittau/Görlitz in 2009, followed by a one year position at a company for microbiological quality monitoring in food and pharmaceuticals. In 2013, he received a $M$. Sc. in Microbiology of the Friedrich-Schiller-University, Jena. Currently, he is a doctoral researcher with Christian Kost, at the Max Planck Institute for Chemical Ecology in Jena, Germany. His research work focusses on the experimental evolution of cooperative interactions in bacteria.

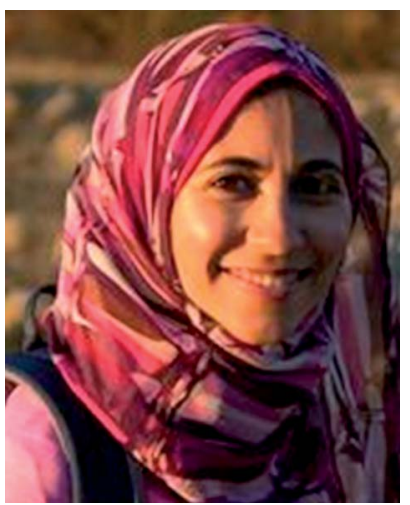

Ghada Yousif is originally from Egypt, where she also works as assistant-lecturer at Beni-Suef University. During her master studies, she spent 10 months at Newcastle University, UK in Michael Goodfellow's lab, where she studied soil bacterial taxonomy and capabilities. Since 2015, she is a doctoral researcher with Christian Kost at the University of Osnabrück, Germany, studying metabolic interdependencies within soil microbial communities. 
and metabolism of other co-occurring organisms. ${ }^{\mathbf{1 2}}$ Strong selection pressures resulting from both of these factors have not only given rise to a plethora of ecological interactions, but also different bacterial strategies to survive and reproduce under these conditions. ${ }^{10}$ Accordingly, a large proportion of a bacterial cell's genetic material (between 17 and 42\%) can encode traits that are involved in mediating ecological interactions. ${ }^{13}$

For heuristic purposes, ecological interactions between two individuals are typically classified based on the net fitness effects that result for the organisms involved. The typological spectrum of interactions resulting from this classification scheme ranges from antagonistic (i.e. negative fitness consequences) over neutral (i.e. no interaction) to beneficial interactions (i.e. positive fitness consequences). ${ }^{10}$ Examples of antagonistic behaviours displayed by bacteria include the active secretion of toxins such as colicins or antibiotics that kill or inhibit the growth of other bacteria, ${ }^{\mathbf{1 4 , 1 5}}$ thus providing the toxin-producing bacteria with a competitive advantage. Evolutionary theory predicts that natural selection should favour such strategies that selfishly enhance the fitness of one organism at the expense of another one. ${ }^{16}$ Indeed, a large body of work has demonstrated the prevalence of antagonistic interactions in natural microbial communities. ${ }^{\mathbf{1 0 , 1 6 , 1 7}}$

However, in recent years, awareness has grown that bacteria also show a range of cooperative behaviours, in which one individual helps another one at a cost to itself. A good example for this is so-called 'public goods'. These are metabolites that are costly to produce, yet are released into the extracellular environment. As a consequence, these public goods do not only benefit the producing cell, but also other cells in the local group or population. Examples include antibiotic-degrading enzymes ${ }^{18}$ motility-enhancing biosurfactants, ${ }^{19}$ matrix components for biofilms,${ }^{20}$ or iron-scavenging molecules. ${ }^{21}$ Why would cells invest resources into behaviours that can be easily exploited by individuals that reap the benefits without bearing the costs for producing the public good? In most of the abovementioned cases, the individual producing the public good and the beneficiaries are genealogically related. Thus, by

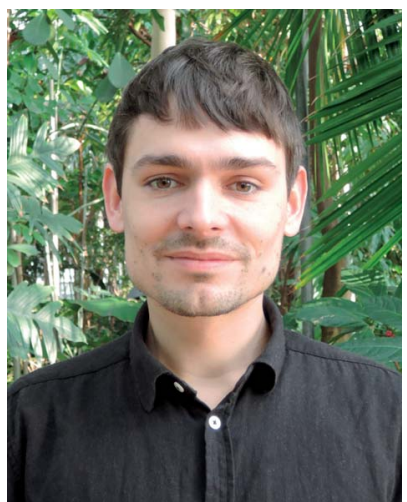

Silvio Waschina received his PhD in Bioinformatics in 2016 from the Friedrich-Schiller-University in Jena, Germany, where he studied the adaptive evolution of bacterial metabolic networks. After that he joined Christoph Kaleta's group at the University of Kiel, Germany, as a postdoctoral fellow. His current research focusses on the development and application of novel systems biology approaches to elucidate the impact of metabolic processes within complex hostassociated bacterial communities on human health. helping its relatives, the cooperative individual can increase the chance that its own genes are indirectly propagated. This socalled 'kin-selection' can explain altruistic cooperative behaviours among closely related individuals. ${ }^{22}$

The situation, however, is different for synergistic interactions that involve unrelated individuals or different species that reciprocally exchange metabolites such as sugars, growth factors, or amino acids with each other. ${ }^{23}$ A number of recent studies have suggested that these types of synergistic interactions might actually be common in the prokaryotic world. ${ }^{24-27}$ In many of these cases, the interactions are also obligatory for the individuals involved, meaning they can only exist when the required metabolite is externally supplied, for example by another bacterium. ${ }^{25,26}$ This type of metabolic interactions begs an evolutionary explanation: why should a bacterium give up its metabolic autonomy and rather rely on other organisms to provide essential metabolites? Moreover, why would a bacterial cell produce metabolites to benefit other, potentially unrelated individuals and not use these resources to maximize its own fitness?

In this article, we address these questions. By particularly focussing on metabolic interactions between two or more bacterial partners, we aim at developing a conceptual framework that allows not only to classify different types of metabolic interactions, but also to explain the evolution and maintenance of these relationships. In addition, we analyse how common metabolic cross-feeding interactions are in nature and what evolutionary consequences result for the organisms involved. The comprehensive picture that emerges from this analysis may provide an orientation to scientists that are new to this interesting field of study and identify avenues for future research.

\section{Metabolic cross-feeding interactions}

\subsection{Historical account}

A first and important step in understanding the origin of metabolic exchange in bacteria is to obtain a historical perspective on

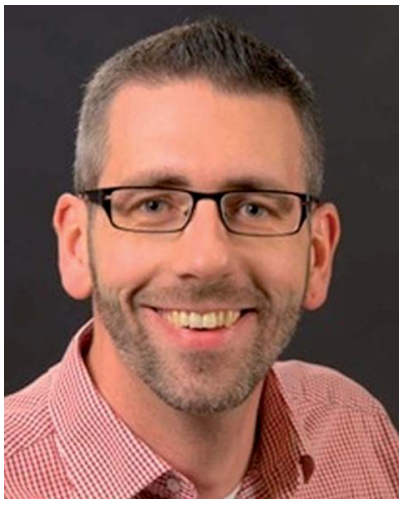

Christian Kost completed his PhD in 2006 in the group of Martin Heil at the Max Planck Institute for Chemical Ecology in Jena, Germany. Subsequently, he joined the lab of Paul Rainey at the University of Auckland/ Massey University in Auckland, New Zealand for postdoctoral research. In 2009, he established the independent research group Experimental Ecology and Evolution at the Max Planck Institute for Chemical Ecology in Jena. Since 2016, he is a full professor for Ecology at the University of Osnabrück, Germany. His research focusses on the ecology and evolution of metabolite crossfeeding interactions among microorganisms. 
the discovery of this phenomenon. Early studies on what is now known as cross-feeding often discuss the phenomenon in the context of symbiosis. ${ }^{28,29}$ These studies mainly focussed on microbial interactions that impact plant growth (e.g. root nodule bacteria, ${ }^{30,31}$ mycorrhiza $^{32}$ ) or play important roles for the fermentation of dairy products (i.e. lactic acid bacteria ${ }^{33-35}$ ). Back in 1887, Carl Garrè, a Swiss surgeon, was one of the first to mention that "one organism prepares food for another organism by changing the medium on which it grows". ${ }^{29}$ Later in 1892, the British botanist Marshall Ward stumbled upon cross-feeding while trying to unravel the mystery of the Ginger-beer Plant. The substance in question is used to ferment ginger beer, a nonalcoholic, naturally sweetened beverage, from saccharine and ginger. Ward found out that this plant was, in effect, a symbiotic association between a yeast and bacteria that formed solid, semitranslucent, lumpy masses. More importantly, he found that an exchange of metabolites between both partners was an integral part of the fermentation process. ${ }^{36}$ Around this time, such mixed cultures of microbes were referred to as microbial associations. ${ }^{29}$ In 1897, Wilhelm Pfeffer, a German botanist and plant physiologist, introduced the terms conjunctive and disjunctive symbiosis to highlight the dependency of either partners for growth. ${ }^{37}$ Marshall Ward also proposed the use of terms like antibiosis and metabiosis to distinguish between negative and positive effects that result from an interaction for the partners involved. ${ }^{38}$

The term 'cross-feeding' was coined by Hermann Reinheimer in 1921 - a British biologist who was interested in the evolutionary significance of cooperative symbiotic interactions. ${ }^{39}$ Reinheimer suggested two terms to differentiate the source of food or metabolite, namely 'in-feeding' for within-kingdom exchange and crossfeeding for between-kingdom exchange. This distinction, however, was not adopted by the scientific community at large. Instead, the term cross-feeding was subsequently used to describe interactions that involved an exchange of molecules and, thus, enhanced growth. Interestingly at this time, cross-feeding between auxotrophic strains was also used as a methodological tool to elucidate biochemical pathways. ${ }^{\mathbf{4 0 , 4 1}}$ Notable work was done by Veikko Nurmikko, a Finnish microbiologist, who introduced the use of dialysis chambers to separate two auxotrophic strains of lactic acid bacteria such that they exchange metabolites via diffusion. ${ }^{42}$ In subsequent years, metabolic cross-feeding interactions were used to study the concerted degradation of herbicides ${ }^{43-45}$ or fatty acids, ${ }^{46}$ the enhanced production of amino acids, ${ }^{47}$ and to characterize auxotrophic strains. ${ }^{48-50}$ Interestingly, until today, mixed cultures of natural bacterial isolates are employed to identify novel pathways for the degradation of complex hydrocarbons like crude oil $^{51-53}$ or toxic industrial dyes. ${ }^{54,55}$

Towards the end of the 1980's, microbiologists began to study bacterial interactions from an ecological and evolutionary perspective. Among them, Julian Adams and co-workers initiated long-term chemostat cultures of Escherichia coli in glucose-limited conditions. ${ }^{56,57}$ An intriguing observation from their continuous cultivation experiments was that bacterial strains repeatedly evolved mutations in the acetyl CoA synthetase enzyme. This mutation allowed the uptake of exogenous acetate, resulting in a stable coexistence of these mutants with wild type strains that secreted acetate as a by- product of glucose metabolism. ${ }^{58}$ Several subsequent studies analysed similar cases of diversifying selection in initially clonal populations that resulted from the evolution of metabolic cross-feeding interactions. ${ }^{59-62}$

In recent years, the phenomenon of metabolite exchange has gained momentum with an increasing number of working groups studying this type of ecological interactions from different perspectives and using different methodological approaches. However, depending on their research focus and scientific background, a number of different terms are used to describe qualitatively similar interactions. For example, terms like syntrophy, ${ }^{63}$ synergism, ${ }^{27}$ symbiosis, ${ }^{28}$ mutualism, ${ }^{28}$ or obligately mutualistic metabolism ${ }^{63}$ are often used interchangeably. Each of these terms describes a reciprocal exchange of molecules, yet in specific contexts. For instance, syntrophy denotes cases where the metabolism of two organisms are energetically coupled, ${ }^{63}$ while synergism simply refers to interactions from which both interacting partners benefit. ${ }^{27}$

\subsection{Classification of cross-feeding interactions}

Given that a number of different terminologies are used to describe qualitatively similar ecological interactions, we begin by providing an unambiguous and comprehensive classification scheme to name different types of metabolic cross-feeding interactions. Due to the focus of this review, we only discuss interactions that involve an exchange of primary metabolites. In reality, however, bacteria often trade metabolites against other beneficial services such as detoxification of toxic metabolites or protection from predators. ${ }^{10}$ Even though we do not treat these interactions in detail, a similar nomenclature and conceptual logic can be applied to them as well.

Our classification framework categorizes metabolic interactions along two main axes: (i) the degree of reciprocity (i.e. unidirectional versus bidirectional metabolite flow), and (ii) the investment by the involved partners (i.e. the cost to produce the exchanged metabolite) (Fig. 1). The first parameter, degree of reciprocity, categorizes cross-feeding interactions based on whether the metabolite exchange is unidirectional (one-way) or bidirectional (reciprocal) (Fig. 1). The second parameter, investment, divides cross-feeding interactions according to the cost of biosynthesis that the interacting partners bear during the interaction, resulting into two sub-categories (i) by-product cross-feeding (Fig. 1A and B) and (ii) cooperative cross-feeding (Fig. 1C and D). By-product cross-feeding is the exchange of metabolites that results from a selfish act of the producer. ${ }^{22}$ For example, by-products can be secreted due to the degradation of complex hydrocarbons, ${ }^{64}$ the accidental leakage of metabolites through the bacterial membrane, ${ }^{65}$ or overflow metabolism. ${ }^{66}$ In general, the production of metabolic by-products is independent of the presence of an interaction partner and positively correlated with producer's growth.

In contrast, cooperative cross-feeding occurs if one partner actively invests resources to produce metabolites that benefit an interaction partner (Fig. 1C and D). In this case, the cooperating cell is producing more of the metabolites than it would require for its own growth. Enhanced levels of metabolite production 


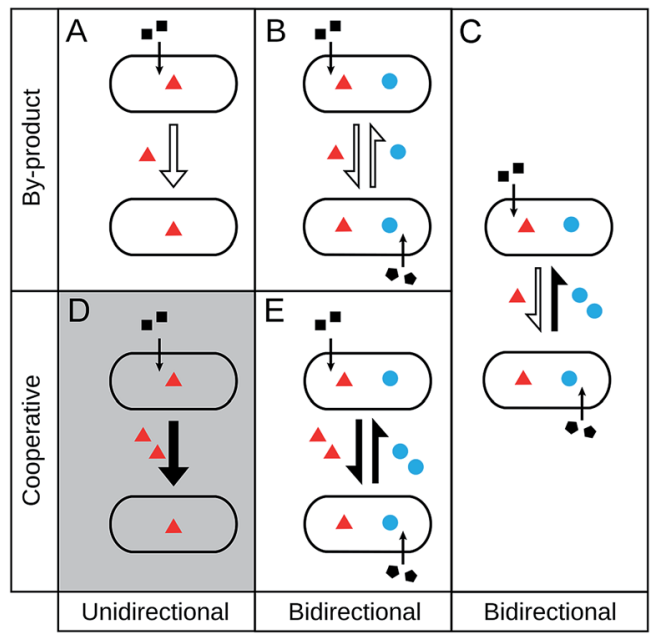

Fig. 1 Types of cross-feeding interactions. Cross-feeding interactions can be classified based on the degree of reciprocity (columns) and the investment of the interacting partners (rows). (A) Unidirectional byproduct cross-feeding: one partner produces a metabolic by-product that benefits the respective other. (B) Bidirectional by-product crossfeeding: reciprocal exchange of metabolic by-products between two partners. (C) By-product reciprocity: one partner produces a costly metabolite to benefit another cell, which in turn supplies the producer with increased amounts of a metabolic by-product. (D) Unidirectional cooperative cross-feeding: one partner bears a cost for producing a metabolite that benefits the respective other one. This box is marked in grey, because this case is hypothetical and expected to be strongly disfavoured by natural selection. (E) Bidirectional cooperative crossfeeding: reciprocal exchange of a costly metabolite that benefits both partners.

can be caused by an increased expression of the corresponding biosynthetic genes, ${ }^{67}$ a greater flux through the respective metabolic pathway, ${ }^{68}$ diverting resources into the production of a given metabolite, ${ }^{69,70}$ or harbouring a multi-copy plasmid that encodes the biosynthetic genes. ${ }^{71}$ In any case, a cell bearing this cost is significantly less fit than a cell that is not carrying the burden of increased metabolite production. ${ }^{69}$ Thus, an important difference between cooperative cross-feeding and an exchange of by-products is that cooperative cross-feeding must have been favoured by natural selection. In other words, a newly emerged mutant that produces increased amounts of a given metabolite found itself in an ecological setting, in which this cooperative trait was selectively favoured despite the concomitant fitness costs.

When cross-feeding interactions are classified in these two dimensions, it is possible to obtain five different outcomes.

2.2.1 Unidirectional by-product cross-feeding. An interaction, in which one cell releases a metabolic by-product that benefits another individual is called 'unidirectional by-product cross-feeding' (Fig. 1A). Ecologically, this type of interaction is equivalent to a commensalism. A classic example is the evolution of acetate-cross-feeding in populations of $E$. coli, ${ }^{59}$ in which glucose-utilizing cells release acetate as a metabolic by-product into the growth environment. Even though acetate contains less energy than glucose, it represents an unexploited resource. Thus, mutants emerge than preferentially use acetate as a carbon source.
2.2.2 Bidirectional by-product cross-feeding. Metabolic interactions, in which by-products are reciprocally exchanged between two partners, are classified as cases of 'bidirectional byproduct cross-feeding' (Fig. 1B). This phenomenon, which is sometimes also referred to as synergism or proto-cooperation, can, for example, be observed between ammonia oxidizing microbes (AOM) and nitrite oxidizing bacteria (NOB). ${ }^{72}$ AOM oxidize ammonia to give nitrite, which is converted to nitrate by the NOB. However, a recent analysis shows that NOB (like Nitrospora sp.) convert urea to ammonia and carbon dioxide, which in turn is taken up by the AOM, thereby resulting in a bidirectional by-product cross-feeding between AOM and NOB. ${ }^{73}$

2.2.3 By-product reciprocity. The next constellation resulting from this classification scheme is a special case called 'byproduct reciprocity' (Fig. 1C). ${ }^{75,76}$ This interaction represents a mixed case, in which one partner produces a costly metabolite to benefit its corresponding partner (i.e. a cooperative act), yet receives metabolic by-product in return. In this case, the cooperative individual produces the costly metabolite to increase the amount of by-product it obtains from its partner. Such an instance of cross-feeding has been observed in experimental cocultures of Salmonella enterica ser. Typhimurium and E. coli, wherein $E$. coli depended on $S$. enterica for methionine, while $S$. enterica consumed metabolic by-products released from $E$. coli. ${ }^{69}$ When both strains evolved in coculture, S. enterica started to produce significantly higher amounts of methionine as compared to evolved monocultures of $S$. enterica ${ }^{69}$ In other words, $S$. enterica started to actively invest in methionine production to maximize the amount of metabolic by-products it obtained from its partner.

2.2.4 Unidirectional cooperative cross-feeding. Unidirectional cooperative cross-feeding is a possibility that only exists theoretically (Fig. 1D). In reality, however, mutants that produce metabolites without being rewarded for the increased investment are strongly selected against and thus should exist only transiently.

2.2.5 Bidirectional cooperative cross-feeding. The term 'bidirectional cooperative cross-feeding' interaction denotes cases, in which each of two partners produces a costly metabolite that benefits the respective other type (Fig. 1E). Unfortunately, due to a lack of the corresponding evolutionary ancestors from which a given interaction evolved, it is usually difficult if not impossible to infer cooperative cross-feeding in natural microbial populations: control genotypes not showing the focal interaction would be needed as a baseline, against which genotypes displaying a cooperative investment can be compared. This is why the best-studied examples come from laboratories, in which this type of interaction has been synthetically engineered. One of these synthetic cross-feeding systems has been generated by gene deletions in E. coli. ${ }^{74}$ The first deletion rendered the cells dependent on a certain amino acid for growth, while the second deletion increased production of the metabolite required by the respective partner for growth. Monocultures of each genotype were unable to grow and amino acid overproduction resulted in a significant fitness cost for the 
corresponding mutants. ${ }^{74}$ In coculture, however, both types were significantly fitter than the corresponding WT, from which all mutants were generated.

\subsection{Ways to study cross-feeding interactions}

In the following two sections, we will provide an overview over different methodological approaches that have been employed to identify and characterize metabolic cross-feeding interactions in bacteria (Fig. 2).
2.3.1 Culture-dependent approaches. Isolating bacteria from environmental samples on agar plates and observing their growth patterns are classical microbiological techniques to study cross-feeding interactions. For this, environmental samples (e.g. soil, water, animal gut) are collected. Next, bacteria are isolated and purified on suitable agar plates that are often composed of a rich growth medium to also allow cultivation of strains with complex nutritional requirements. Finally, the isolated strains are either grown in monoculture or

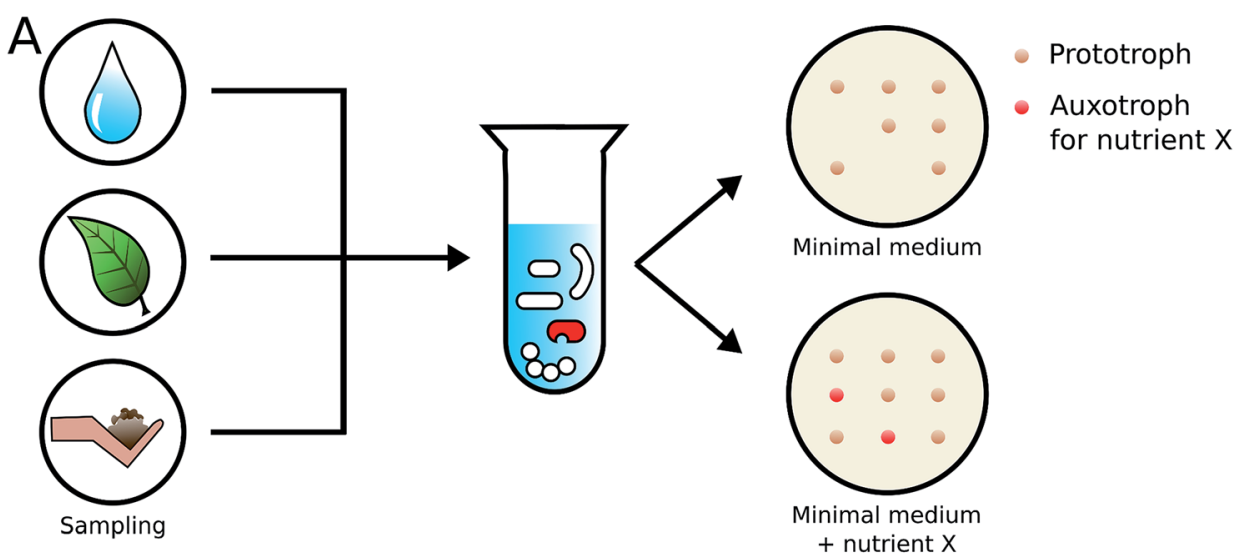

B

Type of cross-feeding

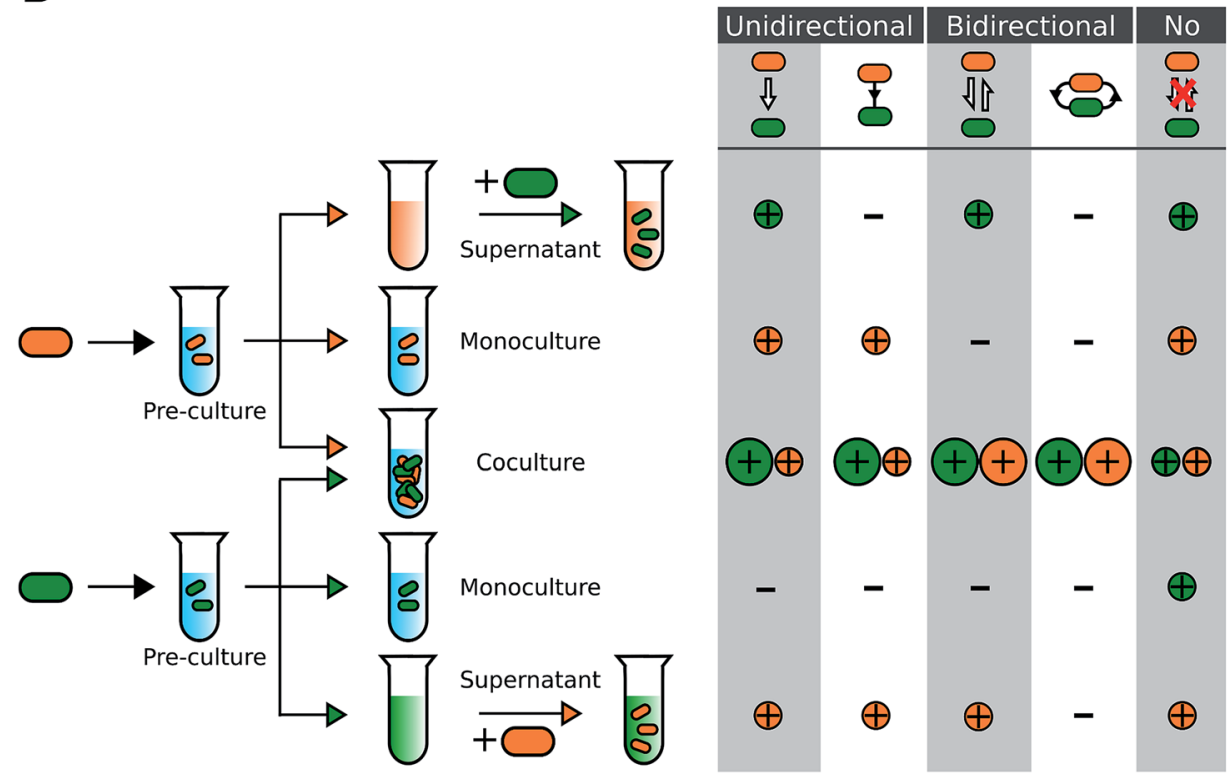

Fig. 2 Experimental identification of metabolic auxotrophies and obligate cross-feeding interactions. (A) Samples obtained from natural environments are plated on selective minimal medium agar plates. Auxotrophic genotypes (shown in red), whose growth depends on an external supply of metabolites such as amino acids, vitamins, or nucleotides, can be identified by comparing their growth on metabolite-supplemented and unsupplemented medium. (B) Isolated strains (indicated in orange and green) are subjected to different diagnostic growth conditions to characterize the type of cross-feeding interaction, in which they engage. Both genotypes are first grown in a minimal medium that is supplemented with components to allow growth of a pre-culture. This culture is then exposed to three growth conditions: (i) centrifugation and filtration to obtain a cell-free supernatant, (ii) inoculation as a monoculture in unsupplemented minimal medium, and (iii) inoculation as a coculture with the second genotype in unsupplemented minimal medium. The cell-free supernatant of one genotype serves as the culture medium for the second genotype. By quantifying the growth of each genotype in each condition (+ = growth, $-=$ no growth) and comparing the growth between conditions (size of the correspondingly coloured circles), the type of cross-feeding interaction can be identified. Besides the directionality (uni- or bidirectional), it can also be determined whether nutrients are exchanged via a transfer through the extracellular environment (white arrow between cells) or in a contact-dependent manner (black lines connecting cells). 
together with different partners in defined minimal growth media. Finding that some of the isolated strains can only grow in coculture yet not alone, is strongly pointing towards metabolic interactions (Fig. 2). ${ }^{77}$ Subsequently, the isolated partners and the exchanged compounds can be identified by genomic and chemical analyses, respectively.

Sequencing, the whole genomes of the isolated strains and/ or manipulating their genome (e.g. by mutagenesis) can shed further light on the molecular basis of the observed interaction. Intrinsic problems of this type of approaches are that only a fraction of the bacteria that were actually present in an environmental sample can be isolated and cultivated under laboratory conditions (see Section 4.5). Moreover, conditions that bacteria face in nature (e.g. spatial structure of soil particles, availability of specific nutrients, $\mathrm{pH}$, etc.) are difficult to simulate under laboratory conditions. Moreover, mixing a certain number of different strains in all possible combinations of pairwise cocultures ${ }^{77,78}$ might bring together strains that would not meet in their natural habitat, thereby biasing the view on the true spectrum of existing interactions. Nevertheless, culture-dependent approaches have provided valuable insights into the rich diversity of metabolic interactions that exists within microbial communities (Fig. 2, Table $\mathrm{S} 1 \dagger)^{79-82}$ and should be seen complementary to the so-called cultureindependent approaches.

2.3.2 Culture-independent approaches. The development of various meta-omics techniques revolutionized the study of microbial communities, because it allowed to also include prokaryotes that cannot be cultivated under laboratory conditions. Many studies using these approaches predicted metabolic cross-feeding interactions among community members through sequencing and annotating the metagenome of the community or the whole genome of individual clones. ${ }^{\mathbf{8 3 - 8 6}}$ Moreover, the combination of selective staining methods (e.g. fluorescence in situ hybridization (FISH)) with high-resolution microscopic techniques affords to analyse spatial arrangements within microbial communities, and thus use close spatial proximities as an indicator for possible metabolic interactions. ${ }^{87-89}$ On the other hand, comparing changes in the transcriptomes of cells in mono- and cocultures (using microarray, RNA-Seq; Table $\mathrm{S} 1 \dagger$ ) provides a powerful tool to qualitatively analyse ecological interactions between two bacterial genotypes. The up-regulation of genes in coculture, which are involved in the production of certain metabolites, hints at a possible exchange of these compounds. ${ }^{79,90,91}$ The next step is usually the chemical identification of the exchanged metabolites in the cell-external environment using mass-spectrometryor NMR-based approaches. ${ }^{\mathbf{9 2 - 9 4}}$

The major advantage of culture-independent approaches is that they provide hypotheses without the laborious and potentially biased isolation of environmental microorganisms. A downside, however, is that these techniques strongly depend on the quality of both the extraction process (i.e. DNA, RNA, or proteins) and the obtained reads. Furthermore, divergent sequences, the presence of metabolic enzyme homologs, and promiscuous enzymes with yet uncharacterized catalytic capabilities could lead to a potential overestimation of metabolic dependencies. As a consequence, the performed studies mainly provide hypotheses that need to be verified in subsequent experiments. Thus, many recent studies combine culturedependent and independent approaches as complementary techniques to capture a more holistic picture of the microbial community. ${ }^{79,90,95}$

\subsection{Distribution of cross-feeding interactions in nature}

How prevalent is metabolite cross-feeding in nature? To address this question, we have screened the available literature for cases, which experimentally demonstrated cross-feeding of building block metabolites in natural bacterial isolates (Table $\mathrm{S} 1 \dagger)$. In total, 77 studies were included that reported about 135 different interactions covering the period of 1952 to 2016. The metabolites identified in these studies were divided into the following six main categories: carbon source, nitrogen source, amino acids, nucleotides, vitamins, and others (i.e. phosphorus, iron, or organic compounds). Hormones, growth factors, or electron exchange were deliberately excluded from the analysis.

The results of this meta-analysis indicated that metabolite cross-feeding is indeed very common both among different bacterial species and between bacteria and members of other kingdoms including archaea, fungi, animals, protists, and plants (Fig. 3). Moreover, cross-feeding of different molecules (Fig. 3B) was remarkably diverse with regards to the lifestyle of the involved partners and the habitats, in which the interaction occurred $^{\mathbf{6 8 , 8 8 , 9 6 - 9 9}}$ (Table S1 $\dagger$ ). Another insight that emerged from this comparative analysis was that in many cases, interacting bacterial cells tended to be localized in close spatial proximity, presumably to facilitate an exchange of metabolites. ${ }^{87,89}$ In general, photosynthetic and nitrogen-fixing organisms commonly traded carbon and nitrogen respectively against other commodities, ${ }^{\mathbf{9 4 , 1 0 0 , 1 0 1}}$ which represents a major input of these fundamental elements into the global biochemical cycles.

Strikingly, the nature of the exchanged metabolites drastically depended on the corresponding partner, with which bacteria interacted (Fig. 3C). For example, plants and protists tended to mainly provide bacteria with (assimilated) carbon. ${ }^{102-104}$ In return, bacteria commonly supplied plants with nitrogen $^{102}$ and algae with vitamins, which $\sim 50 \%$ of all algal species cannot produce autonomously. ${ }^{105}$ In general, bacteria are an important source of nitrogen for fungi, protists, plants, and animals. Animals commonly provide shelter and food to bacteria (e.g. in the gut ${ }^{99}$ ), while receiving a wide range of the metabolites including amino acids and vitamins in return. Interestingly, based on the collected data, bacteria are the only partner who cross-feed nucleotides either with other bacteria ${ }^{\mathbf{1 0 6}}$ or with members of other kingdoms. ${ }^{91}$

Our literature survey also revealed that some specific types of cross-feeding interactions attracted more research attention than others. It is important to keep in mind that this pattern does not reflect an increased prevalence of these interactions in nature. For example, cross-feeding between Streptococcus and Lactobacillus has been extensively studied during the last decades, because of the biotechnological interest in these 
A

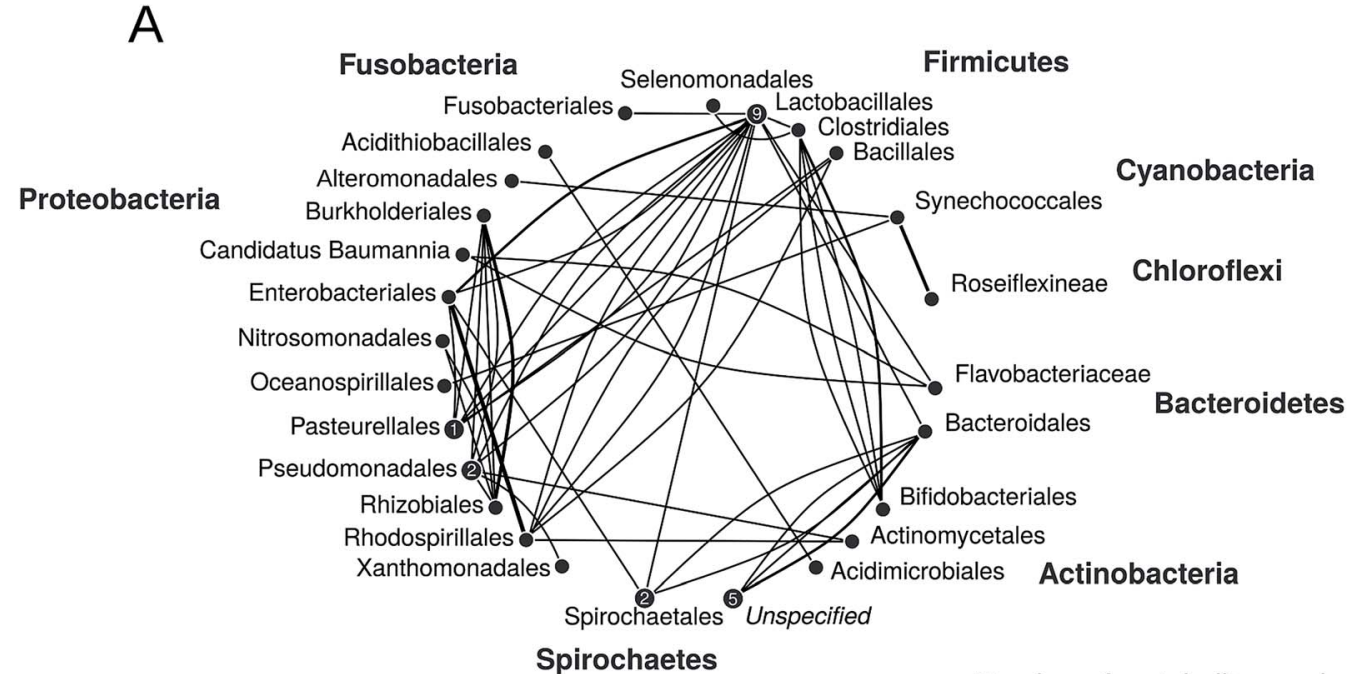

B

Spirochaetes

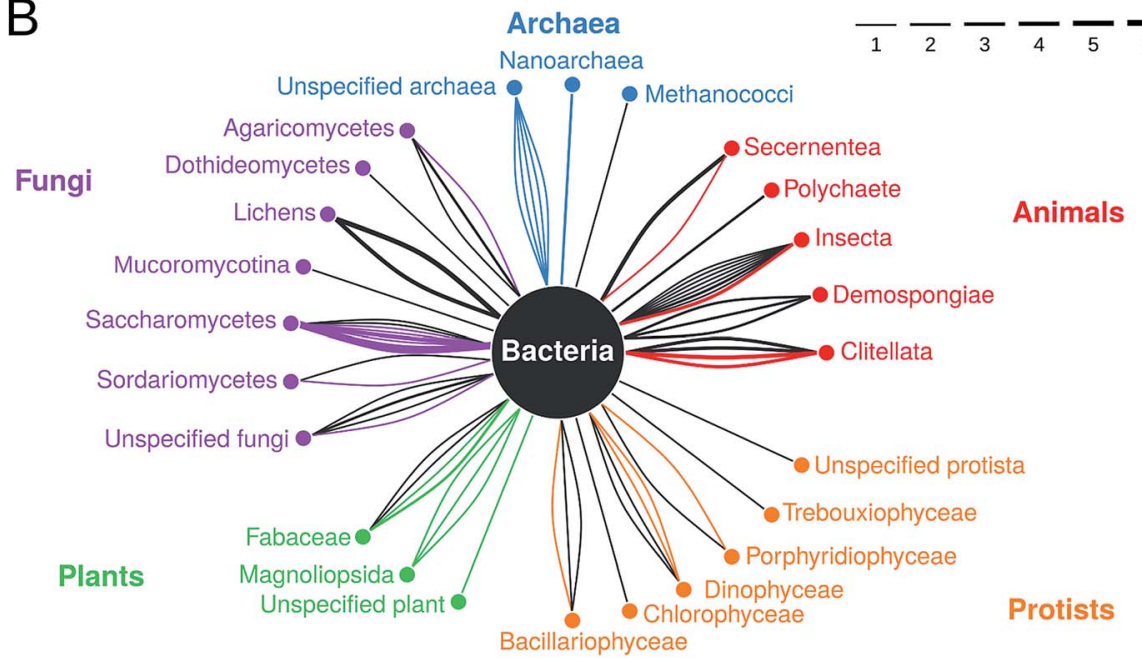

C

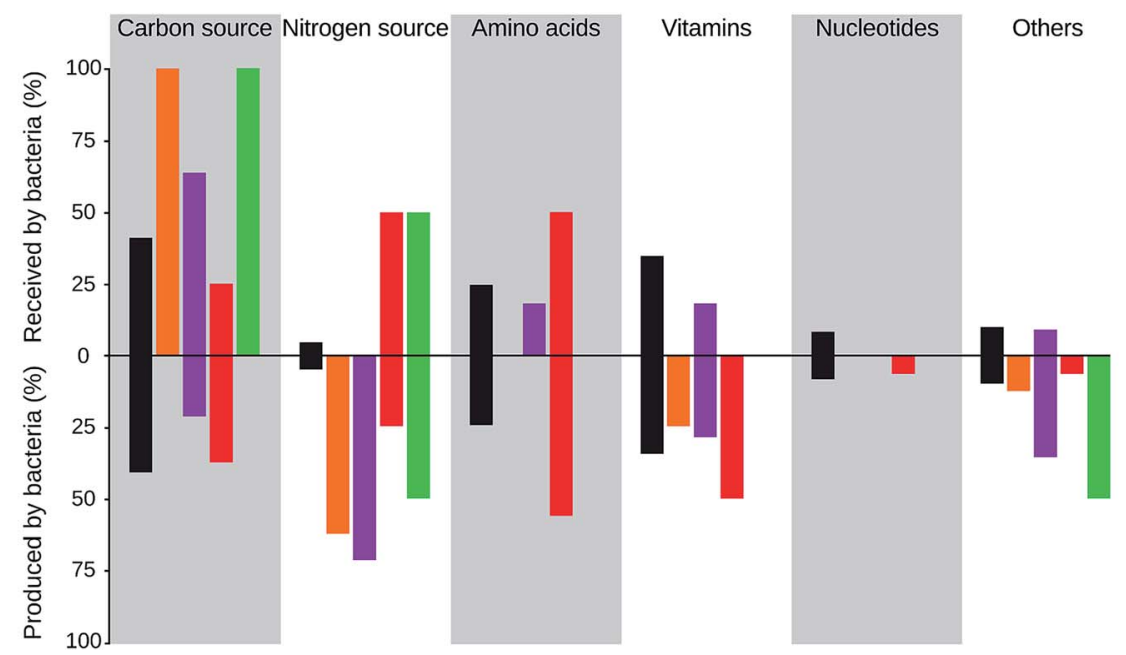

Fig. 3 Prevalence of metabolic cross-feeding interactions. Data is the result of a meta-analysis of 78 studies that included 135 different crossfeeding interactions (Table S1 $\uparrow$ ). (A) Metabolic cross-feeding interactions (edges) between bacteria $(n=68)$. Bacteria from the same order are summarized in nodes and nodes are grouped by the respective phylum. Numbers within nodes represent instances of within-order crossfeeding interactions. The thickness of edges indicates the number of different metabolites that are exchanged. (B) Interactions between bacteria and organisms from other kingdoms $(n=67)$. Edge thickness is scaled as in $(A)$ and its colour corresponds to the partner that is producing the exchanged metabolite. (C) Percentage of specific metabolite classes that are either received (upper half) or produced (lower half) by bacteria in cross-feeding interactions relative to the total number of cases in each category $(n=135)$. 
strains that are used in dairy production. On the other hand, many interactions remain likely undiscovered, because of a lack of scientific inquiry or because technical difficulties thwart the isolation and analysis of the partners involved.

\subsection{Mechanisms of metabolite transfer}

Given that cross-feeding is so common in the microbial world (Fig. 3, Table S1 $\dagger$ ), the question arises how metabolites are transferred between bacterial cells. Considering the large variety of bacterial lifestyles (e.g. biofilm growth versus planktonic cells, endosymbionts versus free-living bacteria) as well as the structural diversity of metabolites that can be exchanged, it is likely that bacteria use different mechanisms to transfer material from one cell to another one. Modes of metabolite exchange can be classified into contactindependent and contact-dependent. In this context, 'contact' refers to a direct physical connection between two or more interacting cells.

2.5.1 Contact-independent mechanisms. Planktonic cells use various mechanisms to exchange metabolites via the extracellular environment (Fig. 4A-D). A metabolite transfer via the surrounding medium can result from an intentional or unintentional release of the focal metabolite into the environment, or alternatively, through the budding-off of vesicles that contain the exchanged good. By secreting a metabolite into the surrounding, it is made available to all neighbouring cells. Such a so-called 'public good' can, however, cannot only be used by the intended recipient (e.g. other cooperative cells), but also by other, non-cooperating genotypes in the surrounding. Another disadvantage of this mode of transfer is that the released metabolite might be chemically altered, ${ }^{107,108}$ degraded, ${ }^{109,110}$ or be lost by diffusion. An alternative transfer mechanism that can help to solve some of these problems is to exchange membrane vesicles that contain the traded commodity. Such vesicles not only protect the transported molecules, but potentially also allow for a more specific and targeted exchange. ${ }^{111}$

2.5.1.1 Passive diffusion. The process of passive diffusion includes the passage of molecules through the cell membrane, often along concentration gradients and without the involvement of ATP (Fig. 4A). This type of exchange is commonly observed for small molecules like hydrogen, formate, potassium, volatile compounds like methanol, ${ }^{112}$ as well as metabolites like vitamins, ${ }^{103}$ acetate, ${ }^{113}$ amino acids, and intermediates of the TCA cycle (e.g. 2-ketoglutaric acid, gluconate) ${ }^{114}$ Metabolites that are transferred in this way are often released as a result of overflow metabolism, ${ }^{66}$ thus giving rise to interactions, in which by-products are being exchanged.

In this type of interactions, the speed of diffusion limits the exchange of metabolites and thus the growth of both interacting partners. For instance, Syntrophomonas wolfei and Methanobacterium formicicum exchange either hydrogen or formate as an electron carrier depending on the spatial distance between cells. ${ }^{115}$ Close proximity promotes electron transfer via hydrogen, because of its rapid diffusion through the medium, whereas formate is used for longer-distances. ${ }^{116}$

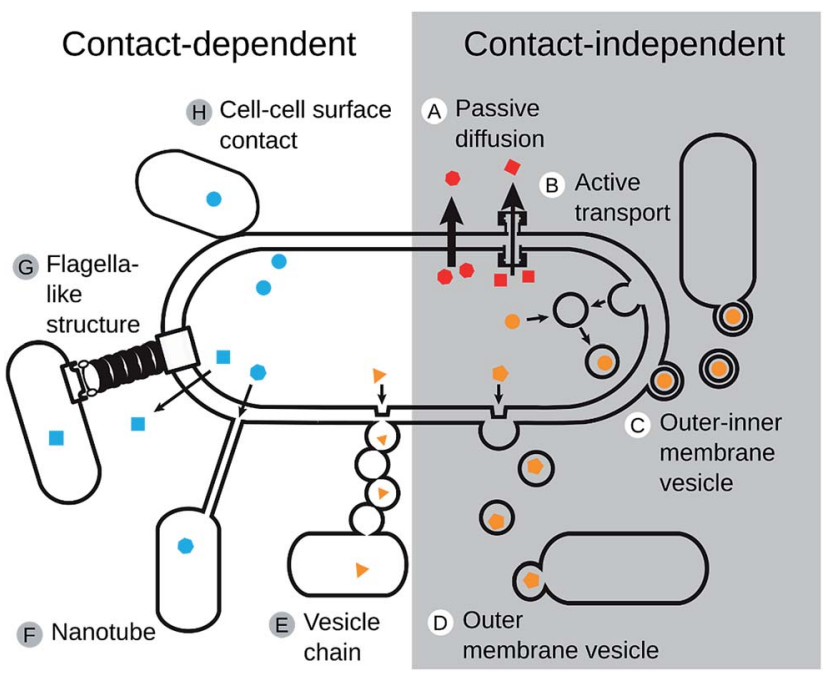

Fig. 4 Mechanisms of metabolite transfer. Molecules can be transferred from one cell to another one using (A-D) contact-independent- or $(E-H)$ contact-dependent means of cross-feeding in bacteria. Contact-independent mechanisms that are based on the diffusion through the extracellular environment require a release of the exchanged molecule by (A) a passive diffusion across the cellular membrane ${ }^{115,116,425}$ or (B) an active transport of molecules via membrane-based transporters. ${ }^{125,126}$ Alternatively, chemicals can be transferred via membrane vesicles with (C) a bilayer formed of the outer and inner membrane ${ }^{140,141}$ or (D) a single membrane. ${ }^{142} \mathrm{~A}$ contact-dependent exchange of metabolites between two cells can be mediated by (E) outer membrane vesicles that link to form a chain. ${ }^{143}$ or (F) intercellular nanotubes that allow an exchange of cytoplasmic contents. ${ }^{145,147}$ Moreover, also (G) flagella-like structures $^{67,148}$ or $(H)$ a direct surface contact ${ }^{149,150}$ can facilitate the exchange of metabolites between cells.

2.5.1.2 Active transport. Molecules that require an active transport are usually unable to cross the bacterial membrane due to their molecular weight, charge, or polarity. Examples include some amino acids, ${ }^{\mathbf{1 1 7}}$ siderophores, ${ }^{\mathbf{1 1 8 , 1 1 9}}$ enzymes, ${ }^{\mathbf{1 2 0}}$ polymers, ${ }^{121,122}$ and vitamins. ${ }^{23}$ In these cases, the exchanged molecule needs to be exported into the extracellular environment, involving energy-dependent transport systems such as the ATPbinding cassette (ABC) transporter family ${ }^{123}$ or the phosphotransferase system. ${ }^{124}$ Also, corrinoids, a group of compounds, which consist of four pyrrole rings, fall into this category. ${ }^{23}$ Both Gram positive and Gram negative bacteria feature specific transporters for corrinoids (i.e. BtuFCD and BtuBFCD, respectively). ${ }^{125}$ Cobalamin (i.e. vitamin $\mathrm{B}_{12}$ ) is such a corrinoid, which is actively transported through the bacterial membrane. Cobalamin and its analogues have been identified in human faeces and are likely produced by members of the gut community. However, not all prokaryotes in the human gut can synthesize cobalamin. For instance, Bacteroides thetaiotaomicron contains multiple transporters for the uptake of externally available cobalamin, ${ }^{126}$ suggesting corrinoid cross-feeding in the gut.

2.5.1.3 Vesicle-mediated transport. Membrane vesicles (MVs) are small, spherical encapsulations that form via protrusion of the outer membrane and subsequent pinching off from the cell $^{127-129}$ (Fig. 4C and D). For this reason, MVs consist primarily 
of outer membrane material (i.e. proteins, lipopolysaccharides, phospholipids) and encapsulate periplasmic components such as proteins, ${ }^{130-133}$ enzymes, ${ }^{18,134,135}$ nucleic acids, ${ }^{136}$ or signalling molecules. ${ }^{137,138}$ In addition, bacterial MVs are well-known shuttles for communication signals, which are especially common in pathogenic bacteria. ${ }^{\mathbf{1 2 8 , 1 3 1 , 1 3 9}}$ As such, MVs provide an enclosed, protected environment for the exchanged molecules from the external chemical milieu.

Currently, two types of membrane vesicles are known from bacterial isolates. The first and most common type are outer membrane vesicles (OMVs). The second kind of vesicles are called outer-inner membrane vesicles (O-IMVs). These O-IMVs are formed by the protrusion of both the inner and outer membrane and contain cellular contents, especially nucleic acids. ${ }^{\mathbf{1 4 0}}$ O-IMVs have been detected in Shewanella vesiculosa, Pseudomonas aeruginosa, Neisseria gonorrhoeae, and Acinetobacter baumannii. ${ }^{\mathbf{1 4 1}}$

Membrane vesicles are common and produced by a variety of different bacterial species. Until recently, research on MVs has mainly focussed on their role in transporting virulence factors from bacteria to host cells. Hence, little is known on whether MVs are also involved in transferring nutrients between bacterial cells. An exception is a study, in which the marine cyanobacterium Prochlorococcus was shown to release large quantities of OMVs. ${ }^{142}$ Besides DNA and RNA, OMVs also contained protein, which supported the growth of other marine bacteria such as Altermonas sp. and Halomonas sp., indicating crossfeeding of organic carbon. More work is necessary to fully evaluate the role of MVs as a means to shuttle nutrients between bacterial cells.

2.5.2 Contact-dependent mechanisms. Contact-dependent means of metabolite transfer are per definition based on a physical contact between interacting cells and in some cases, involve dedicated structures to shuttle materials from one cell to another one. Thus, these types of mechanisms require not only an increased energetic investment to establish these structures, but also a strategy to find and connect to suitable interaction partners. General advantages of this mode of transfer are that the exchanged molecules are protected from the extracellular milieu and that interactions partners can potentially be specifically chosen.

2.5.2.1 Vesicle chains. OMVs are not only used as transporting agents themselves, but also as building block materials to establish cell-cell conduits (Fig. 4E). For instance, predatory bacteria of the species Myxococcus xanthus link multiple individual membrane vesicles together to from socalled vesicle chains. ${ }^{\mathbf{1 4 3}}$ The MVs within these chains contain lipids, sugars (fucose and mannose), carbohydrates ( $N$-acetylglucosamine and $N$-acetylgalactoseamine), and certain proteins that are required for coordinated movement (CglB and Tgl). ${ }^{\mathbf{1 4 4}}$ Vesicle chains provide an intercellular network for material transport. The molecular details, however, of how materials are transported within these interconnected vesicles, remain unknown.

2.5.2.2 Nanotubes. Advancement in imaging techniques to study cocultures of interacting bacteria has led to the discovery of several structures that might be used to transfer cytoplasmic materials between bacterial cells (Fig. 4F). For example, unshaken cells of Bacillus subtilis, for example, use nanotubes for shuttling cytoplasmic proteins and plasmid DNA to cells of the same or different bacterial species. ${ }^{\mathbf{1 4 5 , 1 4 6}}$ These tubes were observed to connect neighbouring cells (intercellular nanotubes) as well as extend from cells into the surrounding (extending nanotubes). ${ }^{\mathbf{1 4 6}}$ The membranous envelope of these structures was found to be constricted at certain points, giving the tube a sequential, bead-like appearance with a continuous lumen that is similar to the abovementioned vesicle chains. ${ }^{\mathbf{1 4 6}}$ In another study, nanotubes were found to be used to transport essential amino acids between auxotrophic genotypes of $E$. coli that have been incubated under shaking conditions. ${ }^{147}$ Here, intercellular connections consisted of membrane-derived lipids, showed a continuous lumen, and were used to transport cytoplasmic materials between bacterial cells of the same or different species. In both nanotube-forming species (i.e. B. subtilis and $E$. coli) it remains unclear whether interaction partners are actively chosen (e.g. by receptors on the cell surface or chemotaxis) or if cell-attachment is unspecific (e.g. mediated by non-specific adhesins or sticky polymers).

2.5.2.3 Flagella-like filaments. A contact-dependent exchange of metabolites does not always rely on dedicated structures such as membrane vesicles or nanotubes, but can also be facilitated by already existing structures that are repurposed (Fig. 4G). The fermentative bacterium Pelotomaculum thermopropionicum was shown to form aggregates when cocultured with the methanogen Methanothermobacter thermautotrophicus to facilitate the transfer of hydrogen. ${ }^{148}$ Analysis of these aggregates indicated that flagellae were mediating this interaction. ${ }^{67}$ Gene expression analysis confirmed that binding of a flagellin protein (i.e. FliD) induced an up-regulation of genes for enzymes involved in methanogenesis. Thus, the flagellum is not only used to ensure physical proximity, but also to synchronize the metabolism of both interacting partners.

2.5.2.4 Cell-cell contact. The formation of extracellular appendages like nanotubes likely represents a significant cost to nutrient-limited cells, which should be avoided by crossfeeding bacteria. When cells are in close physical contact, such as within multicellular aggregates, the metabolite exchange is likely assisted by direct membrane contact (Fig. 4H). The green sulfur bacterium Prosthecochloris aestaurii for example is photoautotrophic, yet requires an electron donor to grow. The latter can be provided by a heterotrophic partner such as Geobacter sulfurreducens, ${ }^{149}$ which supports growth of $P$. aestaurii when both partners show an intimate cell contact. Additionally, a trans-outer membrane cytochrome complex in G. sulfurreducens was shown to be essential for cross-feeding of electrons. Another case of direct cell contact mediating an exchange of cytoplasmic materials was observed in a synthetic consortium of Clostridium acetobutylicum and Desulfovibrio vulgaris Hildenborough. ${ }^{\mathbf{1 5 0}}$ In these cocultures, D. vulgaris could grow despite its inability to grow in monoculture. Differential labelling of cytoplasmic membrane and the peptidoglycan showed the absence of the peptidoglycan layer in the region of cell contact. ${ }^{150}$ 


\section{The evolution and maintenance of metabolic cross-feeding interactions}

The reported ubiquity of metabolic cross-feeding interactions in bacteria raises a fundamental question: why should bacterial cells start to actively invest resources to benefit other, potentially unrelated individuals? Natural selection predicts that organisms should maximize their fitness at the expense of others. How does this reconcile with an exchange of biosynthetic products that, in many cases, incurs significant fitness costs to the producing cell? For cooperative interactions, such as an exchange of costly metabolites, evolutionary theory predicts strategies should be favoured that reap cooperative benefits without reciprocating..$^{22}$ These non-cooperating types, which utilize exchanged metabolites without contributing to their production, gain a significant fitness advantage over cells carrying this burden. Ultimately, the short-term advantage gained by such non-cooperators can, at least theoretically, result in an extinction of cooperating genotypes, ${ }^{151,152}$ thus representing a permanent threat to the existence of cooperative crossfeeding interactions. Consequently, a theory to solve this socalled tragedy of the commons needs to not only explain the emergence of reciprocal cross-feeding interactions, but also to provide mechanisms that can help explain the persistence of these cooperative relationships in the long-run.

The problem, however, is multi-faceted, since different levels of biological organization can affect the dynamics of crossfeeding interactions in different ways. This is because crossfeeding interactions are strongly influenced by, for example, (i) the mode of function and regulation of the individual enzymes involved in the biosynthesis of the exchanged metabolites, (ii) the cellular allocation of limited resources (e.g. nutrients, expression machinery, space) to the cellular functions that are required for the cross-feeding interaction, as well as (iii) the biotic composition of the bacterial community that determines the frequency of potential producers and consumers of exchanged metabolites. Also features of the ecological environment like (i) the diffusibility of chemicals, (ii) the availability of nutrients, or (iii) the degree of spatial structuring will decide about the evolutionary fate of a metabolic cross-feeding interaction.

Hence, understanding the evolutionary trajectories that lead to obligate cross-feeding interactions requires the identification of the metabolic, physiological, and ecological factors enabling metabolite exchange as well as the evolutionary mechanism stabilising these interactions in the bacteria's natural environment.

\subsection{Metabolic factors}

3.1.1 Economics of microbial metabolite trade. Any biosynthetic function that consumes resources incurs a metabolic cost to the cell, because the used resources are not available anymore for other cellular processes. In general, bacterial cells face the problem to optimally allocate limited resources to different cellular functions. ${ }^{\mathbf{1 5 3}}$ One particular resource allocation problem is the distribution of fluxes (i.e. the rate at which a metabolic substrate is converted to a specific product) through the metabolic network to optimally provide building block metabolites like amino acids, nucleotides, or lipids for cell growth. ${ }^{154}$ The biosynthesis of each of these metabolites has a metabolic cost that depends on the resource requirement of the corresponding biosynthetic pathway. As cellular resources and available nutrients in the environment are usually limited, the anabolism of a bacterium is closely linked to its fitness..$^{12}$ As a consequence, a resource-efficient and tightly controlled metabolite production is vital for an organism to successfully compete with other co-occurring species for limited resources. In the case of cross-feeding interactions, each of the two interacting partners invests parts of its resources into the production of shared metabolites. A potential explanation that can account for this behaviour is a division of metabolic labour: the costs for producing increased amounts of metabolites to allow growth of interaction partners may be less than the energy saved for not having to produce other metabolites that each cell receives in return. ${ }^{74}$

This situation strongly resembles trading interactions in human societies and there is growing appreciation in the scientific literature that the advantage of metabolic trade in bacterial communities can be assessed by applying economic models. ${ }^{155,156}$ One particular useful concept to investigate biochemical interdependencies between microorganisms is the theoretical framework of comparative advantages. In 1814, David Ricardo developed this economic theory to explain how two countries could benefit from international trade. ${ }^{157}$ Comparative advantages can quantitatively explain how the resource costs to produce required goods (e.g. metabolites) can translate into mutual benefits if two parties (e.g. different bacterial species) engage in trade of the respective goods (Fig. 5). Hence, such comparative advantages are likely important preconditions for the evolution of specialisation and cooperative biological trade..$^{156}$

Also, trade-offs in the cellular metabolic networks of single organisms could explain the benefits of metabolite exchange between different cells. Metabolic trade-offs occur if improving the metabolic cost efficiency of one metabolic process or pathway (e.g. due to adaptations) is coupled with increased costs for a different process. Such biochemical conflicts are known to play a central role in the evolution of specialisation ${ }^{158}$ and several trade-offs have been identified for a wide range of different metabolic processes in bacteria (for a recent review see Ferenci, 2010 (ref. 159)). Thus, trading metabolites may allow bacteria to increase resource efficiency by segregating conflicting metabolic pathways into separate cells. ${ }^{160}$

3.1.2 Molecular basis for comparative advantages and biochemical conflicts in metabolite production. Several studies stress the importance of metabolic trade-offs ${ }^{24,158,161}$ and comparative advantages ${ }^{155,162}$ for the adaptive evolution of cooperative cross-feeding interactions. However, what molecular mechanisms could cause trade-offs and/or comparative advantages in metabolite production within bacterial communities? Quantitative fitness consequences of metabolic trade in synthetic bacterial communities are often explained by the architecture of the underlying metabolic network or the 


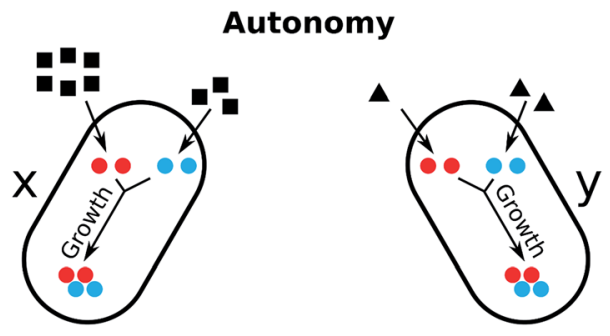

Trade

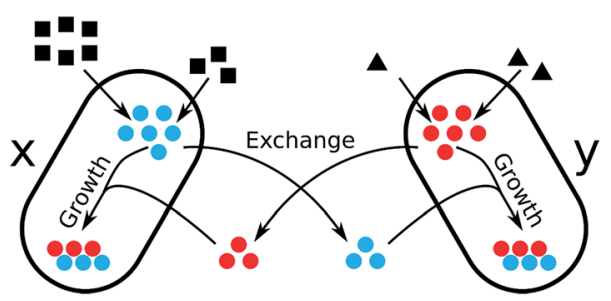

Fig. 5 Economics of microbial metabolite trade and the role of comparative advantages. The scheme depicts the consequences on cell growth resulting from two opposing metabolic strategies, metabolic autonomy (above) and metabolite trade (below), in the presence of comparative advantages. Two bacteria ( $x$ and $y$ ) require two metabolites (red and blue) for cell growth. Each organism uses a different substrate from the environment and is able to produce each metabolite from the respective substrate. Both organisms differ in their metabolic costs to produce the two metabolites: bacterium $\mathrm{x}$ requires 3 units of its substrate to produce 1 unit of the red metabolite and 1.5 units substrate to produce the blue metabolite. In contrast, bacterium y requires 0.5 units of its substrate to produce the red metabolite and 1 unit substrate to synthesise the blue metabolite. Hence, organism y has an absolute advantage to produce both the red and the blue metabolite, as it requires less units of resources to synthesize them compared to bacterium $\mathrm{x}$. However, organism $\mathrm{x}$ has a comparative advantage to produce the blue metabolite, because it can produce twice as many blue as red metabolites when it reallocates all resources from the production of red metabolites to the synthesis of blue. Analogously, organism y has a comparative advantage to produce the blue metabolite over the production of the red metabolite. Let us assume, that red and blue metabolites are required in equal quantities for cell growth. In case of metabolic autonomy, bacterium $x$ requires 9 units of its resource to produce 2 units each of the red and blue metabolite. y requires 3 units of its resource to produce the same amounts. If each organism specialises for the biosynthesis of the metabolite for which it has the comparative advantage ( $\mathrm{x}$ : blue, $\mathrm{y}$ : red) and trades half of the produced metabolites with the other organisms, each organism can dedicate $50 \%$ more of each metabolite to its growth, while consuming the same amount of resources. Thus, the trade of the red and blue metabolites can be mutually beneficial to both organisms. Adapted from ref. 155.

topology of the corresponding biosynthetic pathway. ${ }^{25,70}$ This is because the structure of a species' metabolic network, which determines its ability to produce a given metabolite from available substrates (Fig. 6), is known to determine metabolite production costs. ${ }^{163-165}$

3.1.2.1 Molecular causes of comparative advantages. Differences in the architecture of metabolic networks and/or different resource preferences between bacterial species can entail different costs for metabolite production. This can cause reciprocal comparative advantages that can promote the evolution of cross-feeding interactions. Since different species often differ in the structure of their metabolic network, it is likely that these species also differ in their biosynthetic costs to produce different metabolites. ${ }^{166}$ Hence, reciprocal comparative advantages likely exist between phylogenetically distant species, which also differ in the structures of their metabolic networks. ${ }^{155}$

Another possibility of how the metabolic network structure can generate comparative advantages are different substrate preferences among bacteria. Coexisting bacterial species frequently utilise a distinct sub-set of carbon sources that are available in the environment. ${ }^{167,168}$ Different carbon sources often enter the metabolic network at different locations (Fig. 6B). It has been shown that the point, at which a carbon source enters the central metabolic network, strongly affects the distribution of metabolic fluxes ${ }^{\mathbf{1 6 9 , 1 7 0}}$ and, in this way, also the production costs of individual amino acids. ${ }^{\mathbf{1 6 4}}$ Hence, a consequence of diverse carbon source preferences is that one species of the bacterial community can have a comparative advantage in the biosynthetic cost efficiency of a specific set of metabolites over another species, which in turn has a comparative advantage in the production of another set of metabolites (Fig. 6C).

Comparative advantages can also arise in bacterial communities due to spatial structure. In a spatially structured bacterial population, cells may experience unequal access to different resources due to a heterogeneous distribution of chemicals on a micro-scale. ${ }^{171}$ For instance, in bacterial biofilms, nutrients are mainly accessible for cells residing close to the surface. In contrast, excreted metabolic by-products are likely enriched in the inner part of the biofilm and therefore more available to cells that dwell in the subsurface. ${ }^{171,172}$ In fact, it has been observed for a variety of different biofilm-forming bacteria that cells exhibit distinct metabolic phenotypes depending on their positioning within the biofilm and thus, the local environmental conditions to which cells are exposed. ${ }^{173}$ Such differences in metabolic phenotypes may cause reciprocal comparative advantages in the production of different metabolites that can promote crossfeeding interactions between different cells within the biofilm.

However, heterogeneity in metabolic phenotypes within bacterial populations is not limited to spatially structured environments or species with different genetically determined metabolic capabilities. Phenotypic heterogeneity can also arise in homogenous environments, ${ }^{\mathbf{1 7 4 , 1 7 5}}$ which in turn can give rise to reciprocal comparative advantages between different phenotypes, thereby promoting a cooperative exchange of metabolites. Bacterial populations frequently display heterogeneity, where two essential metabolic functions are partitioned between two subpopulations. Prominent examples are nitrogen fixation and photosynthesis in cyanobacteria ${ }^{176}$ or acetate and acetoin production in Bacillus subtilis populations. ${ }^{177}$

3.1.2.2 Molecular causes of biochemical conflicts. Biochemical conflicts between two metabolic functions commonly arise due to resource allocation trade-offs. ${ }^{159}$ Different metabolic functions usually compete for the same cellular resources, e.g. the same precursor metabolites, ATP, or the use of the cellular transcription-/translation machinery. ${ }^{\mathbf{1 6 3}}$ Importantly, resources that are consumed by one metabolic function are not available anymore to another one. Thus, the metabolic flux through one 
A

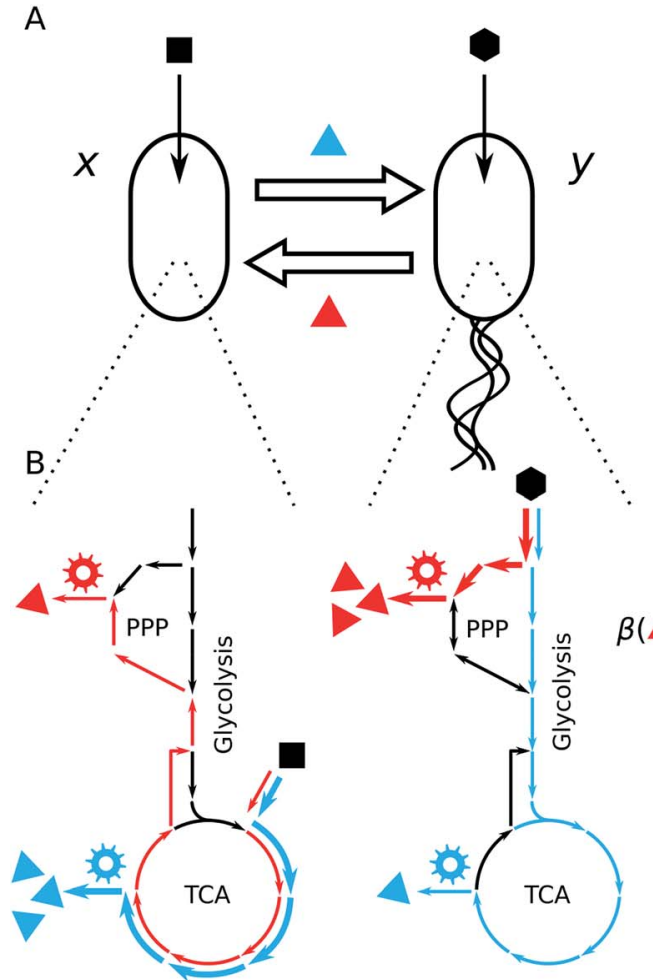

C

Growth / Fitness

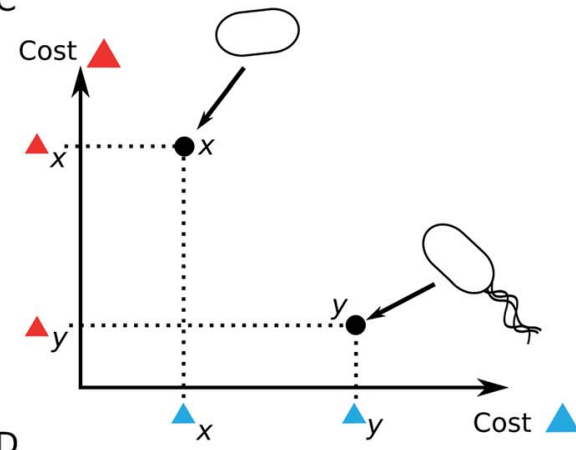

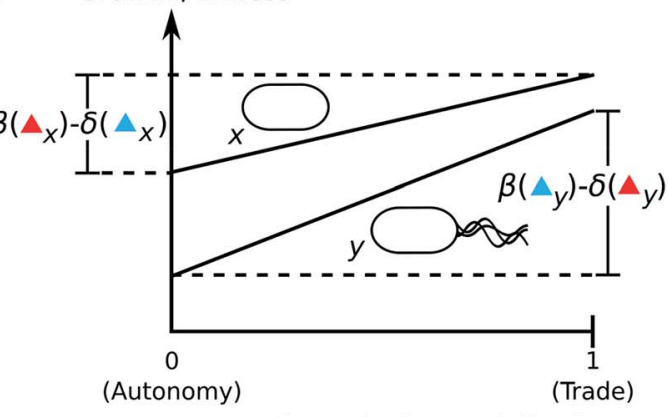

Degree of metabolic specialisation

Fig. 6 Possible advantages of metabolite cross-feeding. (A) Cross-feeding interaction of two metabolites (blue and red triangles) between two different bacterial strains $x$ and $y$. Each strain uses a different growth substrate (black square/hexagon). (B) Scheme of the central metabolic networks including glycolysis, Pentose Phosphate Pathway (PPP), and TCA cycle. The two distinct substrates enter the metabolic networks at different positions. The reactions that are significantly involved in the chemical transformation from the substrate to the exchanged metabolites are highlighted in blue or red, respectively. Gear wheels denote the biosynthetic machineries (i.e. enzymes) that utilise precursor metabolites from central metabolic pathways for the production of the focal metabolites. (C) Schematic diagram of the differences of metabolic costs to synthesize the blue and red metabolites between the different strains. (D) Growth and fitness consequences of metabolic trade. The effect of metabolic trade for strain $\mathrm{x}$ is thus a function of the benefits $\beta$ for not having to synthesise the red metabolite minus the costs $\delta$ that are associated with the overproduction of the metabolite that is produced to cover the demand of strain y. The fitness/growth effect of the cross-feeding interaction for strain $\mathrm{y}$ is determined by the benefits $\beta$ that y receives by not having to synthesise the blue metabolite minus the costs $\delta$ to synthesise the red metabolite for strain $\mathrm{x}$.

pathway might limit the activity of other metabolic processes. ${ }^{178,179}$ Segregating such antagonistic biochemical processes into different bacterial cells can resolve the biochemical conflict between them. ${ }^{158}$

The above-mentioned examples illustrate that comparative advantages, and biochemical conflicts in metabolite production between co-occurring organisms are prevalent in natural bacterial communities and are thus important determinants for the evolution of cooperative metabolite exchange. While biochemical conflicts and comparative advantages can explain the mutual fitness benefit that results from metabolic crossfeeding interactions, it is important to note that in isolation they are not sufficient to explain the evolution of cooperative interactions, since they do not provide a mechanism to prevent the exploitation of exchanged metabolites by non-cooperating cells (see Section 3.5).

\subsection{Metabolite leakage: the first step towards the evolution of metabolic interactions}

Many metabolic functions are leaky, which means that the products of these biochemical transformations are released into the extracellular environment, thus making them available to other cells ${ }^{180,181}$ (Fig. 7A and B). Metabolite leakage can facilitate the evolution of unidirectional by-product crossfeeding interactions as well as metabolic interdependence (Fig. 7A). This is because neighbouring cells can take advantage of the released resource, thus saving the costs of producing these metabolites by themselves (see Section 3.3). Cells, which use the metabolic by-products of other cells, adjust their metabolism by redistributing metabolic fluxes, which in-turn can cause leakage of other metabolites. The resulting mosaic of different metabolic strategies potentially provides the basis for the emergence of new metabolic dependencies (Fig. 7B and C).

\subsection{Emergence of by-product cross-feeding through gene loss}

Loss or deactivation of a metabolic gene by mutation can render the survival of the resulting auxotrophic mutant contingent on an environmental supply of the focal metabolite. Potential sources for this metabolite are besides decaying organic matter, mainly other eukaryotic ${ }^{\mathbf{1 8 2 - 1 8 4}}$ or prokaryotic organisms in the 
A Metabolic autonomy and metabolite leakage

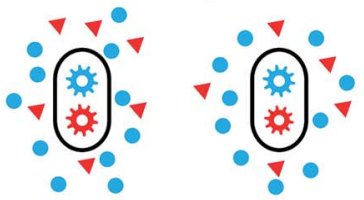

B Emergence of dependencies through gene loss

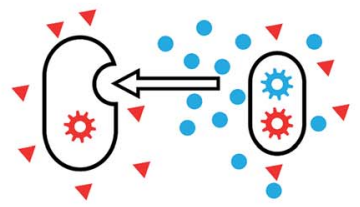

C Emergence of inter-dependencies

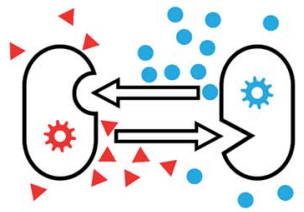

D Emergence of by-product reciprocity

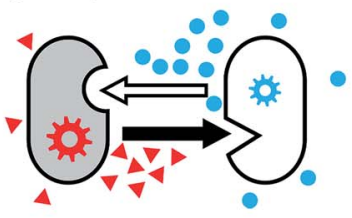

E Emergence of bidirectional

cooperative cross-feeding

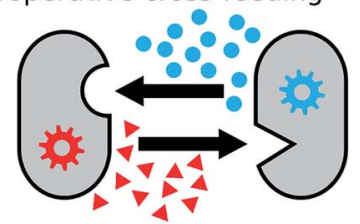

Fig. 7 Hypothetical model to explain the evolution of cooperative metabolic cross-feeding. (A) Initially, each of two strains have the metabolic capacity (gear wheels) to synthesize the two growthrequired metabolites (red triangles and blue circles). Besides the biosynthesis for cell growth, both strains release a fraction of the produced metabolites into the environment (i.e. metabolite leakage, see Section 3.2). (B and C) Metabolites that are released as by-products are available to neighbouring cells. Losing the capacity to synthesize one of the focal compounds and use environmental pools instead (empty arrows) provides a growth advantage (see Section 3.3) and thus results in the establishment of (B) unidirectional and eventually (C) bidirectional cross-feeding interactions. (D) When by-products are reciprocally exchanged, one partner can benefit from unilaterally increasing its metabolite production (filled arrow), because it automatically increases the amount of metabolic by-products (here: blue metabolite) it receives in return. (E) Cooperative cross-feeding interactions emerge if each of the involved organisms starts to actively invest resources into metabolite production to benefit the respective partner. Benefits received by the organisms in each step are indicated by increasing cell size. mutant's environment. ${ }^{\mathbf{1 8 5}-\mathbf{1 8 7}}$ Thus, the mutational loss of a conditionally-essential biosynthetic gene is a key step towards the establishment of an obligate metabolic cross-feeding interaction (Fig. 7B).

3.3.1 Auxotrophies are common in nature. In nature, bacterial genome sizes vary greatly ${ }^{\mathbf{1 8 8}}$ ranging from the largest genomes of about $14 \mathrm{Mb}$ (i.e. Sorangium cellulosum) ${ }^{\mathbf{1 8 9}}$ to the smallest known genomes of $0.16 \mathrm{Mb}$ (i.e. Candidatus Carsonella). ${ }^{190}$ The lower end of this spectrum includes many genomes, which are significantly smaller than the estimated minimal genome size for autonomous bacterial growth and survival of $\sim 400 \mathrm{~kb} .{ }^{190}$ Interestingly, even seemingly identical members of the same bacterial species can differ greatly in their gene repertoire. ${ }^{191,192}$ Observation of this recurring pattern in several bacterial taxa like Salmonella, Escherichia, and Prochlorococcus has led to the development of a concept called the pan-genome. ${ }^{193-195}$ In this framework, all genes that are found in all isolates/genotypes of a given species are called the core genome, while genes that are only present in some genomes are referred to as the pan- or auxiliary genome. ${ }^{194}$ Systematic analyses, in which the ability of known bacterial genomes to produce all primary metabolites a bacterium requires for growth was scrutinized, revealed that in fact $76 \%$ of all 949 eubacterial genomes analysed were unable to produce at least one of 25 different metabolites. ${ }^{26}$ Interestingly, the list of predicted auxotrophic taxa did not only contain endosymbiotic bacteria, but also many bacteria with a free-living lifestyle. Hence, metabolic auxotrophies are likely common in natural microbial communities.

3.3.2 Evolutionary mechanisms driving the loss of biosynthetic genes and functions. What drives the loss of biosynthetic functions from bacterial genomes? Two main evolutionary mechanisms have been suggested to account for these losses: adaptive advantages and genetic drift. Mutants that have lost the ability to autonomously produce a certain metabolite can be selectively favoured over metabolically autonomous genotypes, when the focal compound is sufficiently available in the cell's environment. Alternatively, even if auxotrophic mutants suffer of a reduced fitness relative to prototrophic cells, random genetic drift in small bacterial populations (e.g. of a bacterial endosymbiont) can result in the fixation of these maladaptive mutations on a population-level. Thus, both the environmental availability of metabolites and the size of bacterial populations need to be taken into account when explaining the widespread distribution of biosynthetic loss-of-function mutants in natural microbial communities.

3.3.2.1 Adaptive loss of biosynthetic functions in metaboliterich environments. In principle, two evolutionary explanations can account for an adaptive loss of genes. First, selection is expected to remove a subset of genes from a bacterial genome that might not be essential in a given environment. Retaining genes that do not contribute to a bacterial cell's fitness is costly, because of the burden resulting from the functioning of the corresponding gene products within the cellular context. ${ }^{196}$ Moreover, the expression of unneeded proteins reduces the amount of resources that are available for other cellular processes. ${ }^{197,198}$ This is why mutants that lack these non- 
required functions may be adaptively favoured and thus increase in frequency relative to types that still carry these genes. This process, which is called genome-streamlining, ${ }^{199,200}$ can be considered as a way to cellular economization. ${ }^{199,201}$ This process should be particularly important in large bacterial populations, where the effect of natural selection is very strong. ${ }^{201-203}$ As a consequence, any fitness-enhancing mutation including loss-of-function mutations (e.g. deletions, frameshifts) will be fixed in the population. Indeed, many freeliving bacteria such as Prochlorococcus ${ }^{\mathbf{2 0 4}}$ or Candidatus Pelagibacter ubique, ${ }^{203}$ which are oligotrophic and live in aquatic ecosystems that are relatively nutrient-deficient yet stable in terms of resource turnover, ${ }^{205}$ feature genomes of reduced sizes.

The second possibility is that selection favours a loss of biosynthetic functions in bacteria, when the resulting metabolic deficiency can be compensated by an environmental uptake of the corresponding compound. Indeed, several laboratory-based studies with Bacillus subtilis, ${ }^{206}$ Escherichia coli, ${ }^{\mathbf{2 6 , 2 0 7}}$ and Pseudomonas fluorescens ${ }^{\mathbf{2 0 8}}$ clearly showed that amino acid auxotrophic bacterial strains gain a significant growth advantage (i.e. up to $20 \%$ relative to their prototrophic counterpart) when the metabolite they require for growth was sufficiently available in the environment. What can explain the strong fitness advantage observed in auxotrophic genotypes? Zamenhof and Eichhorn (1967), who first described this phenomenon, suggested that when the metabolite is present in the extracellular environment, bacteria that shut down their endogenous machinery to produce the metabolite gain a selective advantage over prototrophic cells, because they save the costs associated with producing the metabolite. ${ }^{206}$ Costs that could be saved by auxotrophic bacteria include (i) energetic costs that are required to drive biochemical reactions, ${ }^{163,165}$ (ii) ribosome costs that accrue for building the translational machinery, ${ }^{197,209}$ (iii) protein costs that stem from the need to produce the biosynthetic protein machinery, ${ }^{209}$ as well as (iv) carbon costs that result from the allocation of raw materials to produce the focal metabolite. ${ }^{164}$ All in all, a significant proportion of a bacterial cell's energy budget is allocated to amino acid biosynthesis. ${ }^{\mathbf{1 6 5}}$ Given that many natural habitats of bacteria are rich in metabolites that bacterial cells require for growth (e.g. amino acids, ${ }^{210,211}$ vitamins, ${ }^{212}$ and nucleobases $\left.{ }^{213}\right)$, it appears plausible that natural selection may favour auxotrophic mutants that save the costs of metabolite production in these environments.

Compelling evidence for the importance of natural selection for driving gene loss in bacteria comes from several evolution experiments. ${ }^{196,214}$ Lee and Marx (2012) found that nonessential, accessory genes were frequently lost from almost $80 \%$ of evolving Methylobacterium extorquens AM1 populations that adapted to minimal medium. ${ }^{\mathbf{2 1 4}}$ In this case, gene loss was accompanied by an increase in fitness, suggesting that selection favoured the loss of unneeded genes when adapting to a specific environment. ${ }^{214}$ In another study, Koskiniemi (2012) tested the fitness consequences ${ }^{196}$ of losing stretches of DNA from the genome of the bacterium Salmonella enterica and found that fitness-increasing deletions were rapidly fixed in populations that had been serially propagated in the same nutrient environment. Furthermore, E. coli populations that were selected in an amino acid-containing environment frequently lost the ability to autonomously biosynthesize these metabolites, with the evolved auxotrophies conferring an adaptive advantage. ${ }^{\mathbf{2 0 7}}$

3.3.2.1.1 Mutational deactivation versus transcriptional down-regulation of metabolic genes. If gene loss is so beneficial, why then do bacteria not downregulate their biosynthetic machinery when the corresponding product is sufficiently available in the extracellular environment? In this way, cells could enjoy the benefits resulting from gene deactivation, yet retain the ability to grow autonomously when external metabolite pools are depleted. Two main reasons likely explain why a mutational gene loss or deactivation is probably more important in the context of metabolic cross-feeding interactions than a regulatory inactivation of the same biosynthetic pathways. First, the ability to sense environmental conditions in order to determine whether or not it is beneficial to switch from an autonomous metabolite production to an environmental uptake requires the maintenance of an extensive sensory and regulatory machinery. The production and maintenance of such a system likely requires a significant investment of resources and these costs would have to be outweighed by benefits resulting from it - even if the system remains in a certain configuration for extended periods of time. Second, a cell that is able to switch between an environmental uptake and an autonomous metabolite production has to be fitter than a cell, which specializes in just one strategy. A significant factor that works to the disadvantage of a regulation-based phenotype is the time and energy it takes to switch between both states. Indeed, a prototrophic genotype of $E$. coli that was cultivated in a minimal medium only rarely used environmentally supplied amino acids, while an auxotrophic loss-of-function mutant of the same genetic background gained a significant fitness advantage from tapping this resource. ${ }^{26}$ Even though it is not known at the moment whether the same pattern is true for other species as well, the above example clearly illustrates that auxotrophic and prototrophic cells are in different physiological states $^{\mathbf{1 4 7 , 2 1 5 , 2 1 6}}$ and that at least prototrophic $E$. coli cells do not downregulate their amino acid biosynthetic pathways to become functional auxotrophs when the corresponding metabolites are sufficiently available in the environment. ${ }^{26}$

3.3.2.2 Random genetic drift. The second main evolutionary mechanism that has been suggested to explain the loss of biosynthetic genes from bacterial genomes is random genetic drift. In populations of small size, random changes in allele frequencies can result in the fixation of maladaptive genes. Accordingly, genetic drift has been suggested to be the main cause for the extreme genome reduction that is commonly observed in endosymbiotic or endoparasitic bacteria. ${ }^{\mathbf{1 8 5 , 2 1 7 , 2 1 8}}$ Several arguments seem to support this interpretation.

First, bacterial populations within host cells are usually small $\left(10^{3}\right.$ to $10^{4}$ cells per $\left.\mathrm{ml}\right)$ and are subject to repeated reductions in their size (i.e. population bottlenecks) during transmission from parent host to its offspring. ${ }^{182,218,219} \mathrm{~A}$ reduction in effective population sizes $\left(N_{\mathrm{e}}\right)$ can greatly affect the impact of genetic drift. ${ }^{203,219} N_{\mathrm{e}}$ is the size of an idealized population that experiences the same magnitude of genetic drift as 
an existing population. ${ }^{\mathbf{2 0 3 , 2 1 9 , 2 2 0}}$ However, this important parameter is difficult to estimate due to the stochasticity of genetic drift. ${ }^{201,203}$ Accordingly, the fixation probability of a mutant allele in a given populations depends on the product of $N_{\mathrm{e}}$ and $s$ (i.e. the coefficient of selection). ${ }^{201,203}$ When $N_{\mathrm{e}} s>1$, the fate of the mutant allele is primarily determined by selection, whereas when $N_{\mathrm{e}} s<1$, genetic drift determines the fixation probability of this allele. ${ }^{\mathbf{2 0 1 , 2 0 3 , 2 1 9 , 2 2 0}}$ Thus, when $N_{\mathrm{e}}$ is low, mutations with deleterious effects can persist and even become fixed in the populations, ${ }^{219}$ because under these conditions, natural selection is less effective in eliminating deleterious mutation. ${ }^{201}$

Second, intracellular bacteria live in a nutrient-rich and rather constant environment. Thus, losing essential biosynthetic functions may not be penalized as strongly as is the case for bacteria living in nutrient-limiting conditions.

Third, reduced or absent levels of recombination in the intracellular environment of the host significantly restrict the opportunity to purge deleterious mutations. ${ }^{218,219}$ As a consequence, deleterious mutations even in key biosynthetic genes accumulate in the genome - a process, which has been termed Muller's Ratchet. ${ }^{\mathbf{2 0 1 , 2 1 8}}$ Given that deletions of genes from bacterial genomes appear to be much more common than insertions, ${ }^{\mathbf{2 0 0 , 2 2 1}}$ Muller's Ratchet is likely an important evolutionary force to account for gene loss in small bacterial populations. Indeed, Salmonella typhimurium populations that were repeatedly subjected to single-cell bottlenecks in rich medium revealed slow-growing phenotypes and auxotrophic loss of function mutants, which the authors interpret as evidence for an accumulation of deleterious mutations. ${ }^{222}$ Overwhelming evidence for the loss of biosynthetic genes from endosymbiotic or endoparasitic genomes stems from comparative genomic studies. ${ }^{\mathbf{1 8 4 , 1 8 5 , 2 2 3}}$ Unfortunately, due to difficulties to cultivate the bacterial strains involved, it is often not possible to quantify the fitness consequences resulting from gene loss for the corresponding genotypes. Moreover, it often remains unclear whether drift or selection caused the observed pattern.

3.3.3 Physiological consequences of biosynthetic gene loss. The mutational inactivation of a conditionally-essential biosynthetic gene can profoundly affect the physiology and behaviour of the ensuing auxotrophic genotype. Many of these changes help the nutrient-deprived cell to cope with starvation for the focal metabolite. For instance, it has been shown that amino acid auxotrophic $E$. coli strains increase the expression levels of genes associated with cross-membrane transport of the required metabolite. ${ }^{26,224}$

Moreover, the loss of a biosynthetic gene that causes metabolite starvation is well-known to trigger a stringent cellular response, which globally reorganizes the metabolism to economise available resources. ${ }^{215,224}$ Another consequence of auxotrophy-causing mutations, which has been observed in several species, is the formation of intercellular nanotubes ${ }^{\mathbf{1 4 5 , 1 4 7}}$ (Fig. 4F). These physical intercellular connections allow the auxotrophic mutant to derive the focal metabolite from other cells that are still able to produce the required metabolite. Taken together, the abovementioned cellular responses to biosynthetic gene loss represent immediate physiological consequences that promote the evolution of cross-feeding interactions by either helping to establish unidirectional interactions or by adjusting their own metabolic processes to efficiently use the exchanged compounds.

\subsection{The emergence of by-product reciprocity}

A central step towards the evolution of cooperative crossfeeding interactions is the transition from pure by-product cross-feeding between two interacting organisms (Fig. 7C) to an interaction, in which costly metabolites are actively produced by one individual to benefit the corresponding partner (Fig. 7E). This transitional step includes the so-called by-product reciprocity interactions, where one organism performs a costly cooperative act such as an enhanced production of a metabolite, which is consumed by the corresponding partner. The actively overproduced metabolite benefits the recipient organism by fuelling its metabolic processes. As a consequence of the enhanced metabolic activity, the recipient organisms release higher amounts of metabolic byproducts, thus benefiting the organisms that perform the cooperative act (Fig. 7D). ${ }^{225-227}$

It is well-known that increasing the metabolic rate of a microorganism (i.e. population growth) also elevates the amount of metabolic by-products that are released..$^{56227}$ Thus, for two organisms that reciprocally exchange metabolic byproducts, any mutation that will increase the production levels of the exchanged metabolite in one of the two partners, will be immediately rewarded by increased return levels. This automatic feed-back not only stabilizes the costly cooperative investment, but also paves the way for the evolution of reciprocal cooperative cross-feeding interactions.

\subsection{Evolution of cooperative cross-feeding}

The challenge with explaining the evolution of cooperative cross feeding lies in the fact that cooperation, such as the overproduction of metabolites, is costly. Thus, non-cooperating free-riders that do not contribute to the production of the traded metabolite may still benefit from the cooperative interaction. Consequently, whenever both cooperators and noncooperators have an equal probability to gain access to the cooperative public good, natural selection predicts noncooperative genotypes to increase in frequency, which may ultimately result in a collapse of the cooperative interaction. ${ }^{22,228-230}$ Another potential problem in complex microbial communities is that even if cooperative cross-feeding evolved, the respective genotypes need to ensure continued interaction with other, metabolically complementary genotypes. ${ }^{231}$ Hence, a key question in this context is which evolutionary mechanisms can stabilize metabolic cross-feeding within and between bacterial species.

An answer to this question needs to take both the ecophysiological intricacies of the focal interaction as well as its ecoevolutionary context into account. ${ }^{232}$ For example, metabolite exchange via diffusion through the extracellular environment intrinsically imposes several limitations on conditions under which cross feeding can exist. In well-mixed environments, 
these so-called public goods should theoretically be equally available to both producing and non-producing cells ${ }^{167,231}$ and are thus prone to exploitation. Alternatively, metabolites may be transferred in a contact-dependent manner (e.g. via intercellular nanotubes ${ }^{\mathbf{1 4 7}}$ ), which restricts the access to the exchanged metabolites. The ecological conditions under which crossfeeding between bacterial genotypes showing either means of metabolite transport can be maintained, is therefore drastically divergent, and will likely result in divergent evolutionary outcomes.

3.5.1 Positive assortment. Many different evolutionary mechanisms have been suggested to facilitate the emergence and maintenance of cooperative interactions in microbial communities. $^{22,232-234}$ Several of these have been identified for other forms of microbial cooperation than cooperative crossfeeding. However, in many cases, their logic applies equally well to interactions, in which costly metabolites are exchanged. A major conceptual advance in the field was the recognition by Fletcher \& Doebeli (2009) that cooperation will be favoured by natural selection whenever mechanisms exist that either (i) increase the probability that cooperative phenotypes repeatedly interact with other cooperators and/or (ii) decreases the chance of cooperators to encounter non-cooperators. ${ }^{235}$ The beauty of this concept, which has been termed 'positive assortment', is that it accommodates both interactions within- and betweenspecies. Previously, intraspecific cooperation was mainly explained by Hamilton's rule, which predicts that selection will favour cooperative behaviours, if the benefits to the recipient times the relatedness between actor and recipient outweigh the costs to the actor. ${ }^{228}$ The concept of relatedness, however, does clearly not apply to interactions between different species. This is why a range of different theoretical models and conceptual approaches had to be devised for this case..$^{\mathbf{2 2 9}, 235-241}$

3.5.2 Mechanisms promoting positive assortment. In the following, we will classify mechanisms that have been previously suggested to facilitate positive assortment of cooperative phenotypes and which are relevant to the evolution of cooperative cross-feeding. Our framework divides mechanisms into two main categories (Fig. 8): (i) partner fidelity (i.e. staying together ${ }^{232}$ ) - i.e. mechanisms that ensure repeated interactions among cooperators due to a physical colocalisation, and (ii) partner choice (i.e. coming together ${ }^{232}$ ) - i.e. mechanisms that facilitate either the localisation and subsequent association with suitable interaction partners or the antagonizing of unsuitable interaction partners. Each of these main categories can be further subdivided. Partner fidelity can result from limited dispersal in spatially structured environments or be due to permanent adhesion among interacting cells when new groups of cells are formed (Fig. 8). Alternatively, permanent associations such as endosymbiosis or epibiosis can also facilitate repeated interactions among cooperative phenotypes.

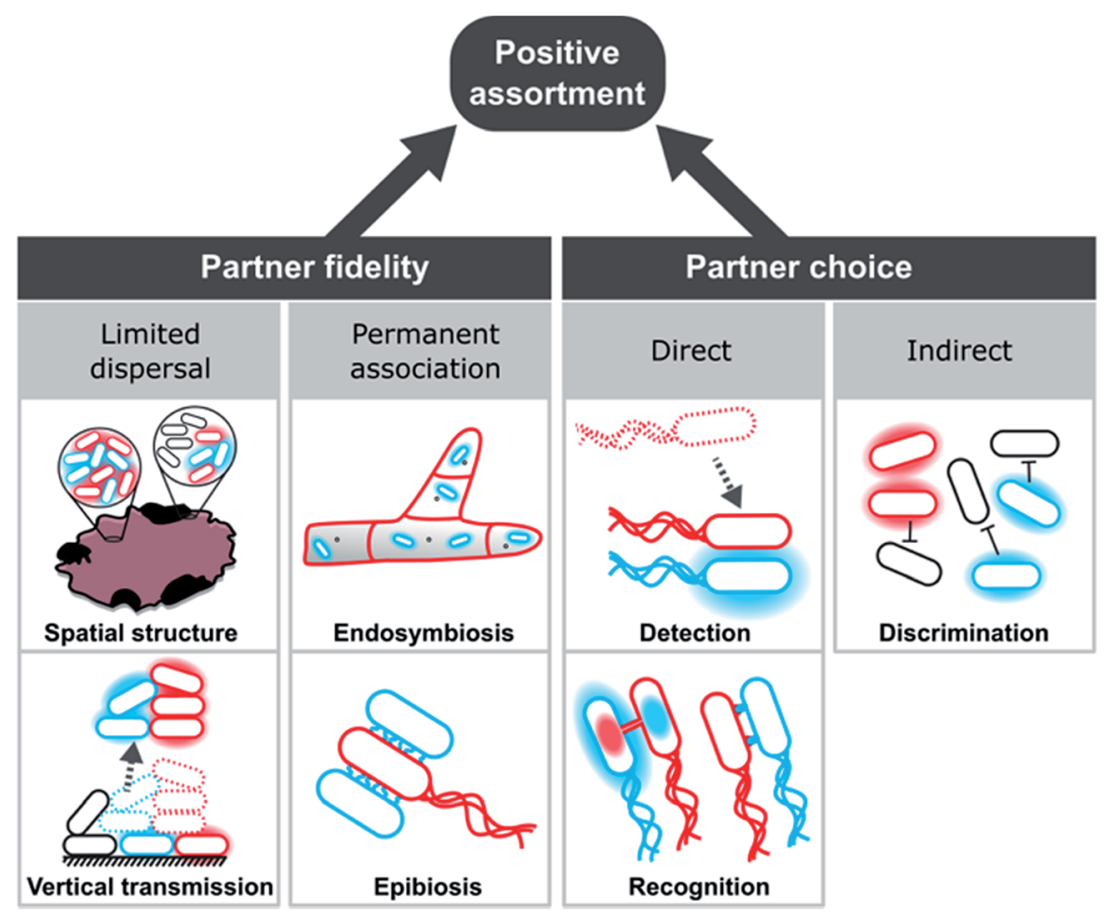

Fig. 8 Evolutionary mechanisms promoting the emergence and maintenance of metabolic cooperation by positive assortment. Red and blue cells represent cooperating genotypes with halos depicting exchanged metabolites, while black cells indicate non-cooperating cells. Positive assortment of cooperating genotypes is either achieved by partner fidelity or partner choice mechanism. Partner fidelity results from limited dispersal in spatially structured environments or from budding/fission events of multicellular clusters (vertical transmission). Alternatively, partner fidelity can be due to permanent associations between partners, as is the case for endosymbiotic or epibiotic interactions. Partner choice mechanisms can be direct or indirect, with the former being achieved by detection or recognition of potential partner cells, while the latter is due to an active discrimination against unsuitable or non-cooperative cells. 
Partner choice can be subdivided into direct and indirect mechanisms (Fig. 8). Direct partner choice can be due to detection, which involves the active finding and subsequent interaction with specific genotypes or recognition that allows cross-feeding genotypes to identify compatible genotypes. Alternatively, indirect partner choice mechanisms operate via the exclusion or inactivation of non-cooperating genotypes. The resulting local enrichment of cooperating cells can also facilitate positive assortment.

These mechanisms should not be seen as mutually exclusive, but multiple processes can operate simultaneously. The contact-dependent inhibition (CDI) system, for instance, exemplifies the combination of partner choice by specific adhesion with non-partner discrimination via inactivation of targeted cells. ${ }^{242}$ Here, a two-component secretion system facilitates binding and toxin delivery into target cells that display specific receptors. However, carriers of immunity proteins, such as close relatives of the cell expressing the CDI system, are unharmed. This system is widely distributed in alpha-, beta-, and gamma-proteobacteria ${ }^{242}$ and can even mediate the specific assembly of multicellular biofilm communities. $^{\text {243,244 }}$ Below, we will explain each of these mechanisms in more detail and highlight a number of relevant examples.

\subsubsection{Partner fidelity}

3.5.2.1.1 Limited dispersal. Limited dispersal refers to cases, in which groups of cells that exchange metabolites with each other, remain associated for extended periods of time. This type of increased population viscosity emerges in spatially structured communities that grow on surfaces or in multicellular aggregates.

In recent years, overwhelming evidence has accumulated that bacteria mainly grow attached to surfaces (i.e. a biofilm) or other bacteria (i.e. free-floating clusters), and thus prefer an aggregative lifestyle over a planktonic, free-living state. ${ }^{\mathbf{2 4 5 - 2 4 8}}$ Simulations demonstrated the formation of such groups can not only facilitate cooperative interactions, ${ }^{249}$ but also conflicts among group members. ${ }^{250}$ Hence, the benefit of a newly established cooperation needs to outweigh the negative effect of conflicts and increased competition in local groups of cells. Importantly, the formation of biofilms and cell clusters can be caused by a number of non-social reasons, such as the protection from the abiotic (oxygen, $\mathrm{pH}$, and drought) and biotic environment (predation, ${ }^{251,252}$ competition, and immune system), colonisation of favourable substrates (energy- and carbon-sources), or joint niche construction and exploitation (synergism). ${ }^{253}$

Once established, several important consequences result for cells that grow in spatially structured communities. First, metabolites that are released into the cell-external environment potentially accumulate ${ }^{254}$ and are thus increasingly available to resident cells. Second, local feedbacks increase the fitness of cell patches with a favourable combination of genotypes, while groups of incompatible types show weaker growth. This results in an interesting effect: the enhanced growth of cooperative groups leads to a spatial segregation of cooperating and noncooperating cells and thus a spatial exclusion of non- cooperators from the shared goods. ${ }^{167,255-258}$ This pattern emerges due to a self-organization of initially well-mixed populations ${ }^{256,257,259-262}$ and can even prevent the invasion of noncooperative, motile cells. ${ }^{263}$ This aspect of matrix-assisted population structure can be conceptualized as a passive means of non-cooperator exclusion. In combination, these effects strongly favour the evolution and maintenance of cooperative cross-feeding interactions as evidenced by numerous theoretical $^{241,259,264}$ as well as experimental studies. ${ }^{255,256,258,261,265-267}$ Empirical evidence from syntrophic bacterial communities further corroborates this interpretation: the spatial distribution of metabolically interdependent members appears to be key to the functioning of these consortia. ${ }^{\mathbf{2 6 8 , 2 6 9}}$ Taken together, various lines of evidence suggest that positive assortment in spatially structured populations can promote cooperation.

Bacterial cells that live in a spatially structured, aggregative community face the problem that with increasing cell density, competition for resources such as space and nutrients also increases. Thus, at one point, colonies need to disperse to populate new substrates. For cells that have started to engage in obligate cooperative cross-feeding, it is therefore crucial to remain associated with other, metabolically complementary cells. Since parts of biofilms are known to get detached, ${ }^{246}$ they likely function as a propagule to initiate a new biofilm. Notably, groups of cells that protrude from a biofilm or cell cluster are prone to be detached and dispersed more easily. In fact, this is the case for highly productive local groups. ${ }^{270}$ In this way, cells that are more cooperative, are more likely to transmit offspring to the next generation, thus enhancing selection for cooperative phenotypes. This type of group dispersal, which represents a type of vertical transmission, ensures that complementary and potentially coevolved genotypes interact for extended periods of time (Fig. 8). This is also the case for planktonic macrostructures and multicellular magnetotactic prokaryotes (MMPs) that exhibit propagule formation and fission of whole cell groups, respectively. ${ }^{253,271}$

3.5.2.1.2 Permanent associations. Extreme cases of staying together are permanent associations (Fig. 8), where prokaryotic cells either live on (epibiosis) or in (endosymbiosis) another organism. Examples include associations among archaea ${ }^{272}$ as well as interactions of bacteria with other bacteria, ${ }^{273-276}$ fungi, ${ }^{277-281}$ protists, $^{282-286}$ or multicellular eukaryotes. ${ }^{284,287,288}$

A characteristic feature of these associations is the enormous potential of vertical transmission over evolutionary time when new generations of host-symbiont interactions are established. The tight fitness coupling of cells living in such close associations aligns their evolutionary interests, thereby limiting conflicts among interacting partners. This is particularly promoted by the fact that the fitness of these consortia is often not a property of individual cells any more, but an emergent feature that results from the interaction among host and symbiont. Selection acting on this level is therefore expected to increase complementarity and enhance metabolic cooperation among partners. Indeed, known cases of both epibiosis and endosymbiosis are frequently based on the reciprocal exchange of metabolites between both partners (Fig. 3B). Thus, to 
understand these systems, it is key to identify the causal mechanisms that initiate the assembly of these associations as well as the evolutionary forces that can tip the balance in favour of cooperative cross-feeding.

The first step in the evolution of a stable endosymbiosis is that a bacterial cell enters the intra- or intercellular environment of its host. Even though cases exist where environmental, commensal or already mutualistic bacteria successfully established as endosymbionts, ${ }^{289}$ parasitic bacterial strains have an advantage. Their intrinsic ability to enter host cells or tissues despite the presence of anti-bacterial defence strategies (e.g. immune system) enables them to persistently colonize the host. ${ }^{277}$ This then provides the opportunity for natural selection to transform the initially antagonistic interaction into a mutually beneficial one. This is corroborated by phylogenetic studies showing that proteobacterial mutualists were more frequently derived from parasitic than from free-living ancestors. ${ }^{\mathbf{2 9 0}}$ Even if bacterial lineages do not feature strategies to repeatedly reinfect their host or be vertically transmitted, the host might strongly benefit from evolving means to transmit beneficial symbionts to its offspring itself. ${ }^{289}$ Unfortunately, direct experimental evidence to identify the factors that complete the transition to an obligately endosymbiotic association is lacking, thus complicating the exact assignment of cause and effect. Two key requirements that likely need to be fulfilled are (i) a strict vertical transfer of bacterial symbionts across host generations and (ii) a mutual benefit arising from this interaction. Whenever these criteria are fulfilled, natural selection can act on the symbiotic interaction. Common outcomes of this coevolutionary process are a drastic reduction in genome size of the symbiotic bacteria ${ }^{\mathbf{2 8 8 , 2 9 1}}$ as well as the emergence of a metabolic complementarity of host and symbiont, where many different metabolites, precursors, or biochemical functions are reciprocally exchanged. ${ }^{\mathbf{2 9 2}}$

The conditions favouring epibiotic associations are rather similar to the ones described previously for endosymbiotic interactions. The prospective epibiont needs to exhibit either features of a parasite or beneficial characteristics of a mutualist to allow repeated interactions with the respective host. In both cases, the ability to attach to the host is required, ultimately enabling the epibiont to exploit and adapt to the resources released by the host. This initially one-sided interaction opens the door to evolve a reciprocal exchange of metabolites, given that host and epibiont complement each other. ${ }^{282,293}$ Benefits that are associated with this interaction for the host and/or the epibiont favour a permanent association. Host-epibiont coevolution as well as competition with other groups of hosts and epibionts should intensify reciprocal interactions like cooperative cross-feeding.

An example for epibiosis is the TM7 phylotype (TM7x) that is obligately associated with Actinomyces odontolyticus in the oral cavity. ${ }^{273}$ The epibiont TM7 features a drastically reduced genome ( $\sim 700$ genes $)^{273}$ and derives all of its amino acids from its host A. odontolyticus. In phases of extreme starvation, TM7 can even kill its host, thus classifying as a parasitic interaction. Another well-studied case is the phototrophic consortium Chlorochromatium aggregatum, in which a flagellated $\beta$ - proteobacterium within the family Comamonadaceae is surrounded by Chlorobium chlorochromatii, a green sulfur bacterium. ${ }^{294}$ In these physiologically highly intertwined consortia, the central bacterium provides motility and receives photosynthetically fixed carbon in return from its epibionts.

3.5.2.2 Partner choice. Partner choice is the second main principle that facilitates positive assortment among cooperative genotypes via either selecting preferred interaction partners (direct partner choice) or antagonizing undesirable or unsuitable cells (indirect partner choice).

Important to recognize for partner choice mechanisms is that they inherently rely on a mixing of interaction partners after every round of association and disassociation. A consequence of this is that these intermittent periods of mixing reduce the chance to repeatedly encounter the exact same genotype in subsequent rounds of interaction. Under these conditions, mutations, whose effects are highly partner-specific, are less likely to spread in the global gene pool, simply because they reduce the number of potential interaction partners. On the other hand, more favourable combinations of interaction partners could result from this process than would be expected to emerge in a regime exclusively relying on limited dispersal. However, at the moment, the above-mentioned populationgenetic consequences are purely hypothetical and await experimental validation.

3.5.2.2.1 Direct partner choice. Detection as a partner choice mechanism involves the ability of bacterial strains, which are unable to produce certain metabolites autonomously, to find and identify other cells that are capable of providing these metabolites. This can be achieved in different ways. First, other cells or groups of cells release the required metabolite into the environment and the focal cell uses chemotaxis to trace the source of these metabolites. More cooperative cells will release more metabolites and are thus easier to find. Hence, the required metabolite is the most reliable indicator of a producing cell and should thus be the preferred cue for an auxotrophic cell. However, the focal cell can also use other chemicals to find suitable cells via positive chemotaxis. Here, in principle any metabolite, which can be sensed and followed along a concentration gradient, can serve as a cue. For example, quorum sensing, when used as a means of interspecific communication, ${ }^{295,296}$ can reveal the species identity of the signalling cell and with it also the potential of competition ${ }^{297}$ or metabolic compatibility. ${ }^{298}$ For interactions with higher organisms, bacteria are well-known to show a specific chemotactic response towards their hosts, ${ }^{299-302}$ while so far only few experimental examples of chemotaxis as a means of recognition among different bacterial species exist. ${ }^{248,303,304}$ Recently, Laganenka et al. (2016) reported that chemotactic accumulation followed by autoaggregation can also occur within species, which in this case, was mediated by the quorum sensing signal autoinducer-2 within populations of $E$. coli. ${ }^{305}$ In general, bacteria feature very sensitive molecular machineries to sense metabolites and quorum sensing molecules. ${ }^{\mathbf{3 0 6 , 3 0 7}}$ Even though these systems likely evolved in a different ecological context, they can dramatically enhance the ability of cells to identify 
possible interaction partners, even in taxonomically diverse communities.

Even though the ability to find other cells can lead to positive assortment, this mechanism alone cannot explain the evolution or maintenance of cooperative cross-feeding. Positive feedback among interactions partners is again also necessary to operate in parallel: more cooperative cells that show positive chemotaxis have a fitness advantage over non-cooperative or nonchemotactic cells, thus increasing their frequency in the local community. This means that after detection of suitable cells, metabolites that are produced and exchanged must preferentially benefit cooperative interaction partners. This can be achieved by recognition mechanism (specific or unspecific) that allow attachment or group formation (see below). Indeed, the combination of chemical signalling with subsequent interspecies aggregation was recently observed in a mutually beneficial interaction between two bacterial species isolated from iron snow. ${ }^{248}$ More research, however, is necessary to fully evaluate the potential of this, at the moment rather theoretical possibility, to serve as a mechanism to identify suitable interaction partners.

The second main group of direct partner choice mechanisms is called recognition. Bacterial cells can recognize suitable interaction partners in two fundamentally different ways. First, recognition can be passive, by unspecifically attaching to other cells in the environment. In this case, growth of the focal cell will depend on the metabolic complementarity and cooperativity of the more or less randomly chosen interaction partner. Nevertheless, positive feed-back within interacting groups should increase the frequency of cooperators in a given population and thus raise the chance for a cooperative cell to encounter other cooperative cross-feeders in subsequent rounds of attachment and detachment (i.e. positive assortment).

Second, bacterial cells can be equipped with mechanisms, which allow them to specifically adhere to clonemates or members of other species that feature certain characteristics. ${ }^{263,308}$ In the context of biofilm formation, such behaviours are commonly referred to as co-aggregation. ${ }^{308,309}$ One evolutionary advantage of specific adhesion over random attachment is that specific adhesion minimizes the chance of associating with harmful, non-complementary, or non-cooperative genotypes. Moreover, adhesion can be key to the establishment of functional groups such as for the joint degradation of organic matter and the associated successful development of multispecies biofilms. ${ }^{308,309}$ Adhesion over multiple generations finally causes progeny to locally accumulate in clusters. Such a formation of interacting groups helps in directing resources to closely-related, cooperative genotypes. Thus, both mechanisms of unspecific adhesion and specific recognition help to solve the public goods dilemma by privatizing the exchanged metabolites within interacting groups. ${ }^{30}$

Recognition in microorganisms predominantly operates via structures on the outer membrane $e^{308,311,312}$ and is generally based on affinity between a receptor and an identification molecule. ${ }^{313}$ Accordingly, the mostly protein-based adhesins represent receptors that facilitate recognition via binding to specific structures on the surface of another cell. ${ }^{314}$ Other specific recognition systems can be pili, ${ }^{314}$ homotypic receptors for self-recognition, ${ }^{315-317}$ the contact-dependent inhibition system (CDI), ${ }^{242}$ and type VI secretion systems (T6SSs). ${ }^{318}$ These systems mediate a remarkable spectrum of partner choice ranging from interactions between different kingdoms such as the host choice of microbiota ${ }^{319}$ to specific autoaggregation with members of the same species. ${ }^{320}$

The molecular machinery that determines whether or not two cells can interact with each other basically functions like a greenbeard gene $e^{233}-i$.e. a gene that allows cooperators to recognize other cooperators and thus to preferentially direct benefits towards them. Increasing evidence demonstrates greenbeards to be substantially more common in microorganisms than originally thought. ${ }^{311,321-323}$ For instance, the Flo1 flocculation gene of the yeast Saccharomyces cerevisiae and the csaA self-adhesion gene in the slime mould Dictyostelium discoideum were identified to represent such greenbeard genes that are key for the establishment of cooperative groups. ${ }^{311,324}$ Only carriers of the greenbeard genes are part of these groups and thus can enjoy cooperative benefits. ${ }^{228,230,321}$ In cooperative cross-feeding, however, recognition and cooperation are two separate functions. Hence, a non-cooperative carrier of the green beard allele could evolve and thus undermine the identification system. Nevertheless, recognition likely requires close physical contact, which automatically entails the abovementioned advantages of spatially structured metabolic interactions. Thus, a dedicated recognition system would still allow narrowing the spectrum of possible interaction partners to a subset of principally suitable cells. While research on microbial cooperation has focused more on traits like protection, reproduction, and siderophore production, cross-feeding of metabolites has received less attention so far. Thus, future work should evaluate how common such genetic recognitions systems are in natural microbial communities and whether they are also involved in stabilizing metabolic interactions.

Another attachment mechanism is the establishment of intercellular connections such as nanotubes, nanopods, or vesicle chains that are used to exchange materials between interacting cells (Fig. 4). In many of these cases, large clusters of interconnected cells emerge ${ }^{143,147}$ that should favour cooperative cross-feeding, because interactions within these clusters are highly localized. Analogous to cells growing on twodimensional surfaces, also the self-organized growth of cells within three-dimensional networks should favour clusters of cooperative cells and penalize non-cooperators by spatial isolation.

3.5.2.2.2 Indirect partner choice. Indirect partner choice mechanisms lead to positive assortment of complementary cooperators by antagonizing non-complementary or noncooperative genotypes. In general, this group of mechanisms either kills other genotypes or species or prevents them from invading a local population/community. Consequently, all cells within the social group need to be resistant to the harmful behaviour. By excluding other, potentially non-cooperating genotypes from cooperative benefits, indirect partner choice 
mechanisms can result in a local enrichment of cooperating genotypes.

Competition for space and other resources is common-place in microbial communities. ${ }^{325-329}$ Under these conditions, genotypes that can exclude or inactivate competitors are clearly at an advantage, thus explaining the widespread distribution of antagonistic behaviours among microorganisms. ${ }^{16,329,330}$ Whenever bacteria antagonize others, an almost automatic consequence is that these behaviours decrease the genetic diversity in the local community, thereby increasing the cohesiveness of the group displaying the harmful behaviour or being immune to its consequences. Antagonistic behaviours can facilitate the emergence and spread of cooperative behaviours within such groups, because metabolites that are produced as a cooperative act are more likely to benefit other group members. Discrimination against others can be achieved passively by generating a restrictive chemical environment, for instance by resource-depletion or $\mathrm{pH}$-modification. ${ }^{331-333}$ The resulting competitive exclusion will reduce the number of genotypes present and possibly enrich close relatives of the strains causing the environmental modification. A property emerging from this process is often that already established bacterial communities, such as the ones colonizing corals, ${ }^{334}$ plant roots, ${ }^{320,335}$ or the intestine of animals, ${ }^{333,336,337}$ cannot be invaded by other bacteria. This phenomenon has been termed bacterial interference or colonization resistance. ${ }^{336,338,339}$ In the context of metabolic cooperation within a spatially structured bacterial community, the ability to prevent the establishment of foreign bacterial genotypes may help to promote the exclusion of exploitative individuals and thus to stabilize metabolic cooperative interactions.

Alternatively, bacteria can actively express phenotypes that inhibit or kill other bacteria in the vicinity. Besides the production of antimicrobial compounds such as antibiotics or bacteriocins, ${ }^{333}$ bacteria use a range of other strategies to eliminate competitors including harmful extracellular vesicles, ${ }^{340}$ contact-dependent inhibition systems (CDI), ${ }^{328}$ or type VI secretion systems (T6SS). ${ }^{328,341}$ Importantly, by killing genotypes that do not carry the gene that confers resistance against the antagonistic trait, cells that express the antagonistic trait and are resistant against it qualify as harming greenbeards. ${ }^{321,323}$ In such a scenario, the local elimination of susceptible genotypes generally increases genetic homogeneity for the greenbeard allele and promotes positive assortment. For example, the CDI-system of B. thailandensis was demonstrated to be capable of antagonizing carriers of different BcpA-CT and BcpI proteins, which were hence successfully excluded from a biofilm. ${ }^{323}$ Mutual antagonism between two bacterial species via the T6SS was demonstrated to cause segregation of different genotypes as well. ${ }^{342}$ Also in Bacillus species that were isolated from fresh water sediments, antagonistic interactions that were based on bacteriocin-like substances facilitated the assembly of cohesive communities, even in a homogeneous, aquatic environment. ${ }^{330}$ Under these conditions, positive assortment can be facilitated when multiple cooperative genotypes display the same antagonistic behaviour. This can even be orchestrated in a synchronized release of the antagonizing molecule in many individuals by quorum sensing. ${ }^{343-345}$
Both passive and active discrimination mechanisms differ drastically in the specificity, with which they affect other genotypes. For example, antibiotics usually kill or inhibit the growth of a broad range of bacterial species. ${ }^{346,347}$ In contrast, bacteriocins typically exhibit a narrow killing spectrum, ${ }^{346}$ enabling producers to specifically target other coexisting species or genotypes of the same species. ${ }^{333,348}$ Increasing evidence suggests that microorganisms are able to discriminate relatives with high selectivity: antagonistic interactions were identified to facilitate positive assortment among conspecific genotypes. ${ }^{233,329,342,349-351}$ Proteus mirabilis, Myxococcus xanthus, and Bacillus subtilis are examples for bacterial species that can identify and antagonize other strains. ${ }^{352-354}$ When different populations of these species grow on two-dimensional surfaces, the formation of physical boundaries, so-called demarcation- or Dienes lines, indicate the presence of discrimination mechanisms. ${ }^{352-354}$ Strikingly, the underlying recognition mechanisms are usually highly selective and allow discrimination even within a species. ${ }^{313,352}$ Differences in a few loci already cause the formation of Dienes lines between swarming colonies of these bacteria.

The often very high specificity of antagonistic discrimination mechanisms combined with the fact that individual bacteria commonly use multiple discrimination mechanisms simultaneously ${ }^{355}$ suggests that bacteria aim at maximizing the chance to interact with desired genotypes of the same or different species. Here, the presence of antagonistic functions and the corresponding resistance genes serves as a system to discriminate bearers of these alleles (kin) from non-bearers (non-kin). ${ }^{355}$ Since these alleles can also be transferred via horizontal gene transfer, ${ }^{356}$ kinship does not necessarily imply affiliation to the same species. For this reason, the term kind discrimination is more applicable under these conditions. ${ }^{233}$ If members of the same kin/kind group engage in a mutualistic interaction, any kin/kind discrimination mechanism will help to protect cooperation from exploitation, as recently demonstrated for swarms of Bacillus subtilis. ${ }^{355}$ Moreover, positive assortment of genotypes in populations of Vibrio cholerae that was mediated via the T6SS correlated with increased cooperation. ${ }^{357}$ Accordingly, a phylogenetic comparison revealed that the extent of released public goods, in this case proteins, correlated with the total number of T6SS per strain, suggesting that positive assortment via killing promotes the evolution of public goods cooperation. ${ }^{357}$ Unfortunately, research in this field is just beginning to appreciate the potential significance of indirect partner choice mechanisms for the evolution of cooperative interactions. Thus, further research is necessary to fully evaluate to which extent positive assortment by specific discrimination mechanisms can favour cooperative cross-feeding among different genotypes or species.

\section{Consequences of obligate metabolite cross-feeding}

The evolutionary transition from a metabolically autonomous, free-living life-style to a state, in which the fitness of a bacterial cell hinges on the obligate cross-feeding of metabolites with other organisms has a number of significant evolutionary 
consequences for the focal genotype. Some of these effects are well-documented, while others are rather based on theoretical considerations. In the following, we will provide an overview over the manifold ramifications arising from obligate cooperative cross-feeding.

\subsection{Negative frequency-dependent selection}

As outlined above, evolutionary theory predicts obligate cooperative interactions that are based on an exchange of public goods to be notoriously unstable. ${ }^{22,228-230}$ Particularly when cooperating and non-cooperating individuals have equal access to the cooperative public good, non-cooperators are expected to gain a significant fitness advantage relative to cooperating types, which ultimately should result in a collapse of the cooperative interaction. Surprisingly, this outcome is rarely observed in cases where essential metabolites are cooperatively exchanged (but see ref. 358). Instead, obligate cooperative cross-feeding interactions are commonly stabilized by negative frequency-dependent selection. Frequency dependence describes an evolutionary process, in which the fitness of a given genotype depends on the relative frequency of other genotypes in the total population. In the case of negative frequency-dependent selection, the fitness of a certain genotype decreases as it becomes more common in a given population. From this, results a stabilizing force that maintains interacting genotypes in the long-run. ${ }^{359-362}$

Negative frequency-dependence has been shown to operate in both one-way by-product ${ }^{207,363}$ and two-way cooperative crossfeeding interactions. ${ }^{74}$ In both cases, frequencies of the two interacting cell types oscillated around a stable equilibrium point that most likely was determined by rates of metabolite production and consumption. Interestingly, the same pattern prevails when non-cooperators are included: also consortia consisting of amino acid cross-feeding $E$. coli cells and non-cooperating auxotrophs $^{74}$ or cocultures between producers of a public good and the corresponding non-cooperators ${ }^{258,360,364-367}$ were stabilized by negative frequency-dependent selection. Observing negative frequency-dependent selection for different types of metabolic interactions in both spatially structured and unstructured environments suggests this pattern is a common principle emerging in synergistic microbial communities.

However, cooperators and non-cooperating individuals of the abovementioned examples are unlikely to have equal access to the cooperatively produced metabolite. Instead, mechanisms of positive assortment, which have either evolved or result as a by-product from other features of the interaction, ensure the cooperatively produced metabolite is predominantly benefitting other producing genotypes. Examples of such mechanisms include a privatization of metabolites or biosynthetic functions due to contact-dependent exchange mechanisms ${ }^{74,147}$ or the localization of public goods in spatially structured environments. ${ }^{255,256,258,261,265-267}$

As a consequence, no genotype can take over in these obligate interactions. Instead, negative frequency-dependence maintains genotypic diversity. ${ }^{167,259,368}$ A prediction that follows from this is that the evolution of cooperative cross-feeding should promote a metabolic and genotypic diversification within microbial communities. Indeed, this pattern has been repeatedly observed in theoretical models ${ }^{\mathbf{1 6 7}}$ and experimentally evolved microbial communities. ${ }^{56,207}$

\subsection{Coevolutionary dynamics}

Unfortunately, very little is known on the coevolutionary consequences resulting from cooperative cross-feeding. ${ }^{369}$ An important aspect is certainly the positive feed-back loop that results when positive assortment assures repeated interactions among complementary partners across generations (i.e. partner fidelity feedback): ${ }^{76}$ in reciprocal cross-feeding interactions, an increased metabolic investment on one side automatically enhances growth and thus also metabolite production on the other side. ${ }^{69}$ Thus, continued coevolution is expected to increase productivity in cross-feeding communities, which is corroborated by experimental evidence. ${ }^{370}$

For antagonistic interactions such as host-parasite interactions, both empirical and theoretical work suggest increased rates of molecular evolution (i.e. red-queen effect), ${ }^{371}$ mainly affecting loci involved in virulence and resistance. In contrast, much less research has been devoted to the question how mutualistic interactions - such as cooperative cross-feeding - affect rates of evolution. Theoretical work implies that in mutualistic interactions, species generally evolve more slowly to increase their share of the benefits (i.e. red-king effect ${ }^{372}$ ). Experimental tests whether horizontally or vertically transmitted bacterial symbionts indeed evolve to some point of evolutionary stasis, ${ }^{373}$ however, revealed inconclusive patterns. ${ }^{374}$ Thus, further work should examine in more detail how synergistic coevolution affects the rate of evolution.

Finally, also the genomic signature that results from synergistic coevolution of cross-feeding genotypes is not very well understood. Given the transient nature of cross-feeding interactions, it is for example unclear, whether a pattern of reciprocal coevolutionary change, in which mutations in one interaction partner favour a specific set of mutations in the other partner, can be expected. Coevolution experiments with syntrophic consortia consisting of a sulfate reducer (Desulfovibrio vulgaris) and a hydrogenotrophic methanogen (Methanococcus maripaludis) for 1000 generations documented an extremely rapid loss of functional independence of Desulfovibrio vulgaris, which was driven by a mutational inactivation of genes involved in sulfate respiration. ${ }^{375}$ Also pairs of lactic acid bacteria (i.e. Streptococcus thermophilus and Lactobacillus delbrueckii subsp. bulgaricus) that have been serially propagated in coculture to ferment yoghurt reciprocally exchange a larger number of metabolites in a mutualistic manner. ${ }^{376}$ This striking metabolic complementarity, which likely evolved in response to the ecological interaction between both species, is largely due to gene loss. ${ }^{377,378}$ Given that consortia of co-occurring bacterial endosymbionts $^{89,223,379}$ display a similar pattern on a genomic level, it is tempting to speculate that metabolic complementarity is a common outcome of a synergistic metabolic coevolution.

\subsection{Formation of intercellular metabolic networks}

The frequent loss of metabolic genes from microbial genomes along with intricate patterns of cross-feeding, where other 
coexisting genotypes compensate the functional deficiency, suggests that within bacterial consortia, metabolism is often a community-level property and not a feature of an individual cell any more. If true, this implies that a bacterial communities' metabolism is in essence a super-metabolic network, where many of its constituents perform specialized biosynthetic or catabolic tasks that also benefit other members of the community. Indeed, recent metagenomic and empirical surveys of environmental bacterial communities have revealed that individual genotypes in a community can have distinct patterns of amino acid auxotrophies, such that some members lack multiple biosynthesis pathways, and, at the same time, specialize in the production of another set of amino acids. ${ }^{23,378,380,381}$ Also specialized genotypes have been found, which provide biosynthetically expensive amino acids to other community members. ${ }^{380}$ Moreover, coevolved symbiotic interactions between bacteria and higher organisms often show signatures of a functional fusion, in which interacting parties operate as one integrated metabolic unit. For instance, the partitioning of biosynthetic pathways between host and endosymbionts $^{219,382}$ or between multiple, co-occurring endosymbionts $^{187,383}$ illustrates that only the sum of the organismal metabolic pathways can satisfy the nutritional needs of all interacting parties. ${ }^{\mathbf{1 8 7}}$

Metabolic cross-feeding interactions can strongly determine community structure and function. ${ }^{380}$ As discussed above, the establishment of such interactions is driven by a complex interplay between fitness-advantages of individual mutants and the eco-evolutionary dynamics between multiple genotypes. Ultimately, the highly-conserved structure of core metabolic pathways in otherwise rather divergent bacterial lineages could guide the evolutionary self-organization of metabolic exchange even between very different bacterial species. ${ }^{384}$ Whether and to which extent microbial communities act as one integrated metabolic unit that maximizes both productivity and stability of the entire consortium, however, needs to be addressed in future studies. Here, targeted analyses of the metabolic abilities and activities of individual strains living in natural bacterial communities are necessary to identify whether the distribution of metabolic functions within these communities is indeed determined by global constraints that are dictated by the structure of the underlying metabolic network..$^{385,386}$

\subsection{Bacterial unculturability}

In 1932, Razumov was isolating freshwater bacteria and noticed that the majority of bacteria, which he observed under the microscope, resisted cultivation on agar plates. ${ }^{387}$ Since then, microbiologists have repeatedly corroborated that less than $1 \%$ of all archaea and bacteria can be grown in vitro ${ }^{388}$ - a problem that has been popularized as the great plate count anomaly. ${ }^{389}$ Accordingly, recent advances in metagenome sequencing of environmental samples revealed not only the presence of a tremendous microbial diversity, but also discovered completely novel genera and even phyla, which have not been isolated yet. . $^{390-392}$
Many potential explanations have been proposed to account for the unculturability of most bacterial species. These can be grouped into four main categories:

(1) Niche mismatch: Mismatch between the physiological and nutritional requirements of a bacterial strain and the conditions provided (e.g. $\mathrm{pH}$, temperature, salts, minerals, and nutrient levels). ${ }^{393,394}$

(2) Dormancy: Bacterial cells might be viable, but unculturable. .95,396 $^{395}$

(3) Antagonistic effects: Competitively superior strains outcompete others and/or produce toxic compounds (e.g. antibiotics) to kill or inhibit other strains. ${ }^{\mathbf{1 4 , 3 9 7}}$

(4) Obligate metabolic interactions: Bacterial strains have evolved obligate metabolic relationships with other neighbours in their environment. Thus, attempts to isolate a single species must fail, because of the lacking nutrients or biochemical functions. ${ }^{398,399}$

Although all of the above-mentioned reasons likely contribute to explaining the unculturability of many bacterial isolates, accumulating experimental evidence suggests that an obligate exchange of metabolites or biochemical functions among bacterial strains is particularly important in this context. For example, attempts to preserve ecological interaction within microbial communities has significantly increased bacterial recovery. In 2002, Kaeberlein et al. designed a diffusion chamber, which allowed an exchange of metabolites between cells and their environment, but prevented a mixing of cells. ${ }^{\mathbf{4 0 0}}$ Using this system, the authors managed to isolate novel cultures, which increased bacterial culturability to up to $50 \%{ }^{401}$ Interestingly, some of the isolated strains did not grow on synthetic media afterwards, indicating that a direct contact with the native microbial community was essentially required for growth. ${ }^{\mathbf{4 0 0}}$ Other related isolation techniques are enrichment cultures, in which environmental conditions are tailored to favour certain genotypes, ${ }^{\mathbf{4 0 2}}$ or dilution cultures, where environmental samples are diluted to low, but known cell numbers. ${ }^{403}$ Both approaches frequently do not result in the isolation of individual strains, but mixtures of strains that can only grow together, but not in isolation. ${ }^{85}$ Thus, this method provides the opportunity to isolate coexisting genotypes that cross-feed essential metabolites and study their interaction in more detail. Taken together, the available evidence suggests that metabolic interdependencies within natural microbial communities are an important determinant of the commonly observed unculturability of natural bacterial isolates.

\subsection{Levels of selection and transitions in individuality}

When auxotrophic bacteria engage in cooperative cross-feeding with other bacterial cells, the question arises whether natural selection acts on individual bacterial cells or if groups of cells are the unit of selection. Before addressing this question, some relevant key terms need to be defined: an 'evolutionary individual' is the unit, whose frequencies are adjusted by natural selection. ${ }^{\mathbf{4 0 4 , 4 0 5}}$ Traits that determine the Darwinian fitness of such an individual must be heritable, variable, and give rise to differential reproduction among competing individuals that 
differ in the respective trait. ${ }^{\mathbf{4 0 4 , 4 0 6}}$ As a consequence, natural selection does not only act on, for example, populations of bacterial cells, but can simultaneously operate on lower (e.g. plasmids inside of bacterial cells) or higher levels (e.g. multicellular prokaryotes such as cyanobacteria). A transition in individuality is now observed when the level of selection is shifted from lower level units that are units of selection themselves, to a higher-level entity, which is composed of several lower-level units. ${ }^{406}$ The fitness of the collective that emerges during this transition is not proportional to the average fitness of the assembled lower-level units, but an emergent property of the higher-level entity. ${ }^{407-409}$ Moreover, after the transition, "genetic information is transmitted between generations" such that "entities that were capable of independent replication before the transition can replicate only as part of a larger whole of it". ${ }^{410}$ Major leaps in biological complexity have resulted from evolutionary transitions, during which previously independent organisms were functionally integrated to form a new, higherlevel entity. ${ }^{\text {411-413 }}$ Eminent examples of such transformative events include the origin of the eukaryotic cell ${ }^{\mathbf{4 1 4 , 4 1 5}}$ or the emergence of plastids from a cyanobacterial progenitor. ${ }^{\mathbf{4 1 6}}$

How does natural selection now act in bacterial communities that engage in obligate cooperative cross-feeding of metabolites? First, it is important to recognize that under these conditions, fitness is not only determined by the traits of the individual cells, but is a property that emerges from interactions among cells. ${ }^{74,417}$ Even if cells that do not invest in the cooperative production of shared metabolites may save the cost of metabolite production, ${ }^{\mathbf{4 1 8}, \mathbf{4 1 9}}$ their lack of investment in cooperative cross-feeding likely curtails their own fitness. This is largely due to the fact that multi-level selection acts on both the level of individual cells and on groups of cells (e.g. subpopulations, different parts of the same biofilm, cell clusters, and so on). Auxotrophic cells of a local community assemble in groups to facilitate the exchange of metabolites. ${ }^{\mathbf{1 4 7 , 4 2 0}}$ Growth of cells within such a group depends on the genotypic composition of the whole group: clusters that contain more cooperative cells grow more than clusters consisting mainly of non-cooperators (Fig. 9). Even if noncooperators gain an advantage in their local group, they are selected against on a global level, if more cooperative groups export their productivity in subsequent rounds of assembly and disassembly. Different mechanisms of positive assortment (Fig. 8) and principles of self-organization, ${ }^{256,260}$ ensure that cooperative cells remain associated with other cooperators over time.

A second important consequence of living in a close metabolic entanglement with other bacterial cells is that the mutational landscape, which is available to a cell to improve its fitness, will likely dependent on the current interaction partner. Thus, the spectrum of mutations that is expected to be favoured within cross feeding interactions should be radically different from those that might be beneficial in a metabolically autonomous bacterium. Hence, mutations that arise from within these interactions and which improve the performance of the cell group (e.g. mutations increasing among-cell adhesion or levels of metabolite production), are

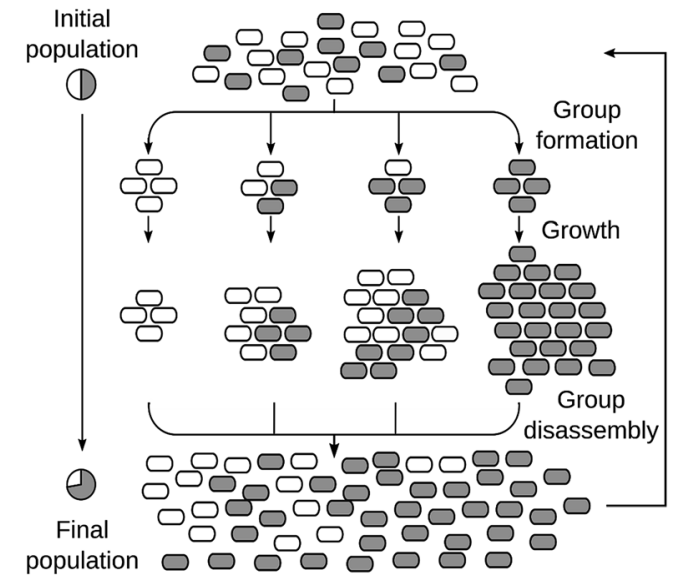

Fig. 9 Multi-level selection favours cooperative cross-feeding. Cells in a global pool assemble into clusters consisting of non-cooperative (white) and cooperative (grey) cells. On a cluster-level, non-cooperating cells gain a selective advantage over cooperators, because they save the costs of metabolite production. However, the productivity of clusters depends on the relative proportion of cooperative cells within a cluster. As a consequence, differential growth of clusters selects against non-cooperation and favours cooperation on a global level. Modified after ref. 426 and 427.

likely maladaptive outside these interactions and thus, should be interpreted as group-level adaptations.

Finally, the question remains: are groups of bacteria, whose survival depends on obligate cross-feeding of metabolites, evolutionary individuals? Put differently: what is the unit that is most relevant to evolution - the individual cell that is unable to survive in isolation, or the group of cells, in which auxotrophic bacteria can thrive? If groups were the relevant evolutionary individual, cell groups would have undergone a transition in individuality. To answer this question, it is useful to consider cases, in which a new individual has been formed by natural selection upon the merging of previously independent lower-level units and identify hallmarks that characterize these cases (Table 1).

Evaluating whether consortia of cross-feeding bacteria fulfil these criteria indicates that even though important features such as mutual dependence, functional specialisation, cooperation, and cell-attachment result almost automatically from cooperative cross-feeding, a striking difference is that these interactions are often transient (Table 1). Due to the often nonpermanent nature of association between cells, heritability of group-traits is likely low. Moreover, cross-feeding consortia do not form a cohesive unit that is clearly delimitable from other cells in the environment, but rather a delicate network of transiently interacting cells. Nevertheless, selection is expected to favour extended associations between compatible genotypes. Moreover, frequency-dependent selection and spatial selforganization within clusters should adjust the mixture and the positioning of cells within clusters, thus maximizing the supply of limiting metabolites for cooperative cells. ${ }^{\mathbf{4 2 0}}$ Mutations that were favourable in the context of one group, might work equally well when the focal mutant is combined with other genotypes, thus compensating for the lack of a strict vertical transmission. Finally, repeated bouts of association and 
Table 1 Consortia of bacteria that engage in obligate cooperative cross-feeding of metabolites show hallmarks of a transition in individuality

\begin{tabular}{lll}
\hline Characteristic & Cooperative cross-feeding bacteria & Example \\
\hline Mutual dependence $^{a}$ & Yes & 428 \\
Functional specialisation of cells/division of labour $^{b}$ & Yes & 429 and 430 \\
Cooperation $^{c}$ & Yes & 151 and 431 \\
Group-level reproduction $^{c}$ & Likely yes, to some extent & 432 \\
Cell-attachment $_{\text {Strict vertical transmission }}$ & Yes, but likely transient \\
Conflict resolution strategies & Likely not & 147 and 419 \\
Coordination of cellular activities & Yes & 256 and 433 \\
& Yes & 417 and 426
\end{tabular}

${ }^{a}$ Reproduction only as part of a multicellular consortium. ${ }^{b}$ Synergistic fitness benefit arises upon combination of functions. ${ }^{c}$ Groups of crossfeeding bacteria beget new groups.

disassociation allow to purge detrimental mutations on a cluster-level, thus accelerating molecular evolution. Taken together, consortia of bacteria that engage in obligate cooperative cross-feeding do not form a coherent, multicellular organism. Still, their performance results from complex metabolic interactions among the constituent cells, which is more than the sum of its parts. Future work is necessary to determine how durable cross-feeding interactions are and how this affects coevolution of interacting cells.

\section{Concluding remarks}

Our comprehensive analysis of the available literature revealed how commonly bacteria are involved in metabolic cross-feeding interactions with other bacteria, archaea, or eukaryotic organisms (Fig. 3). Particularly striking was the tremendous diversity in terms of mode of metabolite exchange that characterized the analysed interactions (Fig. 4). What also became obvious from screening the available literature, however, is that despite intensive efforts to study the molecular details of numerous metabolic cross-feeding interactions during the past decades, ${ }^{\mathbf{2 3 , 6 3 , 3 7 6}}$ ecological or evolutionary aspects of these interactions are still notoriously understudied. Moreover, research attention so far has been mainly directed towards a relatively small set of model systems that have been studied in more detail. ${ }^{23,63,376}$ Thus, more empirical work is required to systematically compare cross-feeding interactions of different environmental origins and taxonomic compositions. In addition, the prevalence and ecological significance of metabolite cross-feeding should be increasingly analysed in different natural microbial communities, especially focussing on its importance for structuring these communities. Finally, the analysis of isolated consortia should be complemented by studies of synthetically engineered or experimentally evolved interactions, in which the causal molecular and evolutionary factors can be identified much easier.

With the growing realization that metabolic interactions within microbial communities and populations are key for determining human health, ${ }^{8}$ global biogeochemical cycles ${ }^{6}$ or the yield in biotechnological production processes, ${ }^{\mathbf{4 2 1}}$ the need to understand the rules that govern the emergence and evolution of these interactions is becoming particularly urgent.
Undoubtedly, the development of new technologies to chemically identify and characterize exchanged metabolites, to derive transcriptional and proteomic information of individual genotypes in a coculture context, as well as to differentially label and image interacting cells under controlled conditions, will significantly advance the study of microbial metabolite exchange. ${ }^{13}$ Especially the possibility to combine different methods will provide exciting opportunities, such as to image living cocultures on a single-cell level and simultaneously visualize the distribution of metabolites with a high spatial resolution. Moreover, current computational advances in simulating metabolic processes of cells that are embedded in complex communities hold the potential to predict bacterial metabolite exchange interactions based on the genome sequence of the organisms present in the community. ${ }^{\mathbf{4 2 2 , 4 2 3}}$

A wealth of exciting research opportunities is waiting in this rapidly emerging field. Interesting questions that should be addressed in the future include (i) which ecological factors determine the assembly of metabolically interacting consortia in natural microbial communities (e.g. motility, chemotaxis, antagonistic interactions)? (ii) How stable/transient are obligate metabolic interactions in natural environments? (iii) Which evolutionary consequences result for genotypes that transition into an obligate metabolic dependency with other genotypes (e.g. local adaptation, genome streamlining, improved efficiency)? (iv) Which rules govern the division of metabolic functions within microbial communities? or (v) Are clusters of metabolite cross-feeding cells evolutionary individuals?

Evolution does not only proceed by giving rise to new species, but also by merging previously independent organisms into new life-forms. ${ }^{\mathbf{4 2 4}}$ Consequently, intricate metabolic interdependencies between two or more individuals are a general feature of life. Answering the abovementioned questions using metabolite cross-feeding within microbial communities as a tractable model therefore holds the potential to help resolve the fundamental evolutionary problem of how biological complexity can emerge from the establishment of cooperative interactions among simpler units.

\section{Conflicts of interest}

There are no conflicts of interest to declare. 


\section{Acknowledgements}

We thank Wilhelm Boland and Martin Ackermann for support as well as Christoph Kaleta, Martin Kaltenpoth, Paul Rainey, Will Ratcliff as well as the whole Research Group Insect Symbiosis for fruitful discussions. Funding from the Jena School of Microbial Communication (SW, DP, CK), the Volkswagen Foundation (I/85 290 to GD, SS, CK), the DAAD GERLS program (GY, CK), the German Research Foundation (SFB 944P19 and KO 3909/2-1 to DP, SS, CK), the ETH-Zürich postdoctoral fellowship program (GD), the Marie Curie Actions for People COFUND Program (GD), the Simons Collaboration on the Principles of Microbial Ecosystems (GD), and the Cluster of Excellence 'Inflammation at Interfaces' (ExC 306 to SW) is gratefully acknowledged.

\section{References}

1 W. B. Whitman, D. C. Coleman and W. J. Wiebe, Proc. Natl. Acad. Sci. U. S. A., 1998, 95, 6578-6583.

2 M. C. Horner-Devine, K. M. Carney and B. J. Bohannan, Proc. R. Soc. London, Ser. B, 2004, 271, 113-122.

3 J. O. McInerney, Nat. Microbiol., 2016, 1, 16139.

4 M. C. Weiss, F. L. Sousa, N. Mrnjavac, S. Neukirchen, M. Roettger, S. Nelson-Sathi and W. F. Martin, Nat. Microbiol., 2016, 1, 16116.

5 F. U. Battistuzzi, A. Feijao and S. B. Hedges, BMC Evol. Biol., 2004, 4, 44.

6 P. G. Falkowski, T. Fenchel and E. F. Delong, Science, 2008, 320, 1034-1039.

7 J. E. Lovelock and L. Margulis, Tellus, 1974, 26, 2-10.

8 M. McFall-Ngai, M. G. Hadfield, T. C. Bosch, H. V. Carey, T. Domazet-Lošo, A. E. Douglas, N. Dubilier, G. Eberl, T. Fukami and S. F. Gilbert, Proc. Natl. Acad. Sci. U. S. A., 2013, 110, 3229-3236.

9 S. Mitri and K. R. Foster, Annu. Rev. Genet., 2013, 47, 247273.

10 A. E. Little, C. J. Robinson, S. B. Peterson, K. F. Raffa and J. Handelsman, Annu. Rev. Microbiol., 2008, 62, 375-401.

11 J. L. Sachs and A. C. Hollowell, mBio, 2012, 3(3), e00099-12.

12 R. González-Cabaleiro, I. D. Ofiţeru, J. M. Lema and J. Rodríguez, ISME J., 2015, 9, 2630-2641.

13 V. V. Phelan, W.-T. Liu, K. Pogliano and P. C. Dorrestein, Nat. Chem. Biol., 2012, 8, 26-35.

14 B. Kerr, M. A. Riley, M. W. Feldman and B. J. Bohannan, Nature, 2002, 418, 171-174.

15 B. C. Kirkup and M. A. Riley, Nature, 2004, 428, 412-414.

16 K. R. Foster and T. Bell, Curr. Biol., 2012, 22, 1845-1850.

17 M. E. Hibbing, C. Fuqua, M. R. Parsek and S. B. Peterson, Nat. Rev. Microbiol., 2009, 8, nrmicro2259.

18 O. Ciofu, T. J. Beveridge, J. Kadurugamuwa, J. WaltherRasmussen and N. Høiby, J. Antimicrob. Chemother., 2000, 45, 9-13.

19 R. Daniels, J. Vanderleyden and J. Michiels, FEMS Microbiol. Rev., 2004, 28, 261-289.

20 D. Davies and G. Geesey, Appl. Environ. Microbiol., 1995, 61, 860-867.
21 A. S. Griffin, S. A. West and A. Buckling, Nature, 2004, 430, 1024-1027.

22 S. A. West, A. S. Griffin, A. Gardner and S. P. Diggle, Nat. Rev. Microbiol., 2006, 4, 597-607.

23 E. C. Seth and M. E. Taga, Front. Microbiol., 2014, 5, 350.

24 A. Zelezniak, S. Andrejev, O. Ponomarova, D. R. Mende, P. Bork and K. R. Patil, Proc. Natl. Acad. Sci. U. S. A., 2015, 112, 6449-6454.

25 M. T. Mee, J. J. Collins, G. M. Church and H. H. Wang, Proc. Natl. Acad. Sci. U. S. A., 2014, 111, E2149-E2156.

26 G. D'Souza, S. Waschina, S. Pande, K. Bohl, C. Kaleta and C. Kost, Evolution, 2014, 68, 2559-2570.

27 B. Schink, Antonie van Leeuwenhoek, 2002, 81, 257-261.

28 R. Pound, Am. Nat., 1893, 27, 509-520.

29 C. E. Marshall, Science, 1915, 306-312.

30 M. Dawson, Proc. R. Soc. London, Ser. B, 1899, 64, 167-168. 31 D. T. MacDougal, Bull. Torrey Bot. Club, 1899, 26, 511-530. 32 T. P. Ferguson and G. Bond, Ann. Bot., 1954, 18, 385-396.

33 M. S. Marshall, J. Dairy Sci., 1920, 3, 406-413.

34 V. Graham, J. Bacteriol., 1943, 45, 51.

35 D. A. Soulides, Appl. Microbiol., 1955, 3, 129-131.

36 H. M. Ward, Philos. Trans. R. Soc., B, 1892, 183, 125-197.

37 W. Pfeffer, Pflanzenphysiologie: ein Handbuch der Lehre vom Stoffwechsel und Kraftwechsel in der Pflanze, Engelmann, Leipzig, 1897.

38 H. Marshall Ward D.Sc, Ann. Bot., 1899, 549-562.

$39 \mathrm{H}$. Reinheimer, Symbiogenesis, the universal law of progressive evolution, Knapp, Drewett, 1915.

40 F. Gibson and M. Jones, J. Sci. Comput., 1954, 17, 33-34.

41 V. Nurmikko, Experientia, 1956, 12, 245-249.

42 V. Nurmikko, Acta Chem. Scand., 1955, 9, 1317-1322.

43 S. R. Sørensen, Z. Ronen and J. Aamand, Appl. Environ. Microbiol., 2002, 68, 3478-3485.

44 M. L. de Souza, D. Newcombe, S. Alvey, D. E. Crowley, A. Hay, M. J. Sadowsky and L. P. Wackett, Appl. Environ. Microbiol., 1998, 64, 178-184.

45 S. J. Roberts, A. Walker, N. R. Parekh, S. J. Welch and M. J. Waddington, Pest Manage. Sci., 1993, 39, 71-78.

46 M. J. McInerney, M. P. Bryant and N. Pfennig, Arch. Microbiol., 1979, 122, 129-135.

47 P. Fildes, Microbiology, 1956, 15, 636-642.

48 W. B. Dempsey and P. F. Pachler, J. Bacteriol., 1966, 91, 642645.

49 S. Pomper, J. Bacteriol., 1952, 63, 707.

50 E. Glanville and M. Demerec, Genetics, 1960, 45, 1359.

51 K. Rahman, J. Thahira-Rahman, P. Lakshmanaperumalsamy and I. Banat, Bioresour. Technol., 2002, 85, 257-261.

52 A. Haritash and C. Kaushik, J. Hazard. Mater., 2009, 169, 115.

53 N. Das and P. Chandran, Biotechnol. Res. Int., 2011, 2011, 941810.

54 H. Ali, Water, Air, Soil Pollut., 2010, 213, 251-273.

55 R. G. Saratale, G. D. Saratale, J.-S. Chang and S. Govindwar, J. Taiwan Inst. Chem. Eng., 2011, 42, 138-157.

56 D. S. Treves, S. Manning and J. Adams, Mol. Biol. Evol., 1998, 15, 789-797. 
57 R. B. Helling, T. Kinney and J. Adams, Microbiology, 1981, 123, 129-141.

58 R. B. Helling, C. N. Vargas and J. Adams, Genetics, 1987, 116, 349-358.

59 R. F. Rosenzweig, R. Sharp, D. S. Treves and J. Adams, Genetics, 1994, 137, 903-917.

60 P. E. Turner, V. Souza and R. E. Lenski, Ecology, 1996, 77, 2119-2129.

61 M. L. Friesen, G. Saxer, M. Travisano and M. Doebeli, Evolution, 2004, 58, 245-260.

62 T. Pfeiffer and S. Bonhoeffer, Am. Nat., 2004, 163, E126E135.

63 B. E. Morris, R. Henneberger, H. Huber and C. MoisslEichinger, FEMS Microbiol. Rev., 2013, 37, 384-406.

64 E. Doyle, L. Muckian, A. M. Hickey and N. Clipson, Adv. Appl. Microbiol., 2008, 65, 27-66.

65 I. Shiio, S.-I. Ôtsuka and M. Takahashi, J. Biochem., 1962, 51, 56-62.

66 N. Paczia, A. Nilgen, T. Lehmann, J. Gätgens, W. Wiechert and S. Noack, Microb. Cell Fact., 2012, 11, 122.

67 T. Shimoyama, S. Kato, S. i. Ishii and K. Watanabe, Science, 2009, 323, 1574.

68 A. Belenguer, S. H. Duncan, A. G. Calder, G. Holtrop, P. Louis, G. E. Lobley and H. J. Flint, Appl. Environ. Microbiol., 2006, 72, 3593-3599.

69 W. Harcombe, Evolution, 2010, 64, 2166-2172.

70 E. H. Wintermute and P. A. Silver, Mol. Syst. Biol., 2010, 6, 407.

71 L. Baumann, P. Baumann, N. A. Moran, J. Sandström and M. L. Thao, J. Mol. Evol., 1999, 48, 77-85.

72 F. Lipschultz, O. Zafiriou, S. Wofsy, M. McElroy, F. Valois and S. Watson, Nature, 1981, 294, 641-643.

73 H. Koch, S. Lücker, M. Albertsen, K. Kitzinger, C. Herbold, E. Spieck, P. H. Nielsen, M. Wagner and H. Daims, Proc. Natl. Acad. Sci. U. S. A., 2015, 112, 11371-11376.

74 S. Pande, H. Merker, K. Bohl, M. Reichelt, S. Schuster, L. F. de Figueiredo, C. Kaleta and C. Kost, ISME J., 2014, 8, 953-962.

75 O. Leimar and R. C. Connor, Genetic and cultural evolution of cooperation, 2003, pp. 203-222.

76 J. L. Sachs, U. G. Mueller, T. P. Wilcox and J. J. Bull, Q. Rev. Biol., 2004, 79, 135-160.

77 J. Russel, H. L. Røder, J. S. Madsen, M. Burmølle and S. J. Sørensen, Proc. Natl. Acad. Sci. U. S. A., 2017, 114, 10684-10688.

78 J. S. Madsen, H. L. Røder, J. Russel, H. Sørensen, M. Burmølle and S. J. Sørensen, Environ. Microbiol., 2016, 18, 2565-2574.

79 A. Z. Rosenthal, E. G. Matson, A. Eldar and J. R. Leadbetter, ISME J., 2011, 5, 1133-1142.

80 J. R. Graber and J. A. Breznak, Appl. Environ. Microbiol., 2005, 71, 1883-1889.

81 P. Kaiser, in Azospirillum VI and Related Microorganisms: Genetics-Physiology-Ecology, ed. I. Fendrik, M. del Gallo, J. Vanderleyden and M. de Zamaroczy, Springer Berlin Heidelberg, Berlin, Heidelberg, 1995, pp. 207-212, DOI: 10.1007/978-3-642-79906-8_21.
82 J. Kives, D. Guadarrama, B. Orgaz, A. Rivera-Sen, J. Vazquez and C. SanJose, J. Dairy Sci., 2005, 88, 4165-4171.

83 T. Woyke, H. Teeling, N. N. Ivanova, M. Huntemann, M. Richter, F. O. Gloeckner, D. Boffelli, I. J. Anderson, K. W. Barry, H. J. Shapiro, E. Szeto, N. C. Kyrpides, M. Mussmann, R. Amann, C. Bergin, C. Ruehland, E. M. Rubin and N. Dubilier, Nature, 2006, 443, 950-955.

84 J. Foster, M. Ganatra, I. Kamal, J. Ware, K. Makarova, N. Ivanova, A. Bhattacharyya, V. Kapatral, S. Kumar, J. Posfai, T. Vincze, J. Ingram, L. Moran, A. Lapidus, M. Omelchenko, N. Kyrpides, E. Ghedin, S. Wang, E. Goltsman, V. Joukov, O. Ostrovskaya, K. Tsukerman, M. Mazur, D. Comb, E. Koonin and B. Slatko, PLoS Biol., 2005, 3(4), e121.

85 S. L. Garcia, M. Buck, K. D. McMahon, H.-P. Grossart, A. Eiler and F. Warnecke, Mol. Ecol., 2015, 24, 4449-4459.

86 S. Ghignone, A. Salvioli, I. Anca, E. Lumini, G. Ortu, L. Petiti, S. Cruveiller, V. Bianciotto, P. Piffanelli, L. Lanfranco and P. Bonfante, ISME J., 2012, 6, 136-145.

87 J. L. Mark Welch, B. J. Rossetti, C. W. Rieken, F. E. Dewhirst and G. G. Borisy, Proc. Natl. Acad. Sci. U. S. A., 2016, 113, E791-E800.

88 A. E. Dekas, R. S. Poretsky and V. J. Orphan, Science, 2009, 326, 422-426.

89 D. Wu, S. C. Daugherty, S. E. Van Aken, G. H. Pai, K. L. Watkins, H. Khouri, L. J. Tallon, J. M. Zaborsky, H. E. Dunbar, P. L. Tran, N. A. Moran and J. A. Eisen, PLoS Biol., 2006, 4, e188.

90 C. B. Walker, A. M. Redding-Johanson, E. E. Baidoo, L. Rajeev, Z. L. He, E. L. Hendrickson, M. P. Joachimiak, S. Stolyar, A. P. Arkin, J. A. Leigh, J. Z. Zhou, J. D. Keasling, A. Mukhopadhyay and D. A. Stahl, ISME J., 2012, 6, 2045-2055.

91 S. Sieuwerts, D. Molenaar, S. van Hijum, M. Beerthuyzen, M. J. A. Stevens, P. W. M. Janssen, C. J. Ingham, F. A. M. de Bok, W. M. de Vos and J. Vlieg, Appl. Environ. Microbiol., 2010, 76, 7775-7784.

92 U. Jahn, R. Summons, H. Sturt, E. Grosjean and H. Huber, Arch. Microbiol., 2004, 182, 404-413.

93 S. Sawanon and Y. Kobayashi, Anim. Sci. J., 2006, 77, 208214.

94 R. A. Foster, M. M. M. Kuypers, T. Vagner, R. W. Paerl, N. Musat and J. P. Zehr, ISME J., 2011, 5, 1484-1493.

95 A. Rivière, M. Gagnon, S. Weckx, D. Roy and L. De Vuyst, Appl. Environ. Microbiol., 2015, 81, 7767-7781.

96 A. Deveau, C. Brulé, B. Palin, D. Champmartin, P. Rubini, J. Garbaye, A. Sarniguet and P. Frey-Klett, Environ. Microbiol. Rep., 2010, 2, 560-568.

97 M. Gobbetti, A. Corsetti and J. Rossi, Appl. Microbiol. Biotechnol., 1994, 41, 456-460.

98 M. M. Ramsey, K. P. Rumbaugh and M. Whiteley, PLoS Pathog., 2011, 7, e1002012.

99 P. Engel and N. A. Moran, FEMS Microbiol. Rev., 2013, 37, 699-735.

100 C. Kaiser, M. R. Kilburn, P. L. Clode, L. Fuchslueger, M. Koranda, J. B. Cliff, Z. M. Solaiman and D. V. Murphy, New Phytol., 2015, 205, 1537-1551. 
101 R. L. Chapman, Mitig. Adapt. Strategies Glob. Change, 2013, 18, 5-12.

102 M. K. Bach, W. E. Magee and R. H. Burris, Plant Physiol., 1958, 33, 118-124.

103 M. T. Croft, A. D. Lawrence, E. Raux-Deery, M. J. Warren and A. G. Smith, Nature, 2005, 438, 90-93.

104 S. A. Amin, D. H. Green, M. C. Hart, F. C. Küpper, W. G. Sunda and C. J. Carrano, Proc. Natl. Acad. Sci. U. S. A., 2009, 106, 17071-17076.

105 M. T. Croft, M. J. Warren and A. G. Smith, Eukaryotic Cell, 2006, 5, 1175-1183.

106 J. Foster, M. Ganatra, I. Kamal, J. Ware, K. Makarova, N. Ivanova, A. Bhattacharyya, V. Kapatral, S. Kumar, J. Posfai, T. Vincze, J. Ingram, L. Moran, A. Lapidus, M. Omelchenko, N. Kyrpides, E. Ghedin, S. Wang, E. Goltsman, V. Joukov, O. Ostrovskaya, K. Tsukerman, M. Mazur, D. Comb, E. Koonin and B. Slatko, PLoS Biol., 2005, 3, e121.

107 M. E. Hibbing, C. Fuqua, M. R. Parsek and S. B. Peterson, Nat. Rev. Microbiol., 2010, 8, 15-25.

108 K. B. Xavier and B. L. Bassler, Nature, 2005, 437, 750-753.

109 S. Uroz, S. R. Chhabra, M. Camara, P. Williams, P. Oger and Y. Dessaux, Microbiology, 2005, 151, 3313-3322.

110 B.-Y. Wang and H. K. Kuramitsu, Appl. Environ. Microbiol., 2005, 71, 354-362.

111 L. M. Mashburn and M. Whiteley, Nature, 2005, 437, 422.

112 H. Nikaido, Microbiol. Mol. Biol. Rev., 2003, 67, 593-656.

113 Z. Ren, T. E. Ward and J. M. Regan, Environ. Sci. Technol., 2007, 41, 4781-4786.

114 J. Zhou, Q. Ma, H. Yi, L. Wang, H. Song and Y.-J. Yuan, Appl. Environ. Microbiol., 2011, 77, 7023-7030.

115 D. R. Boone, R. L. Johnson and Y. Liu, Appl. Environ. Microbiol., 1989, 55, 1735-1741.

116 B. Schink and A. J. M. Stams, in The Prokaryotes: Prokaryotic Communities and Ecophysiology, ed. E. Rosenberg, E. F. DeLong, S. Lory, E. Stackebrandt and F. Thompson, Springer Berlin Heidelberg, Berlin, Heidelberg, 2013, pp. 471-493, DOI: 10.1007/978-3-642-30123-0_59.

117 R. Krämer, FEMS Microbiol. Rev., 1994, 13, 75-93.

118 J. H. Crosa and C. T. Walsh, Microbiol. Mol. Biol. Rev., 2002, 66, 223-249.

119 J. L. Furrer, D. N. Sanders, I. G. Hook-Barnard and M. A. McIntosh, Mol. Microbiol., 2002, 44, 1225-1234.

120 C. Arnosti, Ann. Rev. Mar. Sci., 2011, 3, 401-425.

121 H.-C. Flemming and J. Wingender, Nat. Rev. Microbiol., 2010, 8, 623-633.

122 J. Wingender, T. R. Neu and H.-C. Flemming, in Microbial extracellular polymeric substances, Springer, 1999, pp. 1-19.

123 D. C. Rees, E. Johnson and O. Lewinson, Nat. Rev. Mol. Cell Biol., 2009, 10, 218-227.

124 P. Postma, J. Lengeler and G. Jacobson, Microbiol. Rev., 1993, 57, 543-594.

125 Y. Zhang, D. A. Rodionov, M. S. Gelfand and V. N. Gladyshev, BMC Genom., 2009, 10, 78.

126 P. H. Degnan, N. A. Barry, K. C. Mok, M. E. Taga and A. L. Goodman, Cell Host Microbe, 2014, 15, 47-57.
127 A. Nasarabadi, J. E. Berleman and M. Auer, Biogenesis of Fatty Acids, Lipids and Membranes, 2017, pp. 1-15.

128 A. Kulp and M. J. Kuehn, Annu. Rev. Microbiol., 2010, 64, 163-184.

129 T. J. Beveridge, J. Bacteriol., 1999, 181, 4725-4733.

130 R. Fiocca, V. Necchi, P. Sommi, V. Ricci, J. Telford, T. L. Cover and E. Solcia, J. Pathol., 1999, 188, 220-226.

131 S. Kato, Y. Kowashi and D. R. Demuth, Microb. Pathog., 2002, 32, 1-13.

132 S. N. Wai, B. Lindmark, T. Söderblom, A. Takade, M. Westermark, J. Oscarsson, J. Jass, A. Richter-Dahlfors, Y. Mizunoe and B. E. Uhlin, Cell, 2003, 115, 25-35.

133 K. Yokoyama, T. Horii, T. Yamashino, S. Hashikawa, S. Barua, T. Hasegawa, H. Watanabe and M. Ohta, FEMS Microbiol. Lett., 2000, 192, 139-144.

134 S. Patrick, J. P. McKenna, O. Seamus and E. Dermott, Microb. Pathog., 1996, 20, 191-202.

135 J. L. Kadurugamuwa and T. J. Beveridge, J. Bacteriol., 1995, 177, 3998-4008.

136 D. W. Dorward and C. F. Garon, Appl. Environ. Microbiol., 1990, 56, 1960-1962.

137 L. Mashburn-Warren, R. Mclean and M. Whiteley, Geobiology, 2008, 6, 214-219.

138 J. P. Remis, J. W. Costerton and M. Auer, ISME J., 2010, 4, 1085-1087.

139 H. Yonezawa, T. Osaki, S. Kurata, M. Fukuda, H. Kawakami, K. Ochiai, T. Hanawa and S. Kamiya, BMC Microbiol., 2009, 9, 197.

140 C. Pérez-Cruz, O. Carrión, L. Delgado, G. Martinez, C. López-Iglesias and E. Mercade, Appl. Environ. Microbiol., 2013, 79, 1874-1881.

141 C. Pérez-Cruz, L. Delgado, C. López-Iglesias and E. Mercade, PLoS One, 2015, 10, e0116896.

142 S. J. Biller, F. Schubotz, S. E. Roggensack, A. W. Thompson, R. E. Summons and S. W. Chisholm, Science, 2014, 343, 183-186.

143 J. P. Remis, D. Wei, A. Gorur, M. Zemla, J. Haraga, S. Allen, H. E. Witkowska, J. W. Costerton, J. E. Berleman and M. Auer, Environ. Microbiol., 2014, 16, 598-610.

144 J. E. Berleman, S. Allen, M. A. Danielewicz, J. P. Remis, A. Gorur, J. Cunha, M. Z. Hadi, D. R. Zusman, T. R. Northen and H. E. Witkowska, Front. Microbiol., 2014, 5, 474.

145 G. P. Dubey and S. Ben-Yehuda, Cell, 2011, 144, 590-600. 146 G. P. Dubey, G. B. M. Mohan, A. Dubrovsky, T. Amen, S. Tsipshtein, A. Rouvinski, A. Rosenberg, D. Kaganovich, E. Sherman and O. Medalia, Dev. Cell, 2016, 36, 453-461.

147 S. Pande, S. Shitut, L. Freund, M. Westermann, F. Bertels, C. Colesie, I. B. Bischofs and C. Kost, Nat. Commun., 2015, 6, 6238.

148 S. i. Ishii, T. Kosaka, K. Hori, Y. Hotta and K. Watanabe, Appl. Environ. Microbiol., 2005, 71, 7838-7845.

149 P. T. Ha, S. R. Lindemann, L. Shi, A. C. Dohnalkova, J. K. Fredrickson, M. T. Madigan and H. Beyenal, Nat. Commun., 2017, 8, 13924.

150 S. Benomar, D. Ranava, M. L. Cárdenas, E. Trably, Y. Rafrafi, A. Ducret, J. Hamelin, E. Lojou, J.-P. Steyer and M.-T. Giudici-Orticoni, Nat. Commun., 2015, 6, 6283. 
151 M. A. Nowak, Science, 2006, 314, 1560-1563.

152 G. Hardin, J. Nat. Resour. Pol. Res., 2009, 1, 243-253.

153 A. Goelzer and V. Fromion, Biochim. Biophys. Acta Gen. Subj., 2011, 1810, 978-988.

154 A. Varma and B. O. Palsson, Appl. Environ. Microbiol., 1994, 60, 3724-3731.

155 J. Tasoff, M. T. Mee and H. H. Wang, PLoS One, 2015, 10, e0132907.

156 P. Hammerstein and R. Noë, Philos. Trans. R. Soc., B, 2016, 371, 20150101.

157 D. Ricardo, The works and correspondence of David Ricardo Vol. 1: On the principles of political economy and taxation, 1817.

158 D. R. Johnson, F. Goldschmidt, E. E. Lilja and M. Ackermann, ISME J., 2012, 6, 1985-1991.

159 T. Ferenci, Trends Microbiol., 2016, 24, 209-223.

160 E. E. Lilja and D. R. Johnson, ISME J., 2016, 10, 1568-1578. 161 O. Ponomarova and K. R. Patil, Curr. Opin. Microbiol., 2015, 27, 37-44.

162 G. D. Werner, J. E. Strassmann, A. B. Ivens, D. J. Engelmoer, E. Verbruggen, D. C. Queller, R. Noë, N. C. Johnson, P. Hammerstein and E. T. Kiers, Proc. Natl. Acad. Sci. U. S. A., 2014, 111, 1237-1244.

163 C. Kaleta, S. Schäuble, U. Rinas and S. Schuster, Biotechnol. J., 2013, 8, 1105-1114.

164 S. Waschina, G. D'Souza, C. Kost and C. Kaleta, FEBS J., 2016, 283, 2149-2163.

165 H. Akashi and T. Gojobori, Proc. Natl. Acad. Sci. U. S. A., 2002, 99, 3695-3700.

166 E. M. Heizer Jr, D. W. Raiford, M. L. Raymer, T. E. Doom, R. V. Miller and D. E. Krane, Mol. Biol. Evol., 2006, 23, 1670-1680.

167 S. Germerodt, K. Bohl, A. Lück, S. Pande, A. Schröter, C. Kaleta, S. Schuster and C. Kost, PLoS Comput. Biol., 2016, 12, e1004986.

168 P. Hu, E. A. Dubinsky, A. J. Probst, J. Wang, C. M. Sieber, L. M. Tom, P. R. Gardinali, J. F. Banfield, R. M. Atlas and G. L. Andersen, Proc. Natl. Acad. Sci. U. S. A., 2017, 114, $7432-7437$.

169 J. Zhao and K. Shimizu, J. Biotechnol., 2003, 101, 101-117. 170 V. Sabarly, C. Aubron, J. Glodt, T. Balliau, O. Langella, D. Chevret, O. Rigal, A. Bourgais, B. Picard and D. Vienne, Environ. Microbiol., 2016, 18, 100-117.

171 J. L. M. Welch, B. J. Rossetti, C. W. Rieken, F. E. Dewhirst and G. G. Borisy, Proc. Natl. Acad. Sci. U. S. A., 2016, 113, E791-E800.

172 H.-C. Flemming, J. Wingender, U. Szewzyk, P. Steinberg, S. A. Rice and S. Kjelleberg, Nat. Rev. Microbiol., 2016, 14, 563-575.

173 P. S. Stewart and M. J. Franklin, Nat. Rev. Microbiol., 2008, 6, 199-210.

174 M. Ackermann, Nat. Rev. Microbiol., 2015, 13, 497-508.

175 D. Healey, K. Axelrod and J. Gore, Mol. Syst. Biol., 2016, 12, 877.

176 K. Kumar, R. A. Mella-Herrera and J. W. Golden, Cold Spring Harbor Perspect. Biol., 2010, 2, a000315.
177 A. Z. Rosenthal, Y. Qi, S. Hormoz, J. Park, C. H.-J. Li and M. Elowitz, bioRxiv, 2017, 208686.

178 M. T. Wortel, E. Noor, M. Ferris, F. J. Bruggeman and W. Liebermeister, bioRxiv, 2017, 111161.

179 S. M. Carroll, M.-C. Lee and C. J. Marx, Evolution, 2014, 68, 760-771.

180 J. J. Morris, Trends Genet., 2015, 31, 475-482.

181 Y. Kallus, J. H. Miller and E. Libby, Nat. Commun., 2017, 8, 1361.

182 J. J. Wernegreen, Nat. Rev. Genet., 2002, 3, 850-861.

183 G. H. Thomas, J. Zucker, S. J. Macdonald, A. Sorokin, I. Goryanin and A. E. Douglas, BMC Syst. Biol., 2009, 3, 24.

184 N. A. Moran, J. P. McCutcheon and A. Nakabachi, Annu. Rev. Genet., 2008, 42, 165-190.

185 J. P. McCutcheon and N. A. Moran, Nat. Rev. Microbiol., 2012, 10, 13-26.

186 J. P. McCutcheon and N. A. Moran, Genome Biol. Evol., 2010, 2, 708-718.

187 J. P. McCutcheon and N. A. Moran, Proc. Natl. Acad. Sci. U. S. A., 2007, 104, 19392-19397.

188 A. Mira, L. Klasson and S. G. Andersson, Curr. Opin. Microbiol., 2002, 5, 506-512.

189 K. Han, Z.-f. Li, R. Peng, L.-p. Zhu, T. Zhou, L.-g. Wang, S.-g. Li, X.-b. Zhang, W. Hu and Z.-h. Wu, Sci. Rep., 2013, 3, 2101.

190 A. Nakabachi, A. Yamashita, H. Toh, H. Ishikawa, H. E. Dunbar, N. A. Moran and M. Hattori, Science, 2006, 314, 267.

191 P. Puigbò, A. Lobkovsky, D. Kristensen, Y. Wolf and E. Koonin, BMC Biol., 2014, 12, 1-19.

192 E. N. Gordienko, M. D. Kazanov and M. S. Gelfand, J. Bacteriol., 2013, 195, 2786-2792.

193 H. Tettelin, D. Riley, C. Cattuto and D. Medini, Curr. Opin. Microbiol., 2008, 11, 472-477.

194 D. Medini, C. Donati, H. Tettelin, V. Masignani and R. Rappuoli, Curr. Opin. Genet. Dev., 2005, 15, 589-594.

195 S. J. Biller, P. M. Berube, D. Lindell and S. W. Chisholm, Nat. Rev. Microbiol., 2015, 13, 13-27.

196 S. Koskiniemi, S. Sun, O. G. Berg and D. I. Andersson, PLoS Genet., 2012, 8(6), e1002787.

197 I. Shachrai, A. Zaslaver, U. Alon and E. Dekel, Mol. Cell, 2010, 38, 758-767.

198 E. Dekel and U. Alon, Nature, 2005, 436, 588-592.

199 A. Dufresne, L. Garczarek and F. Partensky, Genome Biol., 2005, 6, R14.

200 A. Mira, H. Ochman and N. A. Moran, Trends Genet., 2001, 17, 589-596.

201 D. J. Martínez-Cano, M. Reyes-Prieto, E. Martínez-Romero, L. P. Partida-Martínez, A. Latorre, A. Moya and L. Delaye, Front. Microbiol., 2014, 5, 742.

202 B. K. Swan, B. Tupper, A. Sczyrba, F. M. Lauro, M. MartinezGarcia, J. M. Gonzalez, H. Luo, J. J. Wright, Z. C. Landry, N. W. Hanson, B. P. Thompson, N. J. Poulton, P. Schwientek, S. G. Acinas, S. J. Giovannoni, M. A. Moran, S. J. Hallam, R. Cavicchioli, T. Woyke and R. Stepanauskas, Proc. Natl. Acad. Sci. U. S. A., 2013, 110, 11463-11468. 
203 B. Batut, C. Knibbe, G. Marais and V. Daubin, Nat. Rev. Microbiol., 2014, 12, 841-850.

204 J. Grote, J. C. Thrash, M. J. Huggett, Z. C. Landry, P. Carini, S. J. Giovannoni and M. S. Rappe, mBio, 2012, 3(5), e0025212.

205 L. A. Bristow, W. Mohr, S. Ahmerkamp and M. M. Kuypers, Curr. Biol., 2017, 27, R474-R478.

206 S. Zamenhof and H. H. Eichhorn, Nature, 1967, 216, 456458.

207 G. D'Souza and C. Kost, PLoS Genet., 2016, 12, e1006364.

208 W. Kim and S. B. Levy, Appl. Environ. Microbiol., 2008, 74, 3644-3651.

209 F. Wessely, M. Bartl, R. Guthke, P. Li, S. Schuster and C. Kaleta, Mol. Syst. Biol., 2011, 7, 515.

210 A. G. Lochhead, Bacteriol. Rev., 1958, 22, 145-153.

211 A. Moura, M. A. Savageau and R. Alves, PLoS One, 2013, 8, e77319.

212 E. Schmidt and R. L. Starkey, Soil Sci., 1951, 71, 221-232.

213 D. J. Levy-Booth, R. G. Campbell, R. H. Gulden, M. M. Hart, J. R. Powell, J. N. Klironomos, K. P. Pauls, C. J. Swanton, J. T. Trevors and K. E. Dunfield, Soil Biol. Biochem., 2007, 39, 2977-2991.

214 M. C. Lee and C. J. Marx, PLoS Genet., 2012, 8, e1002651.

215 B. J. Paul, M. B. Berkmen and R. L. Gourse, Proc. Natl. Acad. Sci. U. S. A., 2005, 102, 7823-7828.

216 V. Santos and I. Hirshfield, PLoS One, 2016, 11, e0157578.

217 D. J. Martínez-Cano, M. Reyes-Prieto, E. Martinez-Romero, L. P. Partida-Martinez, A. Latorre, A. Moya and L. Delaye, Front. Microbiol., 2015, 5, 742.

218 N. A. Moran, Proc. Natl. Acad. Sci. U. S. A., 1996, 93, 28732878.

219 J. J. Wernegreen, Ann. N. Y. Acad. Sci., 2015, 1360, 16-35.

220 J. H. Gillespie, Population genetics: a concise guide, JHU Press, 2010.

221 C.-H. Kuo and H. Ochman, Genome Biol. Evol., 2009, 1, 145152.

222 A. I. Nilsson, S. Koskiniemi, S. Eriksson, E. Kugelberg, J. C. D. Hinton and D. I. Andersson, Proc. Natl. Acad. Sci. U. S. A., 2005, 102, 12112-12116.

223 P. Łukasik, K. Nazario, J. T. Van Leuven, M. A. Campbell, M. Meyer, A. Michalik, P. Pessacq, C. Simon, C. Veloso and J. P. McCutcheon, Proc. Natl. Acad. Sci. U. S. A., 2017, 201712321.

224 M. F. Traxler, S. M. Summers, H. T. Nguyen, V. M. Zacharia, G. A. Hightower, J. T. Smith and T. Conway, Mol. Microbiol., 2008, 68, 1128-1148.

225 D. K. Aanen, H. Henrik, A. J. Debets, N. A. Kerstes, R. F. Hoekstra and J. J. Boomsma, Science, 2009, 326, 1103-1106.

226 R. C. Connor, Anim. Behav., 1986, 34, 1562-1566.

227 J. Sachs and A. Hollowell, mBio, 2012, 3, e00099-12.

228 W. D. Hamilton, J. Theor. Biol., 1964, 7, 1-52.

229 J. M. Smith, Nature, 1964, 201, 1145-1147.

230 R. Dawkins, The selfish gene/Richard Dawkins, Oxford University Press, New York, 1976.

231 N. M. Oliveira, R. Niehus and K. R. Foster, Proc. Natl. Acad. Sci. U.S.A., 2014, 111, 17941-17946.
232 C. E. Tarnita, J. Exp. Biol., 2017, 220, 18-24.

233 J. E. Strassmann, O. M. Gilbert and D. C. Queller, Annu. Rev. Microbiol., 2011, 65, 349-367.

234 R. C. MacLean, Heredity, 2008, 100, 233-239.

235 J. A. Fletcher and M. Doebeli, Proc. R. Soc. B, 2009, 276, 13-19.

236 D. S. Wilson, Proc. Natl. Acad. Sci. U. S. A., 1975, 72, 143146.

237 K. R. Foster and T. Wenseleers, J. Evol. Biol., 2006, 19, 12831293.

238 A. Traulsen and M. A. Nowak, Proc. Natl. Acad. Sci. U. S. A., 2006, 103, 10952-10955.

239 T. Antal, H. Ohtsuki, J. Wakeley, P. D. Taylor and M. A. Nowak, Proc. Natl. Acad. Sci. U. S. A., 2009, 106, 8597-8600.

240 C. D. Nadell, K. R. Foster and J. B. Xavier, PLoS Comput. Biol., 2010, 6, e1000716.

241 M. Doebeli and N. Knowlton, Proc. Natl. Acad. Sci. U. S. A., 1998, 95, 8676-8680.

242 S. K. Aoki, E. J. Diner, C. T. de Roodenbeke, B. R. Burgess, S. J. Poole, B. A. Braaten, A. M. Jones, J. S. Webb, C. S. Hayes, P. A. Cotter and D. A. Low, Nature, 2010, 468, 439-442.

243 E. C. Garcia, M. S. Anderson, J. A. Hagar and P. A. Cotter, Mol. Microbiol., 2013, 89, 1213-1225.

244 M. S. Anderson, E. C. Garcia and P. A. Cotter, PLoS Pathog., 2014, 10, 14.

245 C. E. Zobell, J. Bacteriol., 1943, 46, 39-56.

246 L. Hall-Stoodley, J. W. Costerton and P. Stoodley, Nat. Rev. Microbiol., 2004, 2, 95-108.

247 O. X. Cordero and M. S. Datta, Curr. Opin. Microbiol., 2016, 31, 227-234.

248 J. F. Mori, N. Ueberschaar, S. Lu, R. E. Cooper, G. Pohnert and K. Kusel, ISME J., 2017, 11, 1075-1086.

249 M. van Veelen, J. Garcia and L. Aviles, J. Theor. Biol., 2010, 264, 1240-1253.

250 P. B. Rainey and S. De Monte, Annu. Rev. Ecol. Evol. Syst., 2014, 45, 599-620.

251 G. Corno and K. Jürgens, Appl. Environ. Microbiol., 2006, 72, 78-86.

252 R. Liébana, L. Arregui, A. Santos, A. Murciano, D. Marquina and S. Serrano, FEMS Microbiol. Ecol., 2016, 92, fiw134.

253 N. A. Lyons and R. Kolter, Curr. Opin. Microbiol., 2015, 24, 21-28.

254 H.-C. Flemming, J. Wingender, U. Szewzyk, P. Steinberg, S. A. Rice and S. Kjelleberg, Nat. Rev. Microbiol., 2016, 14, 563-575.

255 J. D. Van Dyken, M. J. I. Müller, K. M. L. Mack and M. M. Desai, Curr. Biol., 2013, 23, 919-923.

256 S. Pande, F. Kaftan, S. Lang, A. Svatos, S. Germerodt and C. Kost, ISME J., 2016, 10, 1413-1423.

257 M. S. Datta, K. S. Korolev, I. Cvijovic, C. Dudley and J. Gore, Proc. Natl. Acad. Sci. U. S. A., 2013, 110, 7354-7359.

258 K. Drescher, C. D. Nadell, H. A. Stone, N. S. Wingreen and B. L. Bassler, Curr. Biol., 2014, 24, 50-55.

259 S. Estrela and S. P. Brown, PLoS Comput. Biol., 2013, 9, e1003398. 
260 J. van Gestel, F. J. Weissing, O. P. Kuipers and A. T. Kovacs, ISME J., 2014, 8, 2069-2079.

261 B. Momeni, A. J. Waite and W. Shou, eLife, 2013, 2, e00960. 262 R. Tecon and D. Or, Sci. Rep., 2017, 7, 43726.

263 C. D. Nadell, K. Drescher, N. S. Wingreen and B. L. Bassler, ISME J., 2015, 9, 1700-1709.

264 M. A. Nowak, S. Bonhoeffer and R. M. May, Proc. Natl. Acad. Sci. U. S. A., 1994, 91, 4877-4881.

265 M. Burmølle, J. S. Webb, D. Rao, L. H. Hansen, S. J. Sørensen and S. Kjelleberg, Appl. Environ. Microbiol., 2006, 72, 3916-3923.

266 J. E. Strassmann and D. C. Queller, Evolution, 2016, 70, 848859.

267 L. M. Wahl, Am. Nat., 2002, 160(1), 135-145.

268 A. Pernthaler, A. E. Dekas, C. T. Brown, S. K. Goffredi, T. Embaye and V. J. Orphan, Proc. Natl. Acad. Sci. U. S. A., 2008, 105, 7052-7057.

269 M. F. Haroon, S. Hu, Y. Shi, M. Imelfort, J. Keller, P. Hugenholtz, Z. Yuan and G. W. Tyson, Nature, 2013, 500, 567-570.

270 Á. T. Kovács, Front. Microbiol., 2014, 5, 649.

271 K. L. I. Norlund, G. Southam, T. Tyliszczak, Y. Hu, C. Karunakaran, M. Obst, A. P. Hitchcock and L. A. Warren, Environ. Sci. Technol., 2009, 43, 8781-8786.

272 U. Jahn, M. Gallenberger, W. Paper, B. Junglas, W. Eisenreich, K. O. Stetter, R. Rachel and H. Huber, J. Bacteriol., 2008, 190, 1743-1750.

273 X. S. He, J. S. McLean, A. Edlund, S. Yooseph, A. P. Hall, S. Y. Liu, P. C. Dorrestein, E. Esquenazi, R. C. Hunter, G. H. Cheng, K. E. Nelson, R. Lux and W. Y. Shi, Proc. Natl. Acad. Sci. U. S. A., 2015, 112, 244-249.

274 F. Husnik and J. P. McCutcheon, Proc. Natl. Acad. Sci. U. S. A., 2016, 113, E5416-E5424.

275 J. Overmann, in Symbiosis: Mechanisms and Model Systems, ed. J. Seckbach, Springer, Netherlands, Dordrecht, 2002, pp. 239-255, DOI: 10.1007/0-306-48173-1_15.

276 Y. Xia, Y. Kong, T. R. Thomsen and P. Halkjær Nielsen, Appl. Environ. Microbiol., 2008, 74, 2229-2238.

277 D. Y. Kobayashi and J. A. Crouch, Annu. Rev. Phytopathol., 2009, 47, 63-82.

278 R. Honegger, in Fungal Associations, ed. B. Hock, Springer Berlin Heidelberg, Berlin, Heidelberg, 2012, pp. 287-339, DOI: 10.1007/978-3-642-30826-0_15.

279 L. P. Partida-Martinez, S. Monajembashi, K.-O. Greulich and C. Hertweck, Curr. Biol., 2007, 17, 773-777.

280 Z. Li, Q. Yao, S. P. Dearth, M. R. Entler, H. F. Castro Gonzalez, J. K. Uehling, R. J. Vilgalys, G. B. Hurst, S. R. Campagna, J. L. Labbé and C. Pan, Environ. Microbiol., 2017, 19, 1041-1053.

281 H. Guo, S. P. Glaeser, I. Alabid, J. Imani, H. Haghighi, P. Kämpfer and K.-H. Kogel, Front. Microbiol., 2017, 8, 629.

282 V. P. Edgcomb, S. A. Breglia, N. Yubuki, D. Beaudoin, D. J. Patterson, B. S. Leander and J. M. Bernhard, ISME J., 2011, 5, 231-243.

283 S. S. Epstein, D. A. Bazylinski and W. H. Fowle, J. Eukaryot. Microbiol., 1998, 45, 64-70.
284 J. M. Bernhard, K. R. Buck, M. A. Farmer and S. S. Bowser, Nature, 2000, 403, 77-80.

285 E. C. M. Nowack and M. Melkonian, Philos. Trans. R. Soc., B, 2010, 365, 699-712.

286 R. Ramanan, B.-H. Kim, D.-H. Cho, H.-M. Oh and H.-S. Kim, Biotechnol. Adv., 2016, 34, 14-29.

287 L. Cai, G. Zhou, R.-M. Tian, H. Tong, W. Zhang, J. Sun, W. Ding, Y. H. Wong, J. Y. Xie, J.-W. Qiu, S. Liu, H. Huang and P.-Y. Qian, Sci. Rep., 2017, 7, 9320.

288 N. A. Moran, J. P. McCutcheon and A. Nakabachi, Annu. Rev. Genet., 2008, 42, 165-190.

289 J. L. Sachs, R. G. Skophammer and J. U. Regus, Proc. Natl. Acad. Sci. U. S. A., 2011, 108, 10800-10807.

290 J. L. Sachs, R. G. Skophammer, N. Bansal and J. E. Stajich, Proc. R. Soc. Lond. B Biol. Sci., 2014, 281, 20132146.

291 C. Toft and S. G. E. Andersson, Nat. Rev. Genet., 2010, 11, 465-475.

292 E. Zientz, T. Dandekar and R. Gross, Microbiol. Mol. Biol. Rev., 2004, 68, 745-770.

293 Z. Liu, J. Müller, T. Li, R. M. Alvey, K. Vogl, N.-U. Frigaard, N. C. Rockwell, E. S. Boyd, L. P. Tomsho, S. C. Schuster, P. Henke, M. Rohde, J. Overmann and D. A. Bryant, Genome Biol., 2013, 14, R127.

294 G. Wanner, K. Vogl and J. Overmann, J. Bacteriol., 2008, 190, 3721-3730.

295 B.-A. Zohar and I. Kolodkin-Gal, in Quorum Sensing vs. Quorum Quenching: A Battle with No End in Sight, ed. V. C. Kalia, Springer, India, New Delhi, 2015, pp. 85-99, DOI: 10.1007/978-81-322-1982-8_9.

296 A. Clinton and K. P. Rumbaugh, Isr. J. Chem., 2016, 56, 265272.

297 R. Levy and E. Borenstein, Proc. Natl. Acad. Sci. U. S. A., 2013, 110, 12804-12809.

298 S. Bernhardsson, P. Gerlee and L. Lizana, BMC Evol. Biol., 2011, 11, 20.

299 S. de Weert, H. Vermeiren, I. H. M. Mulders, I. Kuiper, N. Hendrickx, G. V. Bloemberg, J. Vanderleyden, R. De Mot and B. J. J. Lugtenberg, Mol. Plant-Microbe Interact., 2002, 15, 1173-1180.

300 G. H. Wadhams and J. P. Armitage, Nat. Rev. Mol. Cell Biol., 2004, 5, 1024-1037.

301 G. Bay, N. Nahar, M. Oubre, M. J. Whitehouse, D. A. Wardle, O. Zackrisson, M.-C. Nilsson and U. Rasmussen, New Phytol., 2013, 200, 54-60.

302 J. Tout, T. C. Jeffries, K. Petrou, G. W. Tyson, N. S. Webster, M. Garren, R. Stocker, P. J. Ralph and J. R. Seymour, ISMEJ., 2015, 9, 1764-1777.

303 T. R. Miller, K. Hnilicka, A. Dziedzic, P. Desplats and R. Belas, Appl. Environ. Microbiol., 2004, 70, 4692-4701.

304 R. D. Sieg, K. L. Poulson-Ellestad and J. Kubanek, Nat. Prod. Rep., 2011, 28, 388-399.

305 L. Laganenka, R. Colin and V. Sourjik, Nat. Commun., 2016, 7, 12984.

306 V. Sourjik and H. C. Berg, Proc. Natl. Acad. Sci. U. S. A., 2002, 99, 123-127.

307 J. Müller, C. Kuttler and B. A. Hense, Biosystems, 2008, 92, 76-81. 
308 A. H. Rickard, P. Gilbert, N. J. High, P. E. Kolenbrander and P. S. Handley, Trends Microbiol., 2003, 11, 94-100.

309 S. Katharios-Lanwermeyer, C. Xi, N. S. Jakubovics and A. H. Rickard, Biofouling, 2014, 30, 1235-1251.

310 T. Julou, T. Mora, L. Guillon, V. Croquette, I. J. Schalk, D. Bensimon and N. Desprat, Proc. Natl. Acad. Sci. U. S. A., 2013, 110, 12577-12582.

311 S. Smukalla, M. Caldara, N. Pochet, A. Beauvais, S. Guadagnini, C. Yan, M. D. Vinces, A. Jansen, M. C. Prevost, J.-P. Latgé, G. R. Fink, K. R. Foster and K. J. Verstrepen, Cell, 2008, 135, 726-737.

312 A. Kouzuma, S. Kato and K. Watanabe, Front. Microbiol., 2015, 6, 477.

313 D. Wall, Annu. Rev. Microbiol., 2016, 70, 143-160.

314 K. Vengadesan and S. V. L. Narayana, Protein Sci., 2011, 20, 759-772.

315 N. Dautin and H. D. Bernstein, Annu. Rev. Microbiol., 2007, 61, 89-112.

316 B. Heras, M. Totsika, K. M. Peters, J. J. Paxman, C. L. Gee, R. J. Jarrott, M. A. Perugini, A. E. Whitten and M. A. Schembri, Proc. Natl. Acad. Sci. U. S. A., 2014, 111, 457-462.

317 O. Sherlock, R. M. Vejborg and P. Klemm, Infect. Immun., 2005, 73, 1954-1963.

318 L. Liu, S. Hao, R. Lan, G. Wang, D. Xiao, H. Sun and J. Xu, Infect. Immun., 2015, 83, 2596-2604.

319 K. McLoughlin, J. Schluter, S. Rakoff-Nahoum, A. L. Smith and K. R. Foster, Cell Host Microbe, 2016, 19, 550-559.

320 P. C. Bogino, M. de las Mercedes Oliva, F. G. Sorroche and W. Giordano, Int. J. Mol. Sci., 2013, 14, 15838-15859.

321 A. Gardner and S. A. West, Evolution, 2010, 64, 25-38.

322 J. Heller, J. Zhao, G. Rosenfield, D. J. Kowbel, P. Gladieux and N. L. Glass, PLoS Biol., 2016, 14, e1002431.

323 E. S. Danka, E. C. Garcia and P. A. Cotter, Trends Microbiol., 2017, 25, 391-401.

324 D. C. Queller, E. Ponte, S. Bozzaro and J. E. Strassmann, Science, 2003, 299, 105-106.

325 S. Freilich, R. Zarecki, O. Eilam, E. S. Segal, C. S. Henry, M. Kupiec, U. Gophna, R. Sharan and E. Ruppin, Nat. Commun., 2011, 2, 589.

326 X. Liu, M. M. Ramsey, X. Chen, D. Koley, M. Whiteley and A. J. Bard, Proc. Natl. Acad. Sci. U. S. A., 2011, 108, 26682673.

327 M. E. Hibbing, C. Fuqua, M. R. Parsek and S. B. Peterson, Nat. Rev. Microbiol., 2010, 8, 15-25.

328 R. M. Stubbendieck and P. D. Straight, J. Bacteriol., 2016, 198, 2145-2155.

329 M. Ghoul and S. Mitri, Trends Microbiol., 2016, 24, 833-845.

330 R.-A. Pérez-Gutiérrez, V. López-Ramírez, Á. Islas, L. D. Alcaraz, I. Hernández-González, B. C. L. Olivera, M. Santillán, L. E. Eguiarte, V. Souza, M. Travisano and G. Olmedo-Alvarez, ISME J., 2013, 7, 487-497.

331 M. Sipiczki, Appl. Environ. Microbiol., 2006, 72, 6716-6724. 332 S. E. Lindgren and W. J. Dobrogosz, FEMS Microbiol. Lett., 1990, 87, 149-164.

333 A. G. T. K. M. Fons, Microb. Ecol. Health Dis., 2000, 12, 240246.
334 R. S. Peixoto, P. M. Rosado, D. C. d. A. Leite, A. S. Rosado and D. G. Bourne, Front. Microbiol., 2017, 8, 341.

335 T. Rudrappa, M. L. Biedrzycki and H. P. Bais, FEMS Microbiol. Ecol., 2008, 64, 153-166.

336 C. G. Buffie and E. G. Pamer, Nat. Rev. Immunol., 2013, 13, 790-801.

337 B. Stecher, D. Berry and A. Loy, FEMS Microbiol. Rev., 2013, 37, 793-829.

338 X. He, J. S. McLean, L. Guo, R. Lux and W. Shi, ISME J., 2014, 8, 564-574.

339 S. Caballero, S. Kim, R. A. Carter, I. M. Leiner, B. Susac, L. Miller, G. J. Kim, L. L. Ling and E. G. Pamer, Cell Host Microbe, 2017, 21, 592-602.

340 Z. Li, A. J. Clarke and T. J. Beveridge, J. Bacteriol., 1998, 180, 5478-5483.

341 A. B. Russell, S. B. Peterson and J. D. Mougous, Nat. Rev. Microbiol., 2014, 12, 137.

342 M. J. Q. Wong, X. Liang, M. Smart, L. Tang, R. Moore, B. Ingalls and T. G. Dong, Appl. Environ. Microbiol., 2016, 82, 6881-6888.

343 L. E. N. Quadri, Antonie van Leeuwenhoek, 2002, 82, 133145.

344 E. Shanker and M. J. Federle, Genes, 2017, 8, 15.

345 J. R. van der Ploeg, J. Bacteriol., 2005, 187, 3980-3989.

346 P. D. Cotter, R. P. Ross and C. Hill, Nat. Rev. Microbiol., 2013, 11, 95-105.

347 M. Bassetti, M. Merelli, C. Temperoni and A. Astilean, Ann. Clin. Microbiol. Antimicrob., 2013, 12, 22.

348 M. P. Zacharof and R. W. Lovitt, APCBEE Proc., 2012, 2, 5056.

349 C. D. Nadell, K. Drescher and K. R. Foster, Nat. Rev. Microbiol., 2016, 14, 589-600.

350 L. Chao and B. R. Levin, Proc. Natl. Acad. Sci. U. S. A., 1981, 78, 6324-6328.

351 O. Rendueles, P. C. Zee, I. Dinkelacker, M. Amherd, S. Wielgoss and G. J. Velicer, Proc. Natl. Acad. Sci. U. S. A., 2015, 112, 9076-9081.

352 K. A. Gibbs and E. P. Greenberg, Chem. Rev., 2011, 111, 188194.

353 M. Vos and G. J. Velicer, Curr. Biol., 2009, 19, 1763-1767.

354 P. Stefanic, B. Kraigher, N. A. Lyons, R. Kolter and I. Mandic-Mulec, Proc. Natl. Acad. Sci. U. S. A., 2015, 112, 14042-14047.

355 N. A. Lyons, B. Kraigher, P. Stefanic, I. Mandic-Mulec and R. Kolter, Curr. Biol., 2016, 26, 733-742.

356 S. Borgeaud, L. C. Metzger, T. Scrignari and M. Blokesch, Science, 2015, 347, 63-67.

357 L. McNally, E. Bernardy, J. Thomas, A. Kalziqi, J. Pentz, S. P. Brown, B. K. Hammer, P. J. Yunker and W. C. Ratcliff, Nat. Commun., 2017, 8, 11.

358 A. J. Waite and W. Shou, Proc. Natl. Acad. Sci. U. S. A., 2012, 109, 19079-19086.

359 J. B. Xavier and K. R. Foster, Proc. Natl. Acad. Sci. U. S. A., 2007, 104, 876-881.

360 J. Gore, H. Youk and A. van Oudenaarden, Nature, 2009, 459, 253-256.

361 A. Sanchez and J. Gore, PLoS Biol., 2013, 11, e1001547. 
362 O. X. Cordero and M. F. Polz, Nat. Rev. Microbiol., 2014, 12, 263-273.

363 N. Ribeck and R. E. Lenski, Evolution, 2015, 69, 13131320.

364 D. Greig and M. Travisano, Proc. R. Soc. London, Ser. B, 2004, 271, S25-S26.

365 R. C. MacLean, A. Fuentes-Hernandez, D. Greig, L. D. Hurst and I. Gudelj, PLoS Biol., 2010, 8, e1000486.

366 A. Ross-Gillespie, A. Gardner, S. A. West and A. S. Griffin, Am. Nat., 2007, 170, 331-342.

367 D. B. Borenstein, Y. Meir, J. W. Shaevitz and N. S. Wingreen, PLoS One, 2013, 8, e63304.

368 M. Doebeli and I. Ispolatov, Science, 2010, 328, 494-497.

369 K. L. Hillesland, Ann. N. Y. Acad. Sci., 2017, DOI: 10.1111/ nyas.13515.

370 K. L. Hillesland and D. A. Stahl, Proc. Natl. Acad. Sci. U. S. A., 2010, 107, 2124-2129.

371 S. Paterson, T. Vogwill, A. Buckling, R. Benmayor, A. J. Spiers, N. R. Thomson, M. Quail, F. Smith, D. Walker and B. Libberton, Nature, 2010, 464, 275-278.

372 C. T. Bergstrom and M. Lachmann, Proc. Natl. Acad. Sci. U. S. A., 2003, 100, 593-598.

373 R. Law, The biology of mutualism: Ecology and evolution, 1985, pp. 145-170.

374 J. L. Sachs, C. J. Essenberg and M. M. Turcotte, Trends Ecol. Evol., 2011, 26, 202-209.

375 K. L. Hillesland, S. Lim, J. J. Flowers, S. Turkarslan, N. Pinel, G. M. Zane, N. Elliott, Y. Qin, L. Wu and N. S. Baliga, Proc. Natl. Acad. Sci. U. S. A., 2014, 111, 14822-14827.

376 S. Sieuwerts, F. A. M. de Bok, J. Hugenholtz and J. E. T. van Hylckama Vlieg, Appl. Environ. Microbiol., 2008, 74, 49975007.

377 A. Bolotin, B. Quinquis, P. Renault, A. Sorokin, S. D. Ehrlich, S. Kulakauskas, A. Lapidus, E. Goltsman, M. Mazur, G. D. Pusch, M. Fonstein, R. Overbeek, N. Kyprides, B. Purnelle, D. Prozzi, K. Ngui, D. Masuy, F. Hancy, S. Burteau, M. Boutry, J. Delcour, A. Goffeau and P. Hols, Nat. Biotechnol., 2004, 22, 1554-1558.

378 M. van de Guchte, S. Penaud, C. Grimaldi, V. Barbe, K. Bryson, P. Nicolas, C. Robert, S. Oztas, S. Mangenot, A. Couloux, V. Loux, R. Dervyn, R. Bossy, A. Bolotin, J. M. Batto, T. Walunas, J. F. Gibrat, P. Bessieres, J. Weissenbach, S. D. Ehrlich and E. Maguin, Proc. Natl. Acad. Sci. U. S. A., 2006, 103, 9274-9279.

379 N. Y. Ankrah, J. Luan and A. E. Douglas, J. Bacteriol., 2017, 199, e00872-16.

380 M. Embree, J. K. Liu, M. M. Al-Bassam and K. Zengler, Proc. Natl. Acad. Sci. U. S. A., 2015, 112(50), 15450.

381 S. L. Garcia, K. D. McMahon, M. Martinez-Garcia, A. Srivastava, A. Sczyrba, R. Stepanauskas, H.-P. Grossart, T. Woyke and F. Warnecke, ISME J., 2013, 7, 137-147.

382 S. Shigenobu, H. Watanabe, M. Hattori, Y. Sakaki and H. Ishikawa, Nature, 2000, 407, 81-86.

383 J. P. McCutcheon and C. D. von Dohlen, Curr. Biol., 2011, 21, 1366-1372.

384 R. Braakman, M. J. Follows and S. W. Chisholm, Proc. Natl. Acad. Sci. U. S. A., 2017, 114, E3091-E3100.
385 P. D. Schloss and J. Handelsman, Genome Biol., 2005, 6, 229.

386 H.-C. Chiu, R. Levy and E. Borenstein, PLOS Comput. Biol, 2014, 10(7), e1003695.

387 A. Razumov, Mikrobiologiya, 1932, 1, 131-146.

388 R. I. Amann, W. Ludwig and K. H. Schleifer, Microbiol. Rev., 1995, 59, 143-169.

389 A. J. T. Staley and A. Konopka, Annu. Rev. Microbiol., 1985, 39, 321-346.

390 P. Hugenholtz, B. M. Goebel and N. R. Pace, J. Bacteriol., 1998, 180, 4765-4774.

391 K. C. Wrighton, B. C. Thomas, I. Sharon, C. S. Miller, C. J. Castelle, N. C. VerBerkmoes, M. J. Wilkins, R. L. Hettich, M. S. Lipton, K. H. Williams, P. E. Long and J. F. Banfield, Science, 2012, 337, 1661-1665.

392 M. S. Rappé and S. J. Giovannoni, Annu. Rev. Microbiol., 2003, 57, 369-394.

393 H. Tamaki, Y. Sekiguchi, S. Hanada, K. Nakamura, N. Nomura, M. Matsumura and Y. Kamagata, Appl. Environ. Microbiol., 2005, 71, 2162-2169.

394 E. G. Biosca, R. Flores, R. D. Santander, J. L. Díez-Gil and E. Barreno, PLoS One, 2016, 11, e0160328.

395 X. Huai-Shu, N. Roberts, F. L. Singleton, R. W. Attwell, D. J. Grimes and R. R. Colwell, Microb. Ecol., 1982, 8, 313-323.

396 J. T. Lennon and S. E. Jones, Nat. Rev. Microbiol., 2011, 9, 119-130.

397 G. J. Velicer and H. Mendes-Soares, Curr. Biol., 2009, 19, R55-R56.

398 S. Pande and C. Kost, Trends Microbiol., 2017, 25, 349-361. 399 A. D'Onofrio, J. M. Crawford, E. J. Stewart, K. Witt, E. Gavrish, S. Epstein, J. Clardy and K. Lewis, Chem. Biol., 2010, 17, 254-264.

400 T. Kaeberlein, K. Lewis and S. S. Epstein, Science, 2002, 296, 1127-1129.

401 D. Nichols, N. Cahoon, E. M. Trakhtenberg, L. Pham, A. Mehta, A. Belanger, T. Kanigan, K. Lewis and S. S. Epstein, Appl. Environ. Microbiol., 2010, 76, 2445-2450. 402 S. L. Garcia, K. D. McMahon, H.-P. Grossart and F. Warnecke, Environ. Microbiol. Rep., 2014, 6, 21-27.

403 D. K. Button, F. Schut, P. Quang, R. Martin and B. R. Robertson, Appl. Environ. Microbiol., 1993, 59, 881891.

404 R. C. Lewontin, Annu. Rev. Ecol. Systemat., 1970, 1, 1-18. 405 D. L. Hull, Annu. Rev. Ecol. Systemat., 1980, 11, 311-332.

406 R. E. Michod, Am. Nat., 1997, 150, S5-S21.

407 S. Okasha, Evolution and the levels of selection, Oxford University Press, Oxford, 2006.

408 J. Damuth and I. L. Heisler, Biol. Philos., 1988, 3, 407-430. 409 R. E. Michod, Biol. Philos., 2005, 20, 967-987.

410 J. Maynard Smith and E. Szathmáry, The major transitions in evolution, Oxford University Press, Oxford, 1995.

411 S. A. West, R. M. Fisher, A. Gardner and E. T. Kiers, Proc. Natl. Acad. Sci. U. S. A., 2015, 112, 10112-10119.

412 E. Clarke, J. Biosci., 2014, 39, 303-317.

413 C. M. Fraser, J. D. Gocayne, O. White, M. D. Adams, R. A. Clayton, R. D. Fleischmann, C. J. Bult, A. R. Kerlavage, G. Sutton, J. M. Kelley, J. L. Fritchman, 
J. F. Weidman, K. V. Small, M. Sandusky, J. Fuhrmann, D. Nguyen, T. R. Utterback, D. M. Saudek, C. A. Phillips, J. M. Merrick, J. F. Tomb, B. A. Dougherty, K. F. Bott, P. C. $\mathrm{Hu}$, T. S. Lucier, S. N. Peterson, H. O. Smith, C. A. Hutchison and J. C. Venter, Science, 1995, 270, 397-403.

414 A. E. Douglas, Cold Spring Harbor Perspect. Biol., 2014, 6, a016113.

415 S. Estrela, B. Kerr and J. J. Morris, Curr. Opin. Microbiol., 2016, 31, 191-198.

416 D. Bhattacharya, J. M. Archibald, A. P. M. Weber and A. Reyes-Prieto, BioEssays, 2007, 29, 1239-1246.

417 S. Shitut, T. Ahsendorf, S. Pande, M. Egbert and C. Kost, bioRxiv, 2017, 114462.

418 G. M. Dunny, T. J. Brickman and M. Dworkin, Bioessays, 2008, 30, 296-298.

419 M. Marchal, F. Goldschmidt, S. N. Derksen-Müller, S. Panke, M. Ackermann and D. R. Johnson, BMC Evol. Biol., 2017, 17, 106.

420 W. Shou, S. Ram and J. M. Vilar, Proc. Natl. Acad. Sci. U. S. A., 2007, 104, 1877-1882.

421 M. Cavaliere, S. Feng, O. S. Soyer and J. I. Jiménez, Environ. Microbiol., 2017, 2949-2963.

422 E. Bauer, J. Zimmermann, F. Baldini, I. Thiele and C. Kaleta, PLoS Comput. Biol., 2017, 13, e1005544.
423 W. R. Harcombe, W. J. Riehl, I. Dukovski, B. R. Granger, A. Betts, A. H. Lang, G. Bonilla, A. Kar, N. Leiby and P. Mehta, Cell Rep., 2014, 7, 1104-1115.

424 L. Margulis, Origin of eukaryotic cells: Evidence and research implications for a theory of the origin and evolution of microbial, plant and animal cells on the precambrian Earth, Yale University Press, 1970.

425 S. M. B. Krause, T. Johnson, Y. Samadhi Karunaratne, Y. Fu, D. A. C. Beck, L. Chistoserdova and M. E. Lidstrom, Proc. Natl. Acad. Sci. U. S. A., 2017, 114, 358-363.

426 J. B. Xavier, Mol. Syst. Biol., 2011, 7, 483.

427 E. Sober and D. S. Wilson, Unto others: The evolution and psychology of unselfish behavior, Harvard University Press, 1999.

428 J. Overmann, in Recent Advances in Phototrophic Prokaryotes, Springer, 2010, pp. 15-29.

429 M. Doebeli, Popul. Ecol., 2002, 44, 59-70.

430 S. Estrela, C. H. Trisos and S. P. Brown, Am. Nat., 2012, 180, 566-576.

431 J. M. Biernaskie and S. A. West, Proc. R. Soc. Lond. B Biol. Sci., 2015, 282(1813), 20151075.

432 K. Brenner and F. H. Arnold, PLoS One, 2011, 6, e16791.

433 J. B. Bruce, G. A. Cooper, H. Chabas, S. A. West and A. S. Griffin, Evolution, 2017, 71, 2484-2495. 